$\mathrm{DOE} / \mathrm{BC} / 14662-15$

Distribution Category UC-122

\title{
QUANTITATION OF MICROBIAL PRODUCTS AND THEIR EFFECTIVENESS IN ENHANCED OIL RECOVERY
}

FINAL REPORT

\author{
By \\ Xu Zhang \\ Roy M. Knapp \\ Michael J. Mclnerney
}

February 1995

Work Performed Under Contract No. DE-AC22-90BC14662

Prepared for

U.S. Department of Energy

Assistant Secretary for Fossil Energy

\author{
Gene Pauling, Project Manager \\ Metairie Site Office \\ 900 Commerce Road, East \\ New Orleans, LA 70123
}

\section{Prepared by}

University of Oklahoma

Norman, OK 73019

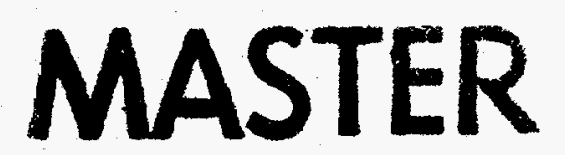

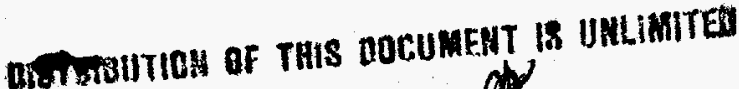




\section{DISCLAIMER}

This report was prepared as an account of work sponsored by an agency of the United States Government. Neither the United States Government nor any agency thereof, nor any of their employees, make any warranty, express or implied, or assumes any legal liability or responsibility for the accuracy, completeness, or usefulness of any information, apparatus, product, or process disclosed, or represents that its use would not infringe privately owned rights. Reference herein to any specific commercial product, process, or service by trade name, trademark, manufacturer, or otherwise does not necessarily constitute or imply its endorsement, recommendation, or favoring by the United States Government or any agency thereof. The views and opinions of authors expressed herein do not necessarily state or reflect those of the United States Government or any agency thereof. 


\section{DISCLAIMER}

Portions of this document may be illegible in electronic image products. Images are produced from the best available original document. 


\section{Page}

TABLE OF CONTENTS

LIST OF TABLES …….............................................................. v

LIST OF FIGURES

$\begin{array}{lll}\text { Chapter Page } & \end{array}$

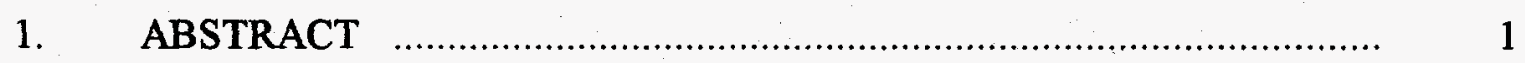

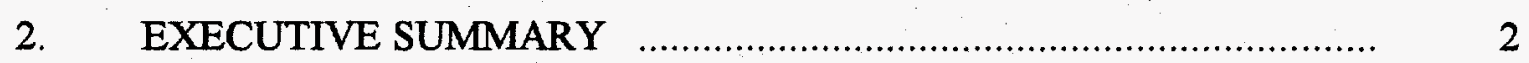

2.1 Executive Summary of Previous Reports ……………………........ 2

2.2 Executive Summary of Current Reports ……………..................... 7

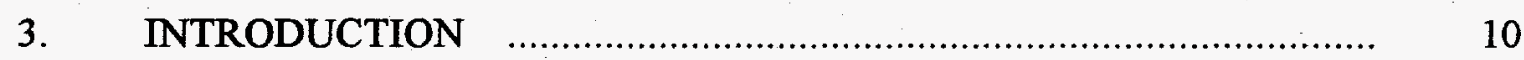

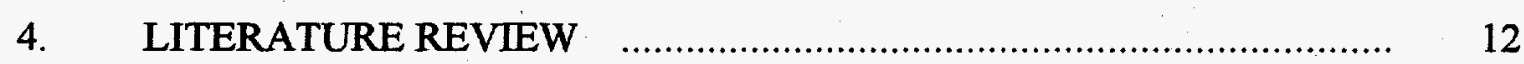

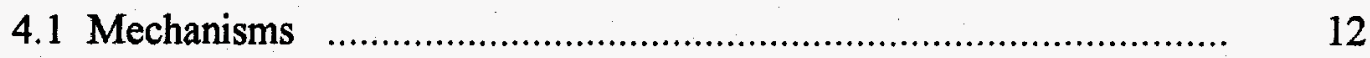

4.2 Mathematical Simulation …………………………………......... 13

5. MATHEMATICAL MODELS ..................................................... 16

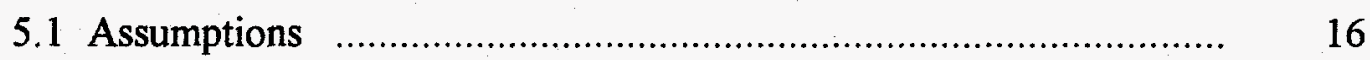

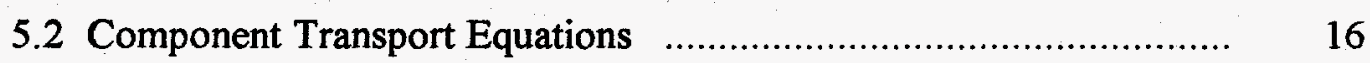

5.3 Growth, Production, and Consumption Rates ................................ 19

5.4 Adsorption .......................................................................... 21

5.5 Permeability Reduction Model ……........................................... 23

5.6 Black Oil Model ......................................................................... 27

5.7 Oil Recovery Model 
6. NUMERICAL FORMULATION ……...........................................

6.1 Grid System

6.2 Pressure Equation Approximation ................................................. 44

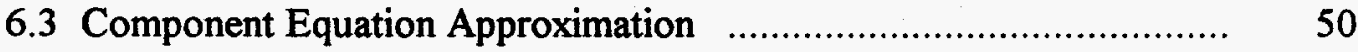

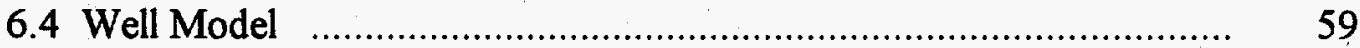

6.5 Time Step Selection

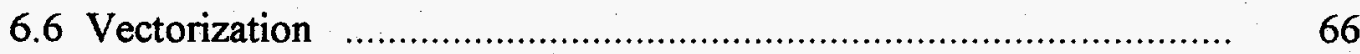

6.7 Computational Procedure …………………………..................... 68

7. SIMULATOR VALIDATION AND APPLICATION …….................... 73

7.1 Verification with Analytical Solutions ………………………........ 73

7.2 Comparison with ECLIPSE Simulator ………...........................

7.3 Case Studies for MEOR Processes ……………......................... 76

7.4 Simulation of Experiments ………................................................ 80

8. CONCLUSIONS AND RECOMMENDATIONS $\ldots \ldots \ldots \ldots \ldots \ldots \ldots \ldots \ldots . . . . . . . . . . .142$

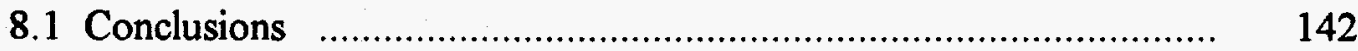

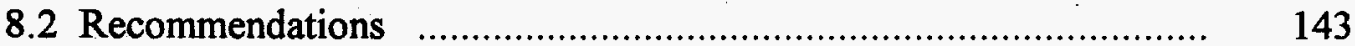

9. NOMENCLATURE _.................................................................. 144

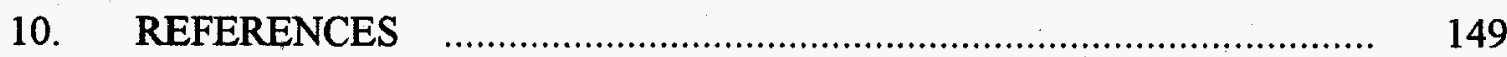




\section{LIST OF TABLES}

Table

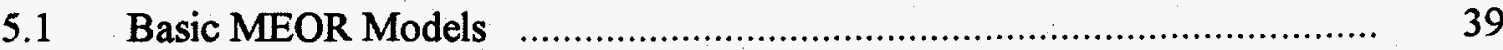

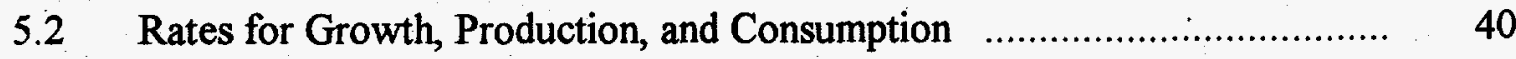

5.3 Adsorption Rates for Components .............................................. 41

$5.4 \quad$ Permeability Reduction Model f................................................. 42

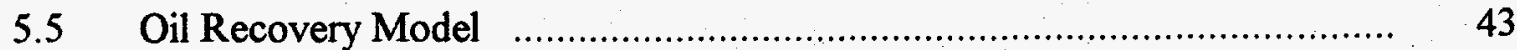

6.1 Finite Difference Equations for Block Oil Model f.............................. 69

6.2 Finite Difference Equation for Component Transport Model ................ 70

7.1 Input Data for One-Dimensional Waterflood Run f............................ 84

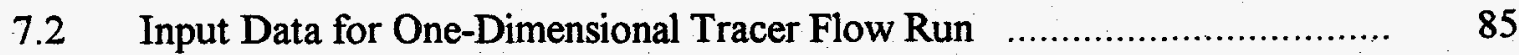

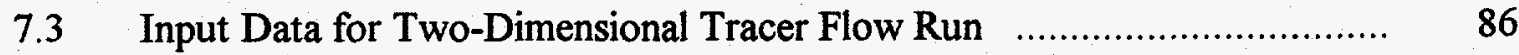

$7.4 \quad$ Input Data for Two-Dimensional Waterflood Run ............................. 87

7.5 Input Data for Alcohol Inhibition Test Run f................................... 88

7.6 Input Data for Chemotaxis Test Run ............................................. 89

7.7 Input Data for Two-Layer Microbial Plugging Test Run ....................... 90

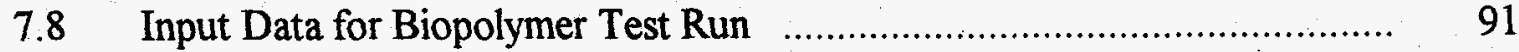

7.9 Input Data for Biosurfactant Test Run ........................................ 92

7.10 Input Data for Carbon Dioxide Test Run …..................................... 93

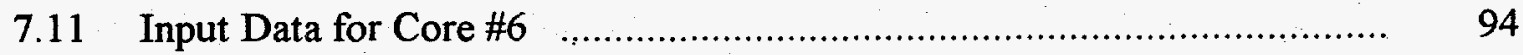

7.12 Input Data for Chemotactic Strain RP437 ...................................... 95

7.13 Input Data for Nonchemotactic Strain RP5232 .............................. 96

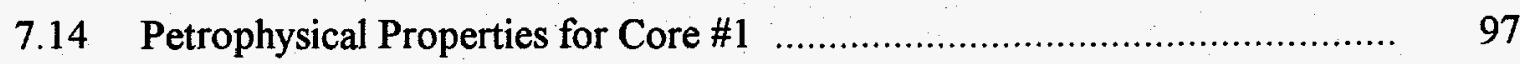


7.15 Experimental Results for Core \#1 …………...................................... 98

7.16 Input Data for Core \#1 ........................................................................ 99

7.17 Petrophysical Properties for Core \#4 ………..................................... 100

7.18 Experimental Results for Core \#4 ...................................................... 101

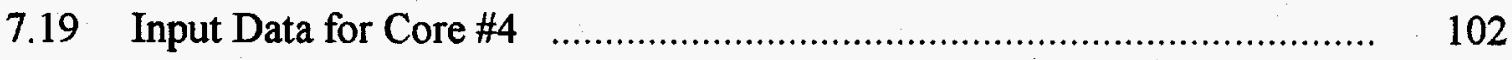




\section{LIST OF FIGURES}

Figure

6.1 Block Numbering for $4 \times 3 \times 2$ Grid System

6.2 Coefficient Matrix of Pressure Equation for $4 \times 3 \times 2$ Grid System

7.1 Comparison of Water Saturation Profiles after 40 Days of Injection

Computed from Buckley-Leverett Equation and MEOR Simulator

103

7.2 Comparison of Concentration Profiles after 50\% Pore Volume

of Injection Computed from Analytical Equation and MEOR

Simulator for Ideal Tracer Flow in an One-Dimensional

Homogeneous Porous Medium

104

7.3 Comparison of Normalized Effluent Concentration Computed

from Analytical Equation and MEOR Simulator for Ideal Tracer

Flow in a Homogeneous Five-Spot Well Pattern

7.4 Comparison of Oil Production Rates Computed from ECLIPSE

and MEOR Simulators for a Waterflooding Process in a

Homogeneous Five-Spot Well Pattern

7.5 Comparison of Water Cut Computed from ECLIPSE

and MEOR Simulators for a Waterflooding Process in a

Homogeneous Five-Spot Well Pattern

107

7.6 Comparison of Water Saturation at Block $(5,5,1)$ Computed from

ECLIPSE and MEOR Simulators for a Waterflooding Process

in a Homogeneous Five-Spot Well Pattern

108

7.7 Comparison of Average Reservoir Pressures Computed from 
ECLIPSE and MEOR Simulators for a Waterflooding Process in a Homogeneous Five-Spot Well Pattern

7.8 Comparison of Injection Bottom Hole Pressures Computed from

ECLIPSE and MEOR Simulators for a Waterflooding Process

in a Homogeneous Five-Spot Well Pattern

7.9 Comparison of Production Bottom Hole Pressures Computed from

ECLIPSE and MEOR Simulators for a Waterflooding Process

in a Homogeneous Five-Spot Well Pattern

7.10 Effect of Alcohol Inhibition on Bacterial Growth

7.11 Comparison of Biomass Profiles after 50 Hours of Incubation for Chemotaxis Effects

7.12 Comparison of Nutrient Profiles after 50 Hours of Incubation for Chemotaxis Effects

7.13 Comparison of Permeability Reduction Factors for Producing

Blocks in High and Low Permeability Zones during Microbial

Plugging Treatment

7.14 Comparison of Oil Production Rates after Water Breakthrough

for Conventional Waterflood and Microbial Plugging Treatment

7.15 Comparison of Oil Recovery Factors after Water Breakthrough for Conventional Waterflood and Microbial Plugging Treatment

7.16 Comparison of Water Saturation Profile after 30\% Pore Volume of

Injection for Conventional Waterflood and Biopolymer-Producing

Bacteria Treatment Processes

7.17 Comparison of Oil Production Rates for Conventional

Waterflood and Biopolymer-Producing Bacteria 
Treatment Processes

7.18 Comparison of Oil Recovery Factors for Conventional

Waterflood and Biopolymer-Producing Bacteria

Treatment Processes

120

7.19 Computed Oil Production Rate and Interfacial Tension at

Producing Block during Post Flushing for Biosurfactant-

Producing Bacteria Treatment Processes

7.20 Computed Oil Recovery Factors and Capillary Number at

Producing Block during Post Flushing for Biosurfactant-

Producing Bacteria Treatment Processes

7.21 Computed $\mathrm{CO}_{2}$ Production, Glucose Consumption,

and Pore Pressure Increase during Incubation for

$\mathrm{CO}_{2}$-Producing Bacteria Treatment Processes

7.22 Comparison of Biomass Growth and Pore Pressure Increase

during Incubation for $\mathrm{CO}_{2}$-Producing Bacteria Treatment

Processes

7.23 Computed Cumulative Production for Oil, Water, and Gas

during Post Flushing for $\mathrm{CO}_{2}$-Producing Bacteria Treatment

processes

7.24 Comparison of Experiment Data and Simulation Results for

Acetate Production from the Berea Core Incubated with

Indigenous Bacteria

7.25 Comparison of Experiment Data and Simulation Results for

Cumulative Gas $\left(\mathrm{CO}_{2}+\mathrm{N}_{2}\right)$ Production from the Berea Core

Incubated with Indigenous Bacteria 
7.26 Comparison of Experiment Data and Simulation Results for Glucose Consumption in the Berea Core

Incubated with Indigenous Bacteria

7.27 Comparison of Experiment Data and Simulation Results for

Nitrate Consumption in the Berea Core

Incubated with Indigenous Bacteria

7.28 Comparison of Experiment Data and Simulation Results for

Permeability Reduction in the Berea Core

Incubated with Indigenous Bacteria

7.29 Comparison of Experiment Data and Simulation Results for

Concentration Profiles of Chemotactic Strain RP437 in the

Sand-Packed Core under Static Conditions

after 70 Hours of Incubation

7.30 Comparison of Experiment Data and Simulation Results for

Concentration Profiles of Nonchemotactic Strain RP5323 in the

Sand-Packed Core under Static Conditions

after 70 Hours of Incubation

7.31 Comparison of Experiment Data and Simulation Results for

Acid Production from the Berea Core Incubated with

Clostridium acetobutylicum

7.32 Comparison of Experiment Data and Simulation Results for

Alcohol Production from the Berea Core Incubated with

Clostridium acetobutylicum

7.33 Comparison of Experiment Data and Simulation Results for Cumulative Gas Production from the Berea Core Incubated 
with Clostridium acetobutylicum

7.34 Comparison of Experiment Data and Simulation Results for

Glucose Consumption in the Berea Core Incubated with

Clostridium acetobutylicum

7.35 Comparison of Experiment Data and Simulation Results for

Permeability Reduction in the Berea Core Incubated with

Clostridium acetobutylicum

7.36 Comparison of Experiment Data and Simulation Results for

Surfactant Production from the Berea Core Incubated with

Bacillus Strain JF-2

7.37 Comparison of Experiment Data and Simulation Results for

Oil Production from the Berea Core Incubated with

Bacillus Strain JF-2

7.38 Comparison of Experiment Data and Simulation Results for

Correlation between Cumulative Oil and Biosurfactant Production

from the Berea Core Incubated with Bacillus Strain JF-2

7.39 Comparison of Experiment Data and Simulation Results for

Permeability Reduction in the Berea Core Incubated with

Bacillus Strain JF-2 


\section{ABSTRACT}

A three-dimensional, three-phase, multiple-component numerical simulator was developed to investigate transport and growth of microorganisms in porous media and the impacts of microbial activities on oil recovery. The microbial activities modeled in this study included: (1) growth, retention, chemotaxis, and end product inhibition of growth, (2) the formation of metabolic products, and (3) the consumption of nutrients.

Major mechanisms for microbial enhanced oil recovery (MEOR) processes were modeled as follows: (1) improvement in sweep efficiency of a displacement process due to in situ plugging of highly-permeable production zones by cell mass or due to improved mobility control achieved by increasing the viscosity of the displacing fluid with a biopolymer, and (2) solubilization and mobilization of residual oil in porous media due to the reduction of the interfacial tension between oleic and aqueous phases by the production of a biosurfactant.

The numerical solutions for mathematical models involved two steps. The distributions of pressure and phase saturations were solved from continuity equations and Darcy flow velocities for the aqueous phase were computed. This was followed by the solution of convection-dispersion equations for individual components.

Numerical solutions from the proposed model were compared to results obtained from analytical equations, commercial simulators, and laboratory experiments. The comparison indicated that the model accurately quantified microbial transport and metabolism in porous media, and predicted additional crude oil recovery due to microbial processes. 


\section{EXECUTIVE SUMMARY}

The goals of this project were to obtain quantitative information on the rate and extent of microbial growth and metabolism in porous materials, and to use this information to model microbial growth activity in porous materials and to predict oil recovery as a consequence of in situ microbial processes. These goals required the development of new experimental system and approaches to obtain the stoichiometric and kinetic information required to validate the mathematical models. Much of the work on the kinetics and stoichiometry of microbial growth and metabolism in porous materials was presented in our two previous reports. ${ }^{49,50}$ The information contained in these two report is summarized below.

\subsection{Executive Summary of Previous Reports}

During the first year, the metabolism and nutritional features of fermentative haloanaerobic bacteria was studied. Fermentative haloanaerobic bacteria were the most numerous organisms present in brine samples collected during a field pilot test of a microbial selective plugging process conducted in a hypersaline petroleum reservoir. Information about the metabolism and physiology of these bacteria was needed to mathematically model their growth and activity in sandstone cores. The fermentation of carbohydrates and the nutritional features of five haloanaerobic bacteria isolated from brine samples from the Vassar reservoir was studied. All of the isolates were strictly anaerobic and obligately halophilic, requiring a minimum of 6 to $9 \%$ (wt/vol) $\mathrm{NaCl}$ for growth in a complex medium. All of the isolates used carbohydrates, but most did not use amino acids or several of the tested aromatic compounds as energy sources. Glucose was 
fermented to $\mathrm{H}_{2}, \mathrm{CO}_{2}$, ethanol, and acetate by all the strains. Formate was an additional product from glucose for strains VS-732 and VS-751. These studies showed that brines from a hypersaline oil reservoir contained a large population of anaerobic bacteria, and that these bacteria use a variety of fermentable carbohydrates to produce products such as acids, solvents, and gases that are potentially useful for enhanced oil recovery.

The metabolism of one these strains, TTL-30, was studied in both liquid culture and in porous materials to determine whether the organism used a different pathway from glucose metabolism in the presence of a solid matrix, or whether the presence of a solid matrix influenced the kinetics of glucose metabolism. TTL-30 produced acetate, ethanol, hydrogen, and carbon dioxide from glucose when grown in liquid culture. The same end products were produced by TTL-30 when grown inside of core packed with sand, crushed sandstone, or crushed limestone. Less acetate and more ethanol were produced when TTL-30 was grown in the presence of crushed sandstone or limestone. The increased buffering capacity provided by the clays and carbonates present in these materials probably prevented the development of a low $\mathrm{pH}$, which is prerequisite for solvent production. Acetate was exponentially produced by TTL-30 in the packs. Thus, the metabolic pathway used for glucose metabolism was same whether or not the organisms were grown in the presence of a solid matrix, and the rate of metabolism in porous materials can be described by commonly mathematical expressions.

A simple porous chamber was designed to obtain statistically reliable data on the in situ rates of microbial growth, substrate consumption, and product formation. This system consisted of a small, plastic tube packed with sand or glass beads that was sealed at each end with rubber stopper. The porous system was used to study the kinetics of growth and the mode of penetration of strains of Escherichia coli through anaerobic, nutrientsaturated, sand-packed cores under static conditions. E. coli was used in these initial 
experiments since its metabolism and growth kinetics are well described, and many mutants which lack important biological functions are available. The rate of growth of a chemotactic, motile strain of $E$. coli, RW262, was about $50 \%$ slower inside chambers than observed in liquid culture. The stoichiometry of galactose metabolism by strain RW262 was same in cores as in liquid culture. Without an applied advective force, RW262 grew exponentially and moved through chambers at a rate of about $0.1 \mathrm{~m} / \mathrm{d}$. Cells moved through chambers in a band-like fashion, as the front of cells had high cell concentrations (greater than $10^{5}$ cells $/ \mathrm{ml}$ ). A motile, nonchemotactic mutant of $E$. coli penetrated cores faster than its chemotactic parental strain. The difference in penetration time between the chemotactic and nonchemotactic motile strains could be explained by differences in their modes of growth inside the chambers. The chemotactic strain grew and moved through cores in a bank-like fashion, as found with strain RW262. The nonchemotactic strain moved through chambers in a diffuse manner where the front of the moving cells had low cell concentrations $\left(\leq 10^{3}\right.$ cells $\left./ \mathrm{ml}\right)$, and where the appearance of cells in a section of the chamber was not necessarily followed by an increase in cell concentration in that section with time. The propagation of a nonmotile strain required a critical cell density in a section of the core before cells were detected in the next section. This suggested that the transport of nonmotile cells through porous material may occur by a physical displacement process where some of the progeny cells are forced into the less populated regions of the core.

The information obtained from studies on the metabolism of fermentative haloanaerobes and from studies on chemotactic migration and growth of bacteria through our simple porous experimental system was used to validate a mathematical model for microbial selective plugging. ${ }^{13}$ A three-phase, multipecies, one-dimensional model was developed to simulate bacterial transport, growth, and metabolism, and to predict the change in permeability as a result of in situ microbial growth. Convection-dispersion 
equations and microbial growth kinetic equations were incorporated into the model to quantify the rate and extent of biomass production, product formation, and nutrient utilization during an MEOR process. Permeability reduction by the MEOR process was assumed to be due to pore plugging by the retention and growth of bacterial cells. The model was applied to static, unconsolidated sand-packed cores and sandstone core-flood experiments to simulate microbial movement, metabolite production, nutrient consumption coupled to microbial growth and to predict the net permeability reduction. Comparisons between numerical solutions and experimental results indicated that the model simulated the essential microbial kinetics of these laboratory experiments and can be extended to provide numerical predictions for the purpose of design and evaluation of MEOR field projects.

In the second year of the project, a new noninvasive method to measure microbial activity in porous materials was developed. The rate of in situ microbial activity was inferred from the rate of change in the pore pressure. The change in pore pressure was monitored continuously using an electronic transducer system. This method was used to determine the effect of pore size on the rate and extent of glucose degradation, and on the efficiency of substrate utilization by microorganisms. Porous chambers packed with different bead sizes, ranging from $75-150$ to $710-1180 \mu \mathrm{m}$, had similar porosities (38\%), but different pore sizes, ranging from 10 to $80 \mu \mathrm{m}$ for chamber packed with the smallest to the largest glass bead size, respectively. The rate of penetration of both motile and nonmotile strains decreased with a decrease in pore size. Nutrient conditions that resulted in faster growth rates also resulted in faster penetration rates. The rate of hydrogen production, the final amount of the hydrogen produced, and the cell concentration decreased with a decrease in pore size. This study showed that pore size is an important factor governing the movement microorganisms through porous material, and suggested 
that the reduced rate of penetration in chambers packed with the smallest pore sizes was due to a restriction of bacterial growth.

Newly developed non-linear regression models were applied to the hydrogen production data obtained in the above experiments. The integrated Monod model was successfully fit to the data from liquid-filled chambers that did not contain a solid matrix, and a maximum specific growth rate of 0.43 per hour was determined. The integrated Michaelis-Menton model more closely approximated that data from chambers where a solid matrix was present. The Michaelis-Menton model is used under conditions where microbial growth does not occur. The fact that Michaelis-Menton model more closely approximated the kinetics of product formation in the chambers than the Monod model did suggests that microbial growth was inhibited in some way by the presence of the porous media.

The fermentation of glucose by a holotolerant, polymer-producing bacterium, strain SP018, was studied in batch and continuous culture under aerobic and anaerobic conditions. Anaerobically, glucose was fermented to lactate, ethanol, carbon dioxide, plus an additional unidentified product. The yields of cells and polymer from glucose, and the maintenance coefficient were determined. Growth yield data indicated that the organism was not very efficient at conserving energy, or that the organism had a high maintenance requirement. The time course of glucose utilization was complex, and exponential decrease in glucose concentration as predicted from Monod kinetics was not observed. The pattern for polymer production was also complex since polymer production was observed at two different times during the course of the fermentation. Thus, predicting polymer production and glucose degradation by this organism will be difficult. 


\subsection{Executive Summary of Current Work}

The three-phase, multispecies, one-dimensional model developed for microbial selective plugging was expended to a three-dimensional, three-phase, multi-component flow model that included mathematical expression for physical, chemical, and biological reactions in porous medià. The model included component transport equations, microbial growth equations, equations for product formation (acids, gases, solvents, polymer, and biosurfactant) and nutrient consumption (glucose and ammonium nitrate), black oil formulations, and oil recovery equations. Transport of microorganisms, nutrients and metabolic products in the aqueous phase occurred by viscous, capillary, gravity, and dispersion forces. The model assumed that bacterial growth was limited by a single substrate, or by two substrates that are in low concentrations. Also, the production of certain end-product such as alcohol inhibited growth. Plugging of porous media by bacterial cells occurred as a consequence of two processes, the deposition of cells on pore surfaces which reduces porosity, and the entrapment of cells near pore throats which blocks fluid flow through these channels. A black oil simulation model was used to describe the simultaneous flow of oil, water, and gas phases in porous media during the microbially enhanced oil recovery (MEOR) processes. Finally, the MEOR simulator contained several mechanisms by which additional oil is recovered by microbial processes. These mechanisms included interfacial tension reduction, capillary desaturation, relative permeability alteration, and mobility control by biopolymers. The phase pressure and component transport equations derived for the MEOR simulator were a set of coupled, nonlinear, partial differential equations. These equations were transformed into discrete forms using finite differences, An implicit pressure, explicit saturation technique (IMPES) 
was used to solve the pressure and phase saturations. This was followed by the solution of component transport equations.

The MEOR simulator was verified using analytical solutions and other simulators. Special cases regarding growth inhibition, chemotaxis, microbial plugging, biopolymer production, biosurfactant production, and gas production were used to test the simulator and investigate the mechanisms involved in MEOR processes. The simulation results showed that additional oil was recovered by the following processes: selective plugging, mobility control due to polymer production, and interfacial tension reduction due to biosurfactant production. Simulation of a microbial process involving gas production showed did not result in additional oil recovery. Apparently, the amount of gas produced during an MEOR process was insufficient to recover additional oil.

Finally, the MEOR simulator was used to model and predict the movement of chemotactic and nonchemotactic strains through sand-packed systems under nonflowing conditions, and the results obtained from MEOR core flood experiments using indigenous halophilic bacteria, an acid/solvent/gas-producing bacterium, and a biosurfactantproducing bacterium. The simulator accurately predicted the consumption of glucose and nitrate and the production of gases by indigenous halophilic bacteria in a Berea sandstone core. The proposed surface retention and pore throat plugging model accurately simulated the observed permeability reductions. Experimental studies showed that chemotactic bacteria move through porous materials in a band-like fashion, while nonchemotactic bacteria move in more diffusive manner. The MEOR simulator accurately simulated these types of bacterial movement. The production gas, acids, and solvents by Clostridium acetobutylicum was accurately predicted by the MEOR simulator. Finally, the simulator showed that oil recovery by a biosurfactant-producing bacterium was proportional to the amount of biosurfactant produced. 
The transport, growth, and metabolism of microorganisms in porous materials was accurately quantified, and this information could be used to predict the amount of oil recovery from MEOR processes. Case studies showed that the major mechanisms for MEOR included improvements in sweep efficiency either by permeability reduction or by mobility control, and increase in the capillary number due to interfacial tension reductions resulting from biosurfactant production. Microbial gas production was not an effective reservoir-wide process for oil recovery. 


\section{INTRODUCTION}

Primary production of crude oil is achieved by the depletion of the natural reservoir energy. Waterflooding as a secondary recovery technique is used to restore the reservoir pressure and displace the oil. After water breakthrough at producing wells, the water to oil ratio begins to increase until oil production is no longer economical. Unfortunately, up to two-thirds of the original oil-in-place remains in subsurface reservoirs after primary and secondary recovery processes reach their economic limits. Enhanced oil recovery (EOR) methods are needed to recover the remaining oil. The tertiary recovery techniques include steam injection, in-situ combustion, $\mathrm{CO}_{2}$ flooding, and chemical flooding. All of these processes aim to improve the volumetric sweep efficiency, or to increase the capillary number. A cost-effective alternative to the above methods is to use microbes during waterflooding stage to improve oil recovery.

Microbially enhanced oil recovery (MEOR) processes involve injection of nutrients and perhaps microorganisms into the reservoir. Microbial growth and biopolymer production may lead to an improvement in the sweep efficiency of waterflood by permeability modification and/or increasing the viscosity of the displacing phase. Metabolic products such as surfactant, acids, and solvent may mobilize trapped crude oil by altering the surface characteristics of the rock or increasing capillary number.

The transport, growth, and metabolism of viable cells in subsurface formations are governed by complex physical, chemical, and biological phenomena. More research needs to be done before MEOR gains wide commercial acceptance. Associated with laboratory work, mathematical models are necessary to understand the mechanisms involved in the MEOR processes and to provide quantitative predictions for the design and evaluation of MEOR field projects. 
The objective of the final part of this project was to develop a mathematical model that simulates transport and metabolism of microorganisms and nutrients in porous media and predicts additional oil recovery as results of those microbial processes. The mathematical formulations include component transport equations, the black oil model, microbial kinetics equations, a permeability reduction model, and models of oil recovery processes. 


\section{LITERATURE REVIEW}

Here, a brief survey of the published literature on microbially enhanced oil recovery (MEOR) processes is presented. The scope of the review focuses on mechanisms involved in MEOR processes and mathematical modeling of MEOR processes.

\subsection{Mechanisms}

Permeability variation is one of the most significant factors affecting the degree of sweep efficiency and thus the performance of waterflooding processes. Many experimental studies $^{1-3}$ focused on testing the feasibility of a microbial process to selectively plug high permeability zones and thereby improve sweep efficiency and increase oil recovery. It has been shown (1) that viable bacteria and nutrients required for growth can be transported through sandstone cores, (2) that the in situ growth of bacteria results in significant reduction in permeability, (3) that the permeability reduction is selective for high permeability cores and improves sweep efficiency even under conditions where cross flow of fluids between regions occurs, and (4) that additional oil is recovered as a result of improved microscopic displacement and sweep efficiency.

Taylor $e l a l^{4,5}$ conducted experimental and theoretical investigations to quantify the permeability reduction caused by enhanced biological growth in a porous media. It was observed that enhanced biological activities in sand column reactors can reduce the permeability significantly. An analytical relationship was established between biofilm thickness and the resulting decrease in permeability.

The formation of gases during MEOR treatments was reported in field trials ${ }^{6}$ as well as in laboratory experiments. ${ }^{7,8}$ It was proposed that the produced gas such as $\mathrm{CO}_{2}$ 
can repressure reservoirs and swell crude oil to aid additional oil recovery. However, the observed increase in pressure and amount of gas produced are far below conditions required for miscibility. It appears that mechanisms of additional oil recovery in the presence of gases generated during microbial growth and metabolism are not clear.

Biosurfactants produced during growth and metabolism of bacteria may reduce interfacial tension between oil and water phases to mobilize residual oil trapped in porous media. Several anaerobic surfactants produced from species of Bacillus and Clostridium were reported. ${ }^{9,10}$ Micromodel studies ${ }^{7}$ with surfactant-producing microorganisms showed that emulsification of crude oil can occur during flow in a porous medium. Alcohol that microorganisms produce may act as a cosurfactant in microemulsion formulation.

Mobility control by high-viscosity biopolymer solutions may improve the sweep efficiency of the displacement process It was reported ${ }^{11}$ that a biopolymer produced anaerobically at $50^{\circ} \mathrm{C}$ and a salinity of $8 \%$ can increase culture viscosity to $4 \mathrm{cp}$ at a shear rate of $150 \mathrm{sec}^{-1}$.

\subsection{Mathematical Simulation}

Knapp et $a l^{12}$ developed an one-dimensional mathematical model to describe the microbial plugging process. The model was used to investigate the impact of cellular growth and retention on the spatial and temporal reduction in permeability of porous media. It was assumed that the development of a stationary phase is due solely to biomass retention, and convective transport is the dominant mechanism for bacterial transport. The governing equations included a convection-dispersion equation for bacteria and nutrient transport and a mass conservation equation for stationary phase development. 
Zhang et $a l^{13}$ reported an one-dimensional, multiple-component model to quantify biomass growth, product formation, substrate consumption involved in the MEOR processes. A modified Monod equation was used to describe bacterial growth assuming two substrates limited growth. Permeability reduction was assumed to be due to poresurface retention and pore-throat plugging by bacterial cells. Thus permeability reduction was modeled as combination of porosity reduction and flow-efficiency decrease. The modeled components included biomass, carbon dioxide, nitrogen, acid, glucose, and ammonium nitrate.

Sarkar, el at $^{14}$ developed an one-dimensional, two-phase, compositional numerical simulator to model the transport and growth of bacteria and oil recovery in MEOR process. The basic equations governing the transport of oil, water, bacteria, nutrient, and metabolites in porous media were component mass conservation equations. Permeability reduction was modeled using the effective medium theory. The oil recovery model is based on mechanisms such as interfacial tension reduction by biosurfactant and selective plugging by biomass. In their model, an implicit-pressure, explicit-concentration algorithm was used to solve pressure and mass conservation equations.

Islam ${ }^{15}$ presented a mathematical formulation to describe microbial transport in multidimensional porous media. In his formulation, multiphase flow equations were coupled with microbe and nutrient transport equations. Physical dispersion terms were neglected in the component transport equations. Since metabolic products were not included in this model, correlations which relate biomass to metabolites and their activities were defined. Numerical simulation runs were conducted to investigate bacterial plugging, interfacial tension reduction, carbon dioxide effects, etc. The results showed that surfactant-producing bacteria appeared to be most promising. 
Chang et $a l^{16,17}$ incorporated the governing equations for microbial and nutrient transport into a three-dimensional, three-phase black oil model. Microbial activities simulated included net flux of microbes by convection and dispersion, microbial growth, decay, and chemotaxis, nutrient consumption, and deposition of microbes on rock grain surfaces. The alteration in rock wettability during microbial treatments was considered as the mechanism for oil recovery. Based on experimental results, empirical correlations between cell concentrations and the rock wettability, and between the rock wettability and residual phase saturations were established. In their simulator, the IMPES procedure was employed to solve pressure and saturations while a direct sparse matrix method was used to obtain solutions for component transport equations. 


\section{MATHEMATICAL MODELS}

In this chapter, mathematical formulations for three-dimensional, three-phase, multiple-component flow with physical, chemical, and biological reactions in porous media have been developed under basic assumptions. The proposed models include component transport equations, the black oil model, microbial kinetics equations, a permeability reduction model, and models of oil recovery processes.

\subsection{Assumptions}

The following major assumptions have been made in developing the mathematical model for MEOR processes:

1. The three-dimensional reservoir is surrounded by impermeable zones.

2. The formation and fluids are slightly compressible.

3. The presence of three fluid phases (oil, water, and gas) is considered.

4. Bacteria, nutrients, and metabolic products are present in the aqueous phase.

5. Biogases generated from microbial growth and metabolism are modeled as in situ source terms for the gas phase.

6. The reservoir is isothermal.

\subsection{Component Transport Equations}

The multiple-component flow in porous media occurs as transport of microorganisms, nutrients, and metabolic products in the aqueous phase under the 
influence of predominant forces such as viscous, capillary, gravity, and dispersion forces. A general material balance equation for component $\mathrm{k}$ can be written as:

$$
\frac{\partial}{\partial t}\left(\frac{\phi S_{w}}{B_{w}} C_{k}+\phi C_{k s}\right)=-\nabla\left(\frac{\vec{u}_{t}}{B_{w}} C_{k}\right)+\nabla\left(\frac{\phi S_{w}}{B_{w}} \vec{D}_{k w} \nabla C_{k}\right)-\frac{q_{w}}{V_{b}} C_{k}+\frac{\phi S_{w}}{B_{w}} R_{k}
$$

where, $\mathrm{C}_{\mathrm{k}}$ and $\mathrm{C}_{\mathrm{ks}}$ are flowing and sorbed mass concentrations at surface conditions for component $k ; \phi$ is rock porosity; $S_{w}, B_{w}$, and $q_{w}$ are saturation, formation volume factor, and volumetric injection/production rate for water phase, respectively; $V_{b}$ is the rock bulk volume; $\vec{u}_{\mathfrak{t}}$ is total flow velocity which is defined as the sum of Darcy and chemotactic velocities for bacteria and the Darcy velocity only for other components; $\overrightarrow{\vec{D}}_{\mathrm{kw}}$ is the physical dispersion tensor for component $k$ in the water phase; $R_{k}$ represents the biological reaction rate for bacterial growth, product formation, or nutrient consumption.

The two terms in the left hand side of Eq (5.1) represent mass accumulation in aqueous phase and mass adsorption within the pore space for component $\mathrm{k}$. The four terms in the right hand side of $\mathrm{Eq}$ (5.1) are convection, dispersion, injection/production, and biological reaction for component $\mathrm{k}$, respectively. Component $\mathrm{k}$ in this equation could be bacteria (b), metabolic products (p), or substrates (s).

The total velocity $\vec{u}_{t}$ in convection term of $\mathrm{Eq}(5.1)$ is defined as follows:

$$
\overrightarrow{\mathrm{u}}_{\mathrm{t}}=\overrightarrow{\mathrm{u}}_{\mathrm{w}}+\overrightarrow{\mathrm{u}}_{\mathrm{c}} \quad \text { for bacteria }
$$

$$
\overrightarrow{\mathrm{u}}_{\mathrm{t}}=\overrightarrow{\mathrm{u}}_{\mathrm{w}} \quad \text { for metabolic products or substrates }
$$


where, $\overrightarrow{\mathrm{u}}_{\mathrm{w}}$ represents the Darcy velocity (flux) for water phase and $\overrightarrow{\mathrm{u}}_{\mathrm{c}}$ is the chemotactic velocity for bacterial migration towards a richer nutrient supply.

Chemotaxis is defined as directed movement of a cell toward an attractant. Microorganisms can sense a nutrient-rich environment in all three dimensions. Darcy flow occurs due to pressure gradient while the chemotactic movement of bacteria is assumed to be proportional to an exponential change in substrate concentration: ${ }^{18}$

$$
\overrightarrow{\mathrm{u}}_{\mathrm{c}}=\mathrm{K}_{\mathrm{c}} \nabla\left(\ln \mathrm{C}_{\mathrm{s}}\right)
$$

where, $\mathrm{K}_{\mathrm{c}}$ is chemotactic coefficient; $\mathrm{C}_{\mathrm{s}}$ is substrate concentration.

Compared with convective flow, the chemotactic movement of bacteria is much slower. Thus chemotaxis becomes significant only under static conditions.

Physical dispersion phenomena is characterized by a full dispersion tensor: ${ }^{19}$

$$
\overrightarrow{\mathrm{D}}_{\mathrm{kw}}=\left[\begin{array}{lll}
\mathrm{D}_{\mathrm{kw}, \mathrm{xx}} & \mathrm{D}_{\mathrm{kw}, \mathrm{xy}} & \mathrm{D}_{\mathrm{kw}, \mathrm{xz}} \\
\mathrm{D}_{\mathrm{kw}, \mathrm{yx}} & \mathrm{D}_{\mathrm{kw}, \mathrm{yy}} & \mathrm{D}_{\mathrm{kw}, \mathrm{yz}} \\
D_{\mathrm{kw}, \mathrm{zx}} & \mathrm{D}_{\mathrm{kw}, \mathrm{zy}} & \mathrm{D}_{\mathrm{kw}, \mathrm{zz}}
\end{array}\right]
$$

The elements of the dispersion tensor include both molecular diffusion and mechanical dispersion. For an isotropic medium, those elements are given as: ${ }^{19}$

$$
\begin{aligned}
& D_{k w, x x}=\frac{D_{k}}{\tau}+\frac{\left(\alpha_{1 w}-\alpha_{t w}\right)}{\phi S_{w}} \frac{u_{w x}^{2}}{\left|\vec{u}_{w}\right|}+\frac{\alpha_{t w}\left|\vec{u}_{w}\right|}{\phi S_{w}} \\
& D_{k w, y y}=\frac{D_{k}}{\tau}+\frac{\left(\alpha_{1 w}-\alpha_{t w}\right)}{\phi S_{w}} \frac{u_{w y}^{2}}{\left|\vec{u}_{w}\right|}+\frac{\alpha_{t w}\left|\vec{u}_{w}\right|}{\phi S_{w}}
\end{aligned}
$$




$$
\begin{aligned}
& D_{k w, z z}=\frac{D_{k}}{\tau}+\frac{\left(\alpha_{l w}-\alpha_{t w}\right)}{\phi S_{w}} \frac{u_{w z}^{2}}{\left|\vec{u}_{w}\right|}+\frac{\alpha_{t w}\left|\vec{u}_{w}\right|}{\phi S_{w}} \\
& D_{k w, x y}=D_{k w, y x}=\frac{\left(\alpha_{l w}-\alpha_{t w}\right)}{\phi S_{w}\left|\vec{u}_{w}\right|}\left|u_{w x} u_{w y}\right| \\
& D_{k w, x z}=D_{k w, z x}=\frac{\left(\alpha_{l w}-\alpha_{t w}\right)}{\phi S_{w}\left|\vec{u}_{w}\right|}\left|u_{w x} u_{w z}\right| \\
& D_{k w, y z}=D_{k w, z y}=\frac{\left(\alpha_{l w}-\alpha_{t w}\right)}{\phi S_{w}\left|\vec{u}_{w}\right|}\left|u_{w y} u_{w z}\right|
\end{aligned}
$$

where, $D_{k}$ is molecular diffusion coefficient for component $k$ in water phase; $\tau$ is tortuosity; $\alpha_{\mathrm{lw}}$ and $\alpha_{\mathrm{tw}}$ are longitudinal and transverse dispersivities; $\mathrm{u}_{\mathrm{wx}}, \mathrm{u}_{\mathrm{wy}}$, and $\mathrm{u}_{\mathrm{wz}}$ are components of Darcy's velocity for water phase in X-, Y-, and Z-directions, respectively. The norm of Darcy velocities for water phase is calculated by:

$$
\left|\vec{u}_{w}\right|=\sqrt{u_{w x}^{2}+u_{w y}^{2}+u_{w z}^{2}}
$$

\subsection{Growth, Production, and Consumption Rates}

Bacterial growth can be limited by either a single-substrate or a double-substrate medium. The growth may be inhibited by some metabolic end products such alcohol. A Monod type of specific growth rate with modifications of double-substrate limitation and product inhibition can be expressed as: ${ }^{20}$ 


$$
\mu_{\mathrm{b}}=\mu_{\mathrm{bm}}\left(\frac{\mathrm{C}_{\mathrm{s} 1}}{\mathrm{~K}_{\mathrm{b} / \mathrm{s} 1}+\mathrm{C}_{\mathrm{s} 1}}\right)\left(\frac{\mathrm{C}_{\mathrm{s} 2}}{\mathrm{~K}_{\mathrm{b} / \mathrm{s} 2}+\mathrm{C}_{\mathrm{s} 2}}\right)\left(\frac{\mathrm{K}_{\mathrm{i}}}{\mathrm{K}_{\mathrm{i}}+\mathrm{C}_{\mathrm{i}}}\right)
$$

where, $\mu_{\mathrm{bm}}$ is maximum specific growth rate; $\mathrm{C}_{\mathrm{s} 1}$ and $\mathrm{C}_{\mathrm{s} 2}$ are concentrations for substrates $\# 1$ and \#2, respectively; $\mathrm{K}_{\mathrm{b} / \mathrm{s} 1}$ and $\mathrm{K}_{\mathrm{b} / \mathrm{2} 2}$ are saturation constants for substrates \#1 and \#2; $\mathrm{K}_{\mathrm{i}}$ is the inhibition constant, and $C_{i}$ is the concentration of inhibitor. If growth is controlled by only one substrate and growth inhibition is negligible, Eq (5.13) is reduced to a regular Monod model:

$$
\mu_{\mathrm{b}}=\mu_{\mathrm{bm}} \frac{\mathrm{C}_{\mathrm{sl}}}{\mathrm{K}_{\mathrm{b} / \mathrm{sl}}+\mathrm{C}_{\mathrm{sl}}}
$$

Thus, biomass production rates for both the planktonic $\left(\mathrm{R}_{\mathrm{b}}\right)$ and sessile $\left(\mathrm{R}_{\mathrm{bs}}\right)$ bacterial phases can be computed by:

$$
\begin{aligned}
& \mathbf{R}_{b f}=\mu_{b} \mathbf{C}_{\mathbf{b}} \\
& \mathbf{R}_{\mathrm{bs}}=\mu_{\mathbf{b}}\left(\sigma \rho_{\mathrm{bsc}}\right)
\end{aligned}
$$

where, $\mathrm{C}_{\mathrm{b}}$ is concentration for the flowing bacteria; $\sigma$ is pore volume fraction occupied by bacteria sorbed on pore surfaces; $\rho_{b s c}$ is biomass density at surface condition.

It is assumed that formation of metabolic end products occurs in both the planktonic and sessile phases of bacteria. A proposed empirical equation ${ }^{21}$ has been used to calculate production rate: 


$$
R_{p}=\mu_{p m}\left(\frac{C_{s}-C_{s c}}{K_{p / s}+C_{s}-C_{s c}}\right)\left(C_{b}+\sigma \rho_{b}\right) \quad \text { for } C_{s}>C_{s c}
$$

where, $\mu_{\mathrm{pm}}$ is maximum specific production rate for product $\mathrm{p} ; \mathrm{K}_{\mathrm{p} / \mathrm{s}}$ is saturation constant for formation of product $\mathrm{p}$ by consumption of substrate $\mathrm{s} ; \mathrm{C}_{\mathrm{sc}}$ is critical substrate concentration for product formation. Metabolic products modeled in this study are nitrogen, carbon dioxide, acid, alcohol, surfactant, and polymer.

Substrates are consumed to multiply cell mass, form metabolic products, and provide energy for maintenance. The rate of substrate utilization is related stoichiometrically to the rates of cell growth and product formation, and also related to maintenance energy: ${ }^{20}$

$$
\mathbf{R}_{s}=-\frac{\mathbf{R}_{b}}{Y_{b / s}}-\left(\sum_{p=1}^{N P} \frac{R_{p}}{Y_{p / s}}\right)-m_{s}\left(\mathbf{C}_{b}+\sigma \rho_{b s c}\right)
$$

where, $R_{s}, R_{b}$, and $R_{p}$ are rates for substrate consumption, bacterial growth, and metabolic product formation, respectively; $\mathrm{Y}_{\mathrm{b} / \mathrm{s}}$ and $\mathrm{Y}_{\mathrm{p} / \mathrm{s}}$ are coefficients for biomass and product yields from substrate, respectively; $m_{s}$ is the coefficient for maintenance energy provided by consuming substrate.

\subsection{Adsorptions}

Adsorption of microorganisms from aqueous suspension onto pore surfaces is considered as the results of dynamic processes which are simultaneous particle exchanges between the flowing and stationary phases of bacteria: ${ }^{22}$ 


$$
\frac{\partial \mathbf{C}_{\mathrm{bs}}}{\partial \mathrm{t}}=\mathbf{R}_{\mathrm{r}}-\mathbf{R}_{\mathbf{d}}
$$

where, $\mathrm{C}_{\mathrm{bs}}$ is sorbed biomass per unit pore volume; $\mathrm{R}_{\mathrm{r}}$ and $\mathrm{R}_{\mathrm{d}}$ are retention and detachment rates for microorganisms, respectively.

The cell retention rate is proportional to biomass entering a given area $"\left|\vec{u}_{w}\right| C_{b} "$ and to the plugging capacity of the porous media " $1-\sigma "$. The cell detachment rate is a function of the retained biomass " $\sigma \rho_{b}$ " and the shear force between the flowing and stationary phases " $\left|\nabla \Phi_{\mathrm{w}}\right| "$ ". Thus $\mathrm{R}_{\mathrm{r}}$ and $\mathrm{R}_{\mathrm{d}}$ can be expressed as: ${ }^{22}$

$$
\begin{aligned}
& \mathbf{R}_{\mathrm{r}}=\mathbf{K}_{\mathrm{r}}\left|\overline{\mathbf{u}}_{\mathrm{w}}\right| \mathrm{C}_{\mathrm{b}}(1-\sigma) \\
& \mathbf{R}_{\mathbf{d}}=\mathbf{K}_{\mathbf{d}}\left(\sigma \rho_{\mathrm{b}}\right)\left|\nabla \Phi_{\mathrm{w}}\right|
\end{aligned}
$$

where, $\mathrm{K}_{\mathrm{r}}$ and $\mathrm{K}_{\mathrm{d}}$ are retention and detachment coefficients and $\Phi_{\mathrm{w}}$ is the water-phase potential.

Adsorption of metabolic products or substrates is modeled by the Langmuir isotherm which assumes instantaneous equilibrium compared with the rate of convection and dispersion: ${ }^{23}$

$$
C_{k s}=\frac{a_{k} C_{k}}{1+b_{k} C_{k}}
$$

where, $C_{k s}$ is the sorbed mass of component $k$ per unit pore volume; $a_{k}$ and $b_{k}$ are Langmuir adsorption constants for component $k ; C_{k}$ is the mass concentration for component $\mathrm{k}$ in aqueous suspension. 


\subsection{Permeability Reduction Model}

Plugging of porous media by bacterial cells occurs in such a way: (1) that cells may deposit on pore surfaces to reduce pore spaces available to fluids and (2) that cells may be trapped at or retained near pore throat to clog or bridge connections between channels through which fluids flow. Thus, permeability is modeled in terms of porosity reduction and flow-efficiency alteration: $12,13,24$

$$
\frac{\mathrm{K}}{\mathrm{K}_{0}}=\mathrm{f}\left(\frac{\phi}{\phi_{0}}\right)^{3}
$$

where, $K_{0}$ and $\phi_{0}$ are initial permeability and porosity, respectively; $K$ and $\phi$ are the instantaneous permeability and porosity during MEOR processes; $f$ is defined as a flow efficiency factor related to pore-throat plugging phenomena.

Porosity reduction is considered only due to biomass development on pore surfaces. Effects of other components on porosity reduction are neglected. The following equation determines instantaneous porosity in the presence of the sessile biomass $(\sigma): 12$

$$
\phi=\phi_{0}(1-\sigma)
$$

The accumulation of bacterial cells deposited on pore surface forms stationary biofilms (sessile bacteria). The sessile bacteria can grow by consumption of nutrients to occupy more pore spaces. A conservation equation states that sessile biomass development depends on bacterial retention $\left(R_{\tau}\right)$, detachment $\left(R_{d}\right)$, and growth $\left(R_{b s}\right): 13,22$ 


$$
\frac{\partial\left(\sigma \rho_{b s c}\right)}{\partial t}=\mathbf{R}_{r}-\mathbf{R}_{d}+\mathbf{R}_{b s}
$$

From a probabilistic point of view, the unplugging or flow efficiency factor (f) can be determined by estimating the likelihood of pore-throat plugging by biomass: ${ }^{24}$

$$
f=1-\frac{\int_{\min }^{x_{\text {cot }}} g(x) d x}{\int_{x_{\min }}^{x_{\max }} g(x) d x}
$$

where, $x_{\min }$ and $x_{\max }$ are minimum and maximum pore throat sizes; $x_{c t}$ is critical pore throat size necessary for microbial plugging; $g(x)$ is the bimodal distribution function for pore throat sizes, which is given by:25

$$
g(x)=w_{1}(x)+(1-w) g_{2}(x)
$$

where, $x$ is pore throat size; $g_{1}(x)$ and $g_{2}(x)$ are two unimodal distribution functions for pore throat sizes; $w$ is weighting factor, $0 \leq w \leq 1 . g_{1}(x)$ and $g_{2}(x)$ are expressed as:25

$$
g_{1}(x)=\frac{\left(x-x_{\min }\right)^{e_{1} m_{1}}\left(x_{\max }-x\right)^{m_{1}}}{\left.\int_{x_{\min }}^{x_{\max }\left(x-x_{\min }\right.}\right)^{e_{1} m_{1}}\left(x_{\max }-x\right)^{m_{1}} d x}
$$




$$
g_{2}(x)=\frac{\left(x-x_{\min }\right)^{e_{2} m_{2}}\left(x_{\text {max }}-x\right)^{m_{2}}}{\int_{x_{\min }}^{x_{\max }}\left(x-x_{\min }\right)^{e_{2} m_{2}}\left(x_{\max }-x\right)^{m_{2}} d x}
$$

where, $e_{1}, e_{2}, m_{1}$, and $m_{2}$ are exponent parameters that control the shapes of distributions.

For computational convenience, the flow efficiency factor and pore-throat distribution functions can be expressed as dimensionless forms:

$$
f=1-\frac{\int_{y_{\min }}^{y_{\text {crt }}} g(y) d y}{y_{y_{\max }}^{\max } g(y) d y}
$$

$$
g(y)=w_{1}(y)+(1-w) g_{2}(y)
$$

$$
g_{1}(y)=\frac{\left(y-y_{\min }\right)^{e_{1} m_{1}}\left(y_{\max }-y\right)^{m_{1}}}{\left(x_{\max }-x_{\min }\right) \int_{y_{\min }}^{y_{\max }}\left(y-y_{\min }\right)^{e_{1} m_{1}}\left(y_{\max }-y\right)^{m_{1}} d y}
$$




$$
g_{2}(y)=\frac{\left(y-y_{\min }\right)^{e_{2} m_{2}}\left(y_{\max }-y\right)^{m_{2}}}{\left(x_{\max }-x_{\min }\right) \int_{y_{\min }}^{y_{\max }}\left(y-y_{\min }\right)^{e_{2} m_{2}}\left(y_{\max }-y\right)^{m_{2}} d y}
$$

where, dimensionless variables are defined as:

$$
\begin{aligned}
& y=\frac{x}{x_{\max }-x_{\min }} \\
& y_{\text {crt }}=\frac{x_{c r t}}{x_{\text {max }}-x_{\min }} \\
& y_{\min }=\frac{x_{\min }}{x_{\max }-x_{\min }} \\
& y_{\max }=\frac{x_{\max }}{x_{\max }-x_{\min }}
\end{aligned}
$$

An empirical expression has been proposed as a criterion to determine microbial plugging of pore throats: ${ }^{13,24}$

$$
\frac{\mathrm{x}}{\mathrm{x}_{\mathrm{cb}}} \leq \alpha_{\mathrm{e}}\left[1-\exp \left(-\beta_{\mathrm{e}} \frac{\mathrm{C}_{\mathrm{b}}\left|\overrightarrow{\mathrm{u}}_{\mathrm{w}}\right|}{\phi}-\gamma_{\mathrm{e}} \sigma\right)\right]
$$


where, $\mathrm{x} / \mathrm{x}_{\mathrm{cb}}$ is a ratio of pore-throat size to cell-body size; $\alpha_{\mathrm{e}}, \beta_{\mathrm{e}}$, and $\gamma_{\mathrm{e}}$ are empirical parameters. Thus a critical pore-throat size $\left(\mathrm{x}_{\mathrm{crt}}\right)$ necessary for clogging and bridging of pore throats by cells can be computed by:

$$
x_{c r t}=\alpha_{e} x_{c b}\left[1-\exp \left(-\beta_{e} \frac{C_{b}\left|\vec{u}_{w}\right|}{\phi}-\gamma_{e} \sigma\right)\right]
$$

where, the bacterial cell size, $x_{c b}$, is assumed to be uniform for all cells.

Eq.(5.39) states that the range of the pore throat $\left(x_{\mathrm{crt}}\right)$ plugged by cells increases as the planktonic bacterium concentration $\left(C_{b}\right)$, the flow velocity $\left(\left|\vec{u}_{w}\right| / \phi\right)$, and the sessile biomass fraction $(\sigma)$ increase during MEOR processes.

\subsection{Black Oil Model}

Beside multiple-component transport equations, a multiphase transport model is developed to describe the simultaneous flow of oil, water, and gas phases in porous media during MEOR processes.

Consider flow of a single component $\mathrm{c}$ which is found in all three fluid phases, i.e. oil (o), water (w) and gas (g). Thus a typical mass balance equation for component $\mathrm{c}$ can be derived:26

$$
\frac{\partial}{\partial \mathrm{t}}\left(\phi \sum_{\ell=\mathbf{o}, \mathbf{w}, \mathbf{g}} \mathrm{x}_{\mathrm{c} \ell} \rho_{\ell} \mathbf{s}_{\ell}\right)=-\nabla\left(\sum_{\ell=\mathbf{o}, \mathbf{w}, \mathbf{g}} \mathrm{x}_{\mathrm{c} \ell} \rho_{\ell} \overrightarrow{\mathbf{u}}_{\ell}\right)-\sum_{\ell=\mathbf{o , w}, \mathbf{g}} \mathbf{x}_{\mathrm{c} \ell} \tilde{\mathrm{m}}_{\ell}
$$


where, $x_{\mathrm{c} \ell}$ is the mass fraction of component $\mathrm{c}$ in phase $\ell ; \rho_{\ell}$ is phase density at reservoir conditions; $S_{\ell}$ is satruation for phase $\ell ; \overrightarrow{\mathrm{u}}_{\ell}$ is Darcy flux for phase $\ell ; \tilde{\mathrm{m}}_{\ell}$ is mass injection/production rate per unit rock bulk volume for phase $\ell$.

For the black oil model, only three pseudocomponents will be considered: oil (o), water (w), and gas (g). Additional assumptions are made (1) that no phase transfer occurs between the water and oil, and (2) that gas can move in and out of the oil and water phases, but the oil and water are not allowed to vaporize into the gas phase. These assumptions lead to the following:

$$
\begin{array}{lll}
x_{o o}=\frac{\rho_{\text {osc }}}{\rho_{0} B_{o}} & x_{w o}=0 & x_{g o}=\frac{\rho_{g s c} R_{s o}}{\rho_{0} B_{o}} \\
x_{o w}=0 & x_{w w}=\frac{\rho_{w s c}}{\rho_{w} B_{w}} & x_{g w}=\frac{\rho_{g s c} R_{s w}}{\rho_{w} B_{w}} \\
x_{0 g}=0 & x_{w g}=0 & x_{g g}=\frac{\rho_{g s c}}{\rho_{g} B_{g}}
\end{array}
$$

where, $\rho_{\mathrm{osc}}, \rho_{\mathrm{wsc}}$, and $\rho_{\mathrm{gsc}}$ are densities for oil, water, and gas phases at surface condition, respectively; $\mathrm{B}_{\mathrm{o}}, \mathrm{B}_{\mathrm{w}}$, and $\mathrm{B}_{\mathrm{g}}$, are formation volume factors for oil, water, and gas phases; $\mathbf{R}_{\mathrm{so}}$ and $\mathbf{R}_{\mathrm{sw}}$ are solution gas-oil and gas-water ratios.

Using above relationships, the following continuity equations for multiphase flow can be obtained: 


$$
\begin{array}{ll}
\frac{\partial}{\partial t}\left(\phi \frac{S_{o}}{B_{o}}\right)=\nabla\left(\frac{\vec{u}_{o}}{B_{o}}\right)-Q_{o} & \text { for oil } \\
\frac{\partial}{\partial t}\left(\phi \frac{S_{w}}{B_{w}}\right)=\nabla\left(\frac{\vec{u}_{w}}{B_{w}}\right)-Q_{w} & \text { for water } \\
\frac{\partial}{\partial t}\left[\phi\left(\frac{S_{g}}{B_{g}}+\frac{R_{s o} S_{o}}{B_{o}}+\frac{R_{s w} S_{w}}{B_{w}}\right)\right]=\nabla\left(\frac{\vec{u}_{g}}{B_{g}}+\frac{R_{s o} \vec{u}_{o}}{B_{o}}+\frac{R_{s w} \vec{u}_{w}}{B_{w}}\right) & \\
-\left(Q_{g}+R_{s o} Q_{o}+R_{s w} Q_{w}\right) & \text { for gas }
\end{array}
$$

where, $Q_{o}, Q_{w}$, and $Q_{g}$ are volumetric flow rates per unit rock bulk volume for oil, water, and gas phases. These rates are defined as:

$$
\mathrm{Q}_{\ell}=\frac{\tilde{\mathrm{m}}_{\ell}}{\rho_{\ell} \mathrm{B}_{\ell}} \quad \ell=\mathrm{o}, \mathrm{w}, \mathrm{g}
$$

Darcy fluxes for oil, water, and gas phases are given:

$$
\overrightarrow{\mathrm{u}}_{\ell}=-\frac{\overline{\mathrm{K}} \mathrm{K}_{\mathrm{r} \ell}}{\mu_{\ell}} \nabla\left(\mathrm{p}_{\ell}-\rho_{\ell} \frac{\mathrm{g}}{\mathrm{g}_{\mathrm{c}}} \mathrm{h}\right)
$$

where, $\overrightarrow{\mathrm{K}}$ is a diagonal permeability tensor; $\mathrm{K}_{\mathrm{r} \ell}, \mu_{\ell}, \mathrm{p}_{\ell}$, and $\rho_{\ell}$ are relative permeability, viscosity, pressure, and density for phase $\ell$, respectively; $g$ is the gravitational acceleration and $g_{c}$ is a conversion constant; $h$ is a positive distance below some horizontal 
reference plane. The densities for oil, water, and oil phases are related to formation volume factor and gas solubilities by:

$$
\begin{aligned}
& \rho_{\mathrm{o}}=\frac{1}{\mathrm{~B}_{\mathrm{o}}}\left(\rho_{\mathrm{osc}}+\mathrm{R}_{\mathrm{so}} \rho_{\mathrm{osc}}\right) \\
& \rho_{\mathrm{w}}=\frac{1}{\mathrm{~B}_{\mathrm{w}}}\left(\rho_{\mathrm{wsc}}+\mathrm{R}_{\mathrm{sw}} \rho_{\mathrm{wsc}}\right) \\
& \rho_{\mathrm{g}}=\frac{\rho_{\mathrm{gsc}}}{\mathrm{B}_{\mathrm{g}}}
\end{aligned}
$$

The differences between phase pressures for oil-water and gas-oil systems are defined by capillary pressure concept:

$$
\begin{aligned}
& p_{\text {cow }}=p_{o}-p_{w} \\
& p_{\text {cgo }}=p_{g}-p_{o}
\end{aligned}
$$

where, $p_{c o w}$ and $p_{c g o}$ are capillary pressures for oil-water and gas-oil systems. Saturations for oil, water, and gas phases satisfy the following relationship:

$$
S_{o}+S_{w}+S_{g}=1
$$


Using IMPES formulation and combining Equations (5.42) through (5.52), a governing equation for the oil phase pressure (p) can be derived:27

$$
\phi \mathrm{C}_{\mathrm{t}} \frac{\partial \mathrm{p}}{\partial \mathrm{t}}=\sum_{\ell=\mathbf{o}, \mathrm{w}, \mathrm{g}} \beta_{\ell}\left[\nabla\left(\Psi_{\ell} \nabla \mathrm{p}\right)+\mathrm{GC}_{\ell}-\frac{\mathrm{q}_{\ell}}{\mathrm{V}_{\mathrm{b}}}\right]
$$

where, $C_{t}$ is total compressibility; $\beta_{\ell}$ is related to formation volume factor for phase $\ell ; \Psi_{\ell}$ represents transmissibility for phase $\ell ; \mathrm{GC}_{\ell}$ is a term including gravity and capillary pressure for phase $\ell ; \mathrm{q}_{\ell}$ is volumetric injection or production rate for phase $\ell$. All these terms are defined as:

$$
\begin{aligned}
& C_{t}=C_{r}+C_{o} S_{o}+C_{w} S_{w}+C_{g} S_{g} \\
& C_{r}=\frac{1}{\phi} \frac{\partial \phi}{\partial p} \\
& C_{o}=-\frac{1}{B_{o}} \frac{\partial B_{0}}{\partial p}+\frac{B_{g}}{B_{o}} \frac{\partial R_{s o}}{\partial p} \\
& C_{w}=-\frac{1}{B_{w}} \frac{\partial B_{w}}{\partial p}+\frac{B_{g}}{B_{w}} \frac{\partial R_{s w}}{\partial p} \\
& C_{g}=-\frac{1}{B_{g}} \frac{\partial B_{g}}{\partial p}
\end{aligned}
$$




$$
\begin{aligned}
& \beta_{o}=B_{o}-R_{s 0} B_{g} \\
& \beta_{w}=B_{w}-R_{s w} B_{g} \\
& \beta_{\mathrm{g}}=\mathrm{B}_{\mathrm{g}} \\
& \Psi_{0}=\frac{\overrightarrow{\hat{K}} K_{r 0}}{B_{0} \mu_{0}} \\
& \Psi_{\mathrm{w}}=\frac{\overrightarrow{\overrightarrow{\mathrm{K}}} \mathrm{K}_{\mathrm{rw}}}{\mathrm{B}_{\mathrm{w}} \mu_{\mathrm{w}}} \\
& \Psi_{\mathrm{g}}=\frac{\overrightarrow{\overline{\mathrm{K}}} \mathrm{K}_{\mathrm{rg}}}{\mathrm{B}_{\mathrm{g}} \mu_{\mathrm{g}}}+\mathrm{R}_{\mathrm{so}} \Psi_{\mathrm{o}}+\mathrm{R}_{\mathrm{sw}} \Psi_{\mathrm{w}} \\
& \overrightarrow{\overrightarrow{\mathbf{K}}}=\left[\begin{array}{lll}
\mathrm{K}_{\mathrm{x}} & & \\
& \mathrm{K}_{\mathrm{y}} & \\
& & \mathrm{K}_{\mathrm{z}}
\end{array}\right] \\
& \mathrm{GC}_{\mathrm{o}}=-\nabla\left[\Psi_{\mathrm{o}} \nabla\left(\rho_{\mathrm{o}} \frac{\mathrm{g}}{\mathrm{g}_{\mathrm{c}}} \mathrm{z}\right)\right] \\
& \mathrm{GC}_{\mathrm{w}}=-\nabla\left[\Psi_{\mathrm{w}} \nabla\left(\rho_{\mathrm{w}} \frac{\mathrm{g}}{\mathrm{g}_{\mathrm{c}}} \mathbf{z}+\mathrm{p}_{\mathrm{cow}}\right)\right]
\end{aligned}
$$




$$
\begin{aligned}
& G_{g}=-\nabla\left[\Psi_{g} \nabla\left(\rho_{g} \frac{g}{g_{c}} z-p_{c g o}\right)\right]+R_{s o} G C_{o}+R_{s w} G C_{w} \\
& q_{o}=Q_{o} V_{b} \\
& q_{w}=Q_{w} V_{b} \\
& q_{g}^{*}=Q_{g} V_{b} \\
& q_{g}=q_{g}^{*}+R_{s o} q_{o}+R_{s w} q_{w}
\end{aligned}
$$

Once the oil phase pressure is determined from the equations above, the phase saturations for oil, water, and gas can be found by using the following equations:

$$
\begin{aligned}
& \frac{\partial}{\partial t}\left(\phi \frac{S_{0}}{B_{o}}\right)=\nabla\left(\Psi_{o} \nabla p\right)+G_{o}-\frac{q_{o}}{V_{b}} \\
& \frac{\partial}{\partial t}\left(\phi \frac{S_{w}}{B_{w}}\right)=\nabla\left(\Psi_{w} \nabla p\right)+G C_{w}-\frac{q_{w}}{V_{b}} \\
& S_{g}=1-S_{o}-S_{w}
\end{aligned}
$$

\subsection{Oil Recovery Model}

In this section, mathematical representations are given to describe mechanisms for enhanced oil recovery by microbial activities. These mechanisms include interfacial tension 
reduction, capillary desaturation, relative permeability alteration, and mobility control by biopolymer.

\subsubsection{Interfacial Tension}

The interfacial tension model used in this simulator is assumed to be a nonlinear correlation between interfacial tension and biosurfactant concentration: ${ }^{28}$

$$
\log \left(\sigma_{o w}\right)=\log \left(\sigma_{\max }\right)-\left[\log \left(\frac{\sigma_{\max }}{\sigma_{\min }}\right)\right]\left(\frac{\mathrm{C}_{6, \max }-\mathrm{C}_{6}}{\mathrm{C}_{6, \max }-\mathrm{C}_{6, \min }}\right)^{\mathbf{e}_{\mathrm{s}}}
$$

where, $\sigma_{\mathrm{ow}}, \sigma_{\min }$, and $\sigma_{\max }$ are instantaneous, minimum, and maximum interfacial tensions between oleic and aqueous phases; $\mathrm{C}_{6}, \mathrm{C}_{6, \min }$, and $\mathrm{C}_{6, \max }$ are instantaneous, minimum, and maximum concentrations for biosurfactant, respectively; $e_{s}$ is an exponent parameter.

\subsubsection{Capillary Desaturation}

Interfacial tension reduction increases the capillary number so that a portion of the residual phase becomes mobile. Thus the residual saturations for oil and water phases are modeled as a function of capillary number:29-31

$$
S_{\ell \mathrm{r}}=\mathrm{S}_{\ell \mathrm{r}}^{\mathrm{h}}+\left(\mathrm{S}_{\ell \mathrm{r}}^{\mathrm{w}}-\mathrm{S}_{\ell \mathrm{r}}^{\mathrm{h}}\right) \mathrm{T}_{\ell 1}\left[\log \left(\mathrm{N}_{\mathrm{c} \ell}\right)+\mathrm{T}_{\ell 2}\right] \quad \mathrm{S}_{\ell \mathrm{r}}^{\mathrm{h}} \leq \mathrm{S}_{\ell \mathrm{r}} \leq \mathrm{S}_{\ell \mathrm{r}}^{\mathrm{w}}
$$

where, subscript $\ell$ represents oil or water phase; $S_{\ell \mathrm{r}}^{\mathrm{w}}$ and $\mathrm{S}_{\ell \mathrm{r}}^{\mathrm{h}}$ are residual saturations for phase $\ell$ at low and high capillary numbers respectively; $\mathrm{N}_{c \ell}$ is capillary number for phase 
$\ell ; \mathrm{T}_{\ell 1}$ and $\mathrm{T}_{\ell 2}$ are parameters related to the capillary desaturation curve (CDC). $\mathrm{T}_{\ell 1}$ and $\mathrm{T}_{\ell 2}$ are defined as:29-31

$$
\begin{aligned}
& \mathrm{T}_{\ell 1}=\left[\log \left(\frac{\mathrm{N}_{\mathrm{c} \ell}^{\mathrm{w}}}{\mathrm{N}_{\mathrm{c} \ell}^{\mathrm{h}}}\right)\right]^{-1} \\
& \mathrm{~T}_{\ell 2}=-\log \left(\mathrm{N}_{\mathrm{c} \ell}^{\mathrm{h}}\right)
\end{aligned}
$$

where, $N_{c \ell}^{w}$ and $N_{c \ell}^{h}$ are the low and high capillary numbers, respectively, which depend on fluid/rock properties such as wettability and pore size distribution.

The capillary number for phase $p$ is computed by: ${ }^{32}$

$$
\mathrm{N}_{\mathrm{c} \ell}=\frac{\left|\overrightarrow{\mathrm{K}} \nabla \Phi_{\ell}\right|}{\sigma_{\mathrm{ow}}}=\frac{\sqrt{\mathrm{K}_{\mathrm{x}} \frac{\partial \Phi_{\ell}}{\partial \mathrm{x}}+\mathrm{K}_{\mathrm{y}} \frac{\partial \Phi_{\ell}}{\partial \mathrm{y}}+\mathrm{K}_{\mathrm{z}} \frac{\partial \Phi_{\ell}}{\partial \mathrm{z}}}}{\sigma_{\mathrm{ow}}}
$$

where, $\overrightarrow{\overrightarrow{\mathrm{K}}}$ is diagonal permeability tensor; $\Phi_{\ell}$ is potential for phase $\ell ; \sigma_{\mathrm{ow}}$ is interfacial tension between oleic and aqueous phases, determined by Eq (5.75).

\subsubsection{Capillary Pressure}

A linear model is proposed to incorporate dependence of the oil-water capillary pressure $\left(\mathrm{p}_{\text {cow }}\right)$ on oil-water interfacial tension $\left(\sigma_{\mathrm{ow}}\right): 28$ 


$$
p_{\text {cow }}=p_{\mathrm{cow}}^{\mathrm{w}}\left(\frac{\sigma_{\mathrm{ow}}-\sigma_{\min }}{\sigma_{\max }-\sigma_{\min }}\right)
$$

where, $p_{c o w}^{w}$ is oil-water capillary pressure at low capillary number.

\subsubsection{Relative Permeability}

The computed residual phase saturations from Eq.(5.77) are then used to determine phase relative permeabilities. Relative permeabilities for oil and water phases during MEOR processes are modeled using the following linear equations: ${ }^{15,28}$

$$
\begin{aligned}
& K_{r o}\left(S_{o}\right)=K_{r o}^{w}\left(S_{o}\right)+\frac{S_{o r}^{w}-S_{o r}}{S_{o r}^{w}-S_{o r}^{h}}\left[K_{r o}^{h}\left(S_{o}\right)-K_{r o}^{w}\left(S_{o}\right)\right] \\
& K_{r w}\left(S_{w}\right)=K_{r w}^{w}\left(S_{w}\right)+\frac{S_{w r}^{w}-S_{w r}}{S_{w r}^{w}-S_{w r}^{h}}\left[K_{r w}^{h}\left(S_{w}\right)-K_{r w}^{w}\left(S_{w}\right)\right]
\end{aligned}
$$

where, supscript $\mathrm{w}$ and $\mathrm{h}$ represent conditions at low and high capillary numbers, respectively. Relative permeabilities for oil and water phases at high capillary number are given by straight line models: ${ }^{15}$

$$
\begin{aligned}
& \mathrm{K}_{\mathrm{ro}}^{\mathrm{h}}=\mathrm{S}_{\mathrm{o}} \\
& \mathrm{K}_{\mathrm{rw}}^{\mathrm{h}}=\mathrm{S}_{\mathrm{w}}
\end{aligned}
$$




\subsubsection{Polymer-Rich Viscosity}

Production of biopolymer during microbial growth and metabolism increases viscosity of the aqueous phase. For relatively small polymer concentration, the polymerrich viscosity $\left(\mu_{\mathrm{pol}}\right)$ can be approximately expressed as the following linear equation with water as the solvent: 28

$$
\mu_{\mathrm{pol}}=\mu_{\mathrm{w}}+\mathrm{K}_{\mathrm{pol}} \mathrm{C}_{7}
$$

where, $\mu_{\mathrm{w}}$ is original water viscosity; $\mathrm{K}_{\mathrm{pol}}$ is a constant; $\mathrm{C}_{7}$ is biopolymer concentration.

\subsubsection{Gases}

Gases considered in this study include nitrogen and carbon dioxide. The contribution of generated biogases to enhanced oil recovery processes is modeled through source terms in the black oil model. Production rates for nitrogen and carbon dioxide are given as:

$$
\begin{aligned}
& q_{g 2}=\frac{R_{2} V_{p w}}{\rho_{2 s c} B_{w}} \\
& q_{g 3}=\frac{R_{3} V_{p w}}{\rho_{3 s c} B_{w}}
\end{aligned}
$$


where, $q_{g 2}$ and $q_{g 3}$ are volumetric production rates at surface condition for nitrogen and carbon dioxide, respectively; $\mathbf{R}_{\mathbf{2}}$ and $\mathbf{R}_{\mathbf{3}}$ are mass generation rates per unit aqueous phase volume for nitrogen and carbon dioxide during growth and metabolism; $V_{p w}$ is pore volume occupied by aqueous phase; $\rho_{2 s c}$ and $\rho_{3 s c}$ are densities at surface condition for nitrogen and carbon dioxide

Finally, the derived equations that describe MEOR processes are summarized in Tables 5.1 to 5.5 . 
Table 5.1 Basic MEOR Models

\begin{tabular}{|c|c|}
\hline Variables & Equations \\
\hline Components & $\begin{array}{c}\frac{\partial}{\partial t}\left(\frac{\phi S_{w}}{B_{w}} C_{k}+\phi C_{k s}\right)=-\nabla\left(\frac{\vec{u}_{t}}{B_{w}} C_{k}\right)+\nabla\left(\frac{\phi S_{w}}{B_{w}} \overline{\bar{D}}_{k w} \nabla C_{k}\right) \\
-\frac{q_{w}}{V_{b}} C_{k}+\frac{\phi S_{w}}{B_{w}} R_{k} \\
k=1,2,3, \ldots \ldots, 10\end{array}$ \\
\hline $\begin{array}{c}\text { Sessile } \\
\text { Bacteria }\end{array}$ & $\frac{\partial\left(\sigma \rho_{1 s c}\right)}{\partial t}=R_{r}-R_{d}+R_{1 s}$ \\
\hline Pressure & $\phi \mathrm{C}_{\mathrm{t}} \frac{\partial \mathrm{p}}{\partial \mathrm{t}}=\sum_{\ell=0, w, \mathrm{~g}} \beta_{\ell}\left[\nabla\left(\Psi_{\ell} \nabla \mathrm{p}\right)+\mathrm{GC}_{\ell}-\frac{\mathrm{q}_{\ell}}{\mathrm{V}_{\mathrm{b}}}\right]$ \\
\hline Saturations & $\begin{array}{l}\frac{\partial}{\partial t}\left(\phi \frac{S_{o}}{B_{o}}\right)=\nabla\left(\Psi_{0} \nabla p_{o}\right)+G C_{o}-\frac{q_{o}}{V_{b}} \\
\frac{\partial}{\partial t}\left(\phi \frac{S_{w}}{B_{w}}\right)=\nabla\left(\Psi_{w} \nabla p_{w}\right)+G C_{w}-\frac{q_{w}}{V_{b}} \\
S_{g}=1-S_{o}-S_{w}\end{array}$ \\
\hline
\end{tabular}


Table 5.2 Rates for Growth, Production, and Consumption

\begin{tabular}{|c|c|}
\hline Variables & Equations \\
\hline Flowing Bacteria & $\mathrm{R}_{1 \mathrm{f}}=\mu_{1 \mathrm{~m}} \frac{\mathrm{C}_{8}}{\mathrm{~K}_{1 / 8}+\mathrm{C}_{8}} \frac{\mathrm{C}_{9}}{\mathrm{~K}_{1 / 9}+\mathrm{C}_{9}} \frac{\mathrm{K}_{5}}{\mathrm{~K}_{5}+\mathrm{C}_{5}} \mathrm{C}_{1}$ \\
\hline Sessile Bacteria & $\mathbf{R}_{1 \mathrm{~s}}=\mu_{1 \mathrm{~m}} \frac{\mathrm{C}_{8}}{\mathrm{~K}_{1 / 8}+\mathrm{C}_{8}} \frac{\mathrm{C}_{9}}{\mathrm{~K}_{1 / 9}+\mathrm{C}_{9}} \frac{\mathrm{K}_{5}}{\mathrm{~K}_{5}+\mathrm{C}_{5}}\left(\sigma \rho_{1 \mathrm{sc}}\right)$ \\
\hline Nitrogen & $R_{2}=\mu_{2 m} \frac{C_{10}-C_{10 c}}{K_{2 / 10}+C_{10}-C_{10 c}}\left(C_{1}+\sigma \rho_{1 s c}\right)$ \\
\hline Carbon Products & $\begin{array}{l}\mathrm{R}_{\mathrm{k}}=\mu_{\mathrm{km}} \frac{\mathrm{C}_{8}-\mathrm{C}_{8 \mathrm{c}}}{\mathrm{K}_{\mathrm{k} / 8}+\mathrm{C}_{8}-\mathrm{C}_{8 \mathrm{c}}}\left(\mathrm{C}_{1}+\sigma \rho_{\mathrm{lsc}}\right) \\
\mathrm{k}=3,4,5,6,7 \text { for } \\
\text { carbon dioxide, acid, alcohol, surfactant, polymer }\end{array}$ \\
\hline Carbon Nutrient & $R_{8}=-\frac{R_{1 f}+R_{1 s}}{Y_{1 / 8}}-\sum_{k=3}^{7} \frac{R_{k}}{Y_{k / 8}}-m_{8}\left(C_{1}+\sigma \rho_{1 s c}\right)$ \\
\hline Nitrogen Nutrient \#1 & $\mathbf{R}_{9}=-\frac{\mathbf{R}_{1 \mathrm{ff}}+\mathbf{R}_{1 \mathrm{~s}}}{\mathbf{Y}_{1 / 9}}-\mathbf{m}_{9}\left(\mathrm{C}_{1}+\sigma \rho_{\mathrm{lsc}}\right)$ \\
\hline Nitrogen Nutrient \#2 & $\mathbf{R}_{10}=-\frac{\mathbf{R}_{2}}{\mathbf{Y}_{2 / 10}}-\mathrm{m}_{10}\left(\mathrm{C}_{1}+\sigma \rho_{1 \mathrm{sc}}\right)$ \\
\hline
\end{tabular}


Table 5.3 Adsorption Rates for Components

\begin{tabular}{|c|c|}
\hline Variables & Equations \\
\hline $\begin{array}{c}\text { Equilibrium Adsorption } \\
\text { for Products and Nutrients }\end{array}$ & $\mathrm{C}_{\mathrm{ks}}=\frac{\mathrm{a}_{\mathrm{k}} \mathrm{C}_{\mathrm{k}}}{1+\mathrm{b}_{\mathrm{k}} \mathrm{C}_{\mathrm{k}} \quad \mathrm{k}=2,3,4, \ldots \ldots, 10}$ \\
\hline $\begin{array}{c}\text { Dynamic Adsorption } \\
\text { for Bacteria }\end{array}$ & $\frac{\partial \mathrm{C}_{\mathrm{ls}}}{\partial \mathrm{t}}=\mathbf{R}_{\mathrm{r}}-\mathbf{R}_{\mathrm{d}}$ \\
\hline $\begin{array}{c}\text { Bacterial } \\
\text { Retention }\end{array}$ & $\mathrm{R}_{\mathrm{r}}=\mathbf{K}_{\mathrm{r}}\left|\overrightarrow{\mathrm{u}}_{\mathrm{w}}\right| \mathrm{C}_{\mathbf{l}}(1-\sigma)$ \\
\hline $\begin{array}{c}\text { Bacterial } \\
\text { Detachment }\end{array}$ & $\mathrm{R}_{\mathrm{d}}=\mathrm{K}_{\mathrm{d}}\left(\sigma \rho_{\mathrm{lsc}}\right)\left|\nabla \Phi_{\mathrm{w}}\right|$ \\
\hline
\end{tabular}


Table 5.4 Permeability Reduction Model

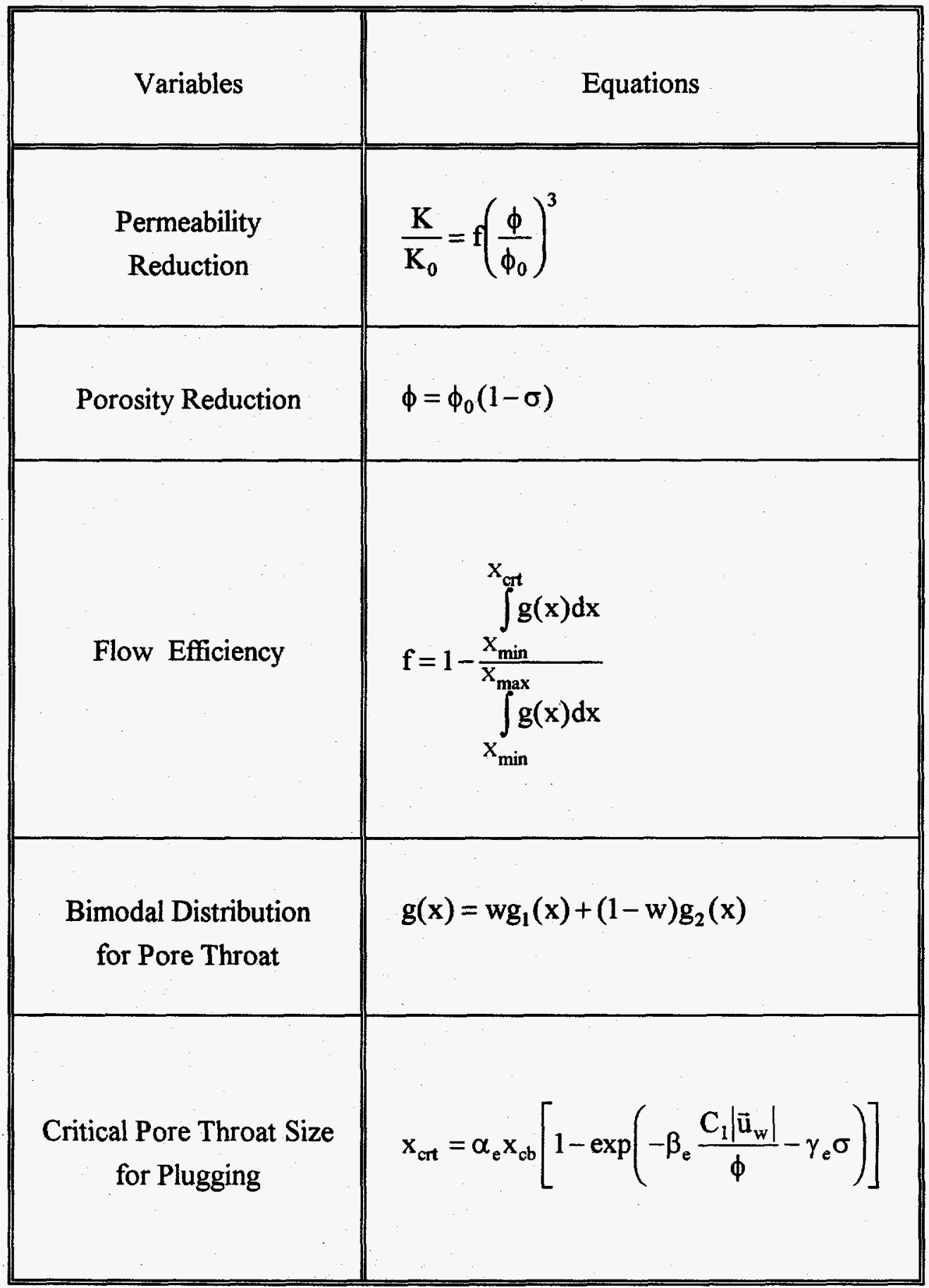


Table 5.5 Oil Recovery Model

\begin{tabular}{|c|c|}
\hline Variables & Equations \\
\hline $\begin{array}{l}\text { Interfacial } \\
\text { Tension }\end{array}$ & $\log \left(\sigma_{\text {ow }}\right)=\log \left(\sigma_{\max }\right)-\left[\log \left(\frac{\sigma_{\max }}{\sigma_{\min }}\right)\right]\left(\frac{\mathrm{C}_{6, \max }-\mathrm{C}_{6}}{\mathrm{C}_{6, \max }-\mathrm{C}_{6, \min }}\right)^{\mathrm{e}_{\mathrm{s}}}$ \\
\hline $\begin{array}{l}\text { Capillary } \\
\text { Numbers }\end{array}$ & $\mathrm{N}_{\mathrm{c} \ell}=\frac{\left|\overrightarrow{\hat{\mathrm{K}}} \nabla \Phi_{\ell}\right|}{\sigma_{\mathrm{ow}}}=\frac{\sqrt{\mathrm{K}_{\mathrm{x}} \frac{\partial \Phi_{\ell}}{\partial \mathrm{x}}+\mathrm{K}_{\mathrm{y}} \frac{\partial \Phi_{\ell}}{\partial \mathrm{y}}+\mathrm{K}_{\mathrm{z}} \frac{\partial \Phi_{\ell}}{\partial \mathrm{z}}}}{\sigma_{\mathrm{ow}}}$ \\
\hline $\begin{array}{c}\text { Residual } \\
\text { Satuartions }\end{array}$ & $S_{\ell \mathrm{r}}=S_{\ell \mathrm{r}}^{\mathrm{h}}+\left(\mathrm{S}_{\ell \mathrm{r}}^{\mathrm{w}}-\mathrm{S}_{\ell \mathrm{r}}^{\mathrm{h}}\right) \mathrm{T}_{\ell 1}\left[\log \left(\mathrm{N}_{\mathrm{c} \ell}\right)+\mathrm{T}_{\ell 2}\right]$ \\
\hline $\begin{array}{c}\text { Relative } \\
\text { Permeabilities }\end{array}$ & $\mathrm{K}_{\mathrm{r} \ell}\left(\mathrm{S}_{\ell}\right)=\mathrm{K}_{\mathrm{r} \ell}^{\mathrm{w}}\left(\mathrm{S}_{\mathrm{p}}\right)+\frac{\mathrm{S}_{\ell \mathrm{r}}^{\mathrm{w}}-\mathrm{S}_{\ell \mathrm{r}}}{\mathrm{S}_{\ell \mathrm{r}}^{\mathrm{w}}-\mathrm{S}_{\ell \mathrm{r}}^{\mathrm{h}}}\left[\mathrm{K}_{\mathrm{r} \ell}^{\mathrm{h}}\left(\mathrm{S}_{\ell}\right)-\mathrm{K}_{\mathrm{r} \ell}^{\mathrm{w}}\left(\mathrm{S}_{\ell}\right)\right]$ \\
\hline Capillary Pressure & $\mathrm{p}_{\mathrm{cow}}=\mathrm{p}_{\mathrm{cow}}^{\mathrm{w}}\left(\frac{\sigma_{\mathrm{ow}}-\sigma_{\min }}{\sigma_{\mathrm{max}}-\sigma_{\min }}\right)$ \\
\hline $\begin{array}{c}\text { Viscosity for } \\
\text { Polymer Solution }\end{array}$ & $\mu_{\text {pol }}=\mu_{w}+K_{p o l} C_{7}$ \\
\hline
\end{tabular}




\section{NUMERICAL FORMULATION}

The phase pressure and component transport equations derived in this study are a set of coupled, nonlinear partial differential equations. These equations are transformed to discrete forms using finite differences. An implicit pressure, explicit saturation (IMPES) technique is used to solve pressure and phase saturations. This is followed by the solution of the component transport equations.

\subsection{Grid System}

The spatial domain of interest is divided into a set of finite blocks. A blockcentered grid system is selected for the finite difference formulation. The X- and Ydirections are defined as areal coordinates and the positive Z-direction is the vertical downward direction. In a natural ordering, blocks in an $N_{x} \times N_{y} \times N_{z}$ system $\left(N_{x}\right.$ blocks in each row, $\mathrm{N}_{\mathrm{y}}$ blocks in each column, and $\mathrm{N}_{\mathrm{z}}$ blocks in each plane) are numbered within a row, row by row and plane by plane in sequence. Figures 4.1 and 4.2 show the gridblock numbering for a $4 \times 3 \times 2$ grid system and the corresponding coefficient-matrix structure.

\subsection{Pressure Equation Approximation}

To approximate the partial differential equation by finite differences, a linear difference operator is defined as:

$$
\Delta \mathrm{A} \Delta \mathrm{U}=\Delta_{\mathrm{X}} \mathrm{A} \Delta_{\mathrm{X}} \mathrm{U}+\Delta_{\mathrm{Y}} \mathrm{A} \Delta_{\mathrm{Y}} \mathrm{U}+\Delta_{\mathrm{Z}} \mathrm{A} \Delta_{\mathrm{Z}} \mathrm{U}
$$


where

$$
\Delta_{m} A \Delta_{m} U=A_{m-1 / 2}\left(U_{m-1}-U_{m}\right)+A_{m+1 / 2}\left(U_{m+1}-U_{m}\right), \quad m=X, Y, Z
$$

The pressure equation (5.53) is multiplied through by the bulk volume element $\left(V_{b}\right)_{x y z}$. Using the above definition of the linear operator, the resulting difference equation becomes:

$$
\begin{aligned}
\left(\frac{V_{p}^{n} C_{t}^{n}}{\Delta t}\right)_{x y z}\left(p^{n+1}-p^{n}\right)_{x y z}= & \left(B_{o}-R_{s o} B_{g}\right)_{x y z}^{n}\left(\Delta A_{o}^{n} \Delta p^{n+1}+G C O T-q_{o}\right)_{x y z}+ \\
& \left(B_{w}-R_{s w} B_{g}\right)_{x y z}^{n}\left(\Delta A_{w}^{n} \Delta p^{n+1}+G C W T-q_{w}\right)_{x y z}+ \\
& \left(B_{g}\right)_{x y z}^{n}\left(\Delta A_{g}^{n} \Delta p^{n+1}+\Delta R_{s o}^{n} A_{o}^{n} \Delta p^{n+1}+\Delta R_{s w}^{n} A_{w}^{n} \Delta p^{n+1}+\right. \\
& \left.G C G T-q_{g}\right)_{x y z}
\end{aligned}
$$

where, $\mathrm{V}_{\mathrm{p}}$ is grid block pore volume; GCOT, GCWT, and GCGT are terms including gravity and capillary pressure. These terms are defined:

$$
\begin{aligned}
& \text { GCOT }=-\Delta A_{o}^{n} \Delta\left(\rho_{o} h\right)^{n} \\
& \text { GCWT }=-\Delta A_{w}^{n} \Delta\left(\rho_{w} h+p_{\text {cow }}\right)^{n} \\
& \text { GCGT }=-\Delta A_{g}^{n} \Delta\left(\rho_{g} h-p_{\text {cgo }}\right)^{n}-R_{\text {so }}^{n} \Delta A_{0}^{n} \Delta\left(\rho_{o} h\right)^{n}-R_{s w}^{n} \Delta A_{w}^{n} \Delta\left(\rho_{w} h+p_{\text {cow }}\right)^{n}
\end{aligned}
$$


The gravity and capillary pressure terms in the $\mathrm{X}$-direction can be expanded as:

$$
\begin{aligned}
& \Delta_{X} A_{\ell}^{\mathrm{n}} \Delta_{X}\left(\rho_{\ell} \mathrm{h}\right)^{\mathrm{n}}= \mathrm{A}_{\ell, \mathrm{x}-1}^{\mathrm{n}}\left(\frac{\rho_{\ell, \mathrm{x}-1}^{\mathrm{n}}+\rho_{\ell, \mathrm{x}}^{\mathrm{n}}}{2}\right)\left(\mathrm{h}_{\mathrm{x}-1}-\mathrm{h}_{\mathrm{x}}\right)+ \\
& \mathrm{A}_{\ell, \mathrm{x}+1}^{\mathrm{n}}\left(\frac{\rho_{\ell, \mathrm{x}+1}^{\mathrm{n}}+\rho_{\ell, \mathrm{x}}^{\mathrm{n}}}{2}\right)\left(\mathrm{h}_{\mathrm{x}+1}-\mathrm{h}_{\mathrm{x}}\right) \\
& \Delta_{\mathrm{X}} \mathrm{A}_{\ell}^{\mathrm{n}} \Delta_{\mathrm{X}}\left(\mathrm{p}_{\mathrm{c} \ell \ell^{\prime}}\right)^{\mathrm{n}}=\mathrm{A}_{\ell, \mathrm{x}-1}^{\mathrm{n}}\left[\left(\mathrm{p}_{\mathrm{c} \ell \ell^{\prime}}\right)_{\mathrm{x}-1}^{\mathrm{n}}-\left(\mathrm{p}_{\mathrm{c} \ell \ell^{\prime}}\right)_{\mathrm{x}}^{\mathrm{n}}\right]+ \\
& \mathrm{A}_{\ell, \mathrm{x}+1}^{\mathrm{n}}\left[\left(\mathrm{p}_{\mathrm{c} \ell \ell^{\prime}}\right)_{\mathrm{x}+1}^{\mathrm{n}}-\left(\mathrm{p}_{\mathrm{c} \ell \ell^{\prime}}\right)_{\mathrm{x}}^{\mathrm{n}}\right]
\end{aligned}
$$

where, $\ell, \ell^{\prime}=0, \mathrm{w}, \mathrm{g} ; \ell \neq \ell^{\prime}$. The gravity and capillary pressure terms in the $\mathrm{Y}-$ and $\mathrm{Z}$ directions can be expanded in similar fashion.

Expanding the linear difference operators, the finite difference equation (6.3) can be further simplified:

$$
A T_{z} p_{z-1}^{n+1}+A S_{y} p_{y-1}^{n+1}+A W_{x} p_{x-1}^{n+1}+A B_{z} p_{z+1}^{n+1}+A N_{y} p_{y+1}^{n+1}+A E_{x} p_{x+1}^{n+1}+E_{x y z} p_{x y z}^{n+1}=B_{x y z}
$$

However, a perturbation in pressure over a time step $\Delta \mathrm{t}^{\mathrm{n}+1}$ is $\delta \mathrm{p}_{\mathrm{xyz}}^{\mathrm{n}+1}$ and the pressure at the new time level can be expressed as:

$$
p_{x y z}^{n+1}=p_{x y z}^{n}+\delta p_{x y z}^{n+1}
$$


Obviously, solving for $\delta p_{\mathrm{xyz}}^{n+1}$ instead of $\mathrm{p}_{\mathrm{xyz}}^{\mathrm{n} y}$ can enhance precision for numerical solutions. Substituting Eq. (6.10) into Eq. (6.9), the resulting finite difference equation is:

$$
\begin{aligned}
& \mathrm{AT}_{\mathrm{z}} \delta p_{z-1}^{\mathrm{n}+1}+\mathrm{AS}_{\mathrm{y}} \delta \mathrm{p}_{\mathrm{y}-1}^{\mathrm{n}+1}+\mathrm{AW}_{\mathrm{x}} \delta \mathrm{p}_{\mathrm{x}-1}^{\mathrm{n}+1}+\mathrm{AB}_{\mathrm{z}} \delta \mathrm{p}_{z+1}^{\mathrm{n}+1}+ \\
& \mathrm{AN}_{\mathrm{y}} \delta \mathrm{p}_{\mathrm{y}+1}^{\mathrm{n}+1}+\mathrm{AE}_{\mathrm{x}} \delta \mathrm{p}_{\mathrm{x}+1}^{\mathrm{n}+1}+\mathrm{E}_{\mathrm{xyz}} \delta p_{\mathrm{xyz}}^{\mathrm{n}+1}=\hat{\mathrm{B}}_{\mathrm{xyz}}
\end{aligned}
$$

where

$$
\begin{aligned}
& \hat{B}_{x y z}=B_{x y z}-\left(A T_{z} p_{z-1}^{n}+A S_{y} p_{y-1}^{n}+A W_{x} p_{x-1}^{n}+\right. \\
&\left.A_{z} p_{z+1}^{n}+A N_{y} p_{y+1}^{n}+A_{x} p_{x+1}^{n}+E_{x y z} p_{x y z}^{n}\right)
\end{aligned}
$$

Coefficients in $\mathrm{Eq}(6.9)$ are defined as follows:

$$
\begin{aligned}
A_{\mathrm{z}}= & {\left[\mathrm{B}_{\mathrm{o}}+0.5 \mathrm{~B}_{\mathrm{g}}\left(\mathrm{R}_{\mathrm{so}, \mathrm{z}-1}-\mathrm{R}_{\mathrm{so}, \mathrm{z}}\right)\right]^{\mathrm{n}} \mathrm{A}_{\mathrm{o}, \mathrm{z}-1 / 2}^{\mathrm{n}}+} \\
& {\left[\mathrm{B}_{\mathrm{w}}+0.5 \mathrm{~B}_{\mathrm{g}}\left(\mathrm{R}_{\mathrm{sw}, \mathrm{z}-1}-\mathrm{R}_{\mathrm{sw}, \mathrm{z}}\right)\right]^{\mathrm{n}} \mathrm{A}_{\mathrm{w}, \mathrm{z}-1 / 2}^{\mathrm{n}}+\mathrm{B}_{\mathrm{g}}^{\mathrm{n}} \mathrm{A}_{\mathrm{g}, \mathrm{z}-1 / 2}^{\mathrm{n}} } \\
\mathrm{AS}_{\mathrm{y}}= & {\left[\mathrm{B}_{\mathrm{o}}+0.5 \mathrm{~B}_{\mathrm{g}}\left(\mathrm{R}_{\mathrm{so}, \mathrm{y}-1}-\mathrm{R}_{\mathrm{so}, \mathrm{y}}\right)\right]^{\mathrm{n}} \mathrm{A}_{\mathrm{o}, \mathrm{y}-1 / 2}^{\mathrm{n}}+} \\
& {\left[\mathrm{B}_{\mathrm{w}}+0.5 \mathrm{~B}_{\mathrm{g}}\left(\mathrm{R}_{\mathrm{sw}, \mathrm{y}-1}-\mathrm{R}_{\mathrm{sw}, \mathrm{y}}\right)\right]^{\mathrm{n}} \mathrm{A}_{\mathrm{w}, \mathrm{y}-1 / 2}^{\mathrm{n}}+\mathrm{B}_{\mathrm{g}}^{\mathrm{n}} \mathrm{A}_{\mathrm{g}, \mathrm{y}-1 / 2}^{\mathrm{n}} } \\
\mathrm{AW}_{\mathrm{x}}= & {\left[\mathrm{B}_{\mathrm{o}}+0.5 \mathrm{~B}_{\mathrm{g}}\left(\mathrm{R}_{\mathrm{so}, \mathrm{x}-1}-\mathrm{R}_{\mathrm{so}, \mathrm{x}}\right)\right]^{\mathrm{n}} \mathrm{A}_{\mathrm{o}, \mathrm{x}-1 / 2}^{\mathrm{n}}+}
\end{aligned}
$$




$$
\begin{aligned}
& {\left[B_{w, y}+0.5 B_{g}\left(R_{s w, x-1}-R_{s w, x}\right)\right]^{n} A_{w, x-1 / 2}^{n}+B_{g}^{n} A_{g, x-1 / 2}^{n}} \\
& \mathrm{AB}_{\mathrm{z}}=\left[\mathrm{B}_{\mathrm{o}}+0.5 \mathrm{~B}_{\mathrm{g}}\left(\mathrm{R}_{\mathrm{so}, \mathrm{z}+1}-\mathrm{R}_{\mathrm{so}, \mathrm{z}}\right)\right]^{\mathrm{n}} \mathrm{A}_{\mathrm{o}, \mathrm{z}+1 / 2}^{\mathrm{n}}+ \\
& {\left[\mathrm{B}_{\mathrm{w}}+0.5 \mathrm{~B}_{\mathrm{g}}\left(\mathrm{R}_{\mathrm{sw}, \mathrm{z}+1}-\mathrm{R}_{\mathrm{sw}, \mathrm{z}}\right)\right]^{\mathrm{n}} \mathrm{A}_{\mathrm{w}, \mathrm{z}+1 / 2}^{\mathrm{n}}+\mathrm{B}_{\mathrm{g}}^{\mathrm{n}} \mathrm{A}_{\mathrm{g}, \mathrm{z}+1 / 2}^{\mathrm{n}}} \\
& \mathrm{AN}_{\mathrm{y}}=\left[\mathrm{B}_{\mathrm{o}}+0.5 \mathrm{~B}_{\mathrm{g}}\left(\mathrm{R}_{\mathrm{so}, y+1}-\mathrm{R}_{\mathrm{so}, y}\right)\right]^{\mathrm{n}} \mathrm{A}_{\mathrm{o}, \mathrm{y}+1 / 2}^{\mathrm{n}}+ \\
& {\left[B_{w}+0.5 B_{g}\left(R_{s w, y+1}-R_{s w, y}\right)\right]^{n} A_{w, y+1 / 2}^{n}+B_{g}^{n} A_{g, y+1 / 2}^{n}} \\
& \mathrm{AE}_{\mathrm{x}}=\left[\mathrm{B}_{\mathrm{o}}+0.5 \mathrm{~B}_{\mathrm{g}}\left(\mathrm{R}_{\mathrm{so}, \mathrm{x}+1}-\mathrm{R}_{\mathrm{so}, \mathrm{x}}\right)\right]^{\mathrm{n}} \mathrm{A}_{\mathrm{o}, \mathrm{x}+1 / 2}^{\mathrm{n}}+ \\
& {\left[\mathrm{B}_{\mathrm{w}, \mathrm{x}}+0.5 \mathrm{~B}_{\mathrm{g}}\left(\mathrm{R}_{\mathrm{sw}, \mathrm{x}+1}-\mathrm{R}_{\mathrm{sw}, \mathrm{x}}\right)\right]^{\mathrm{n}} \mathrm{A}_{\mathrm{w}, \mathrm{x}+1 / 2}^{\mathrm{n}}+\mathrm{B}_{\mathrm{g}}^{\mathrm{n}} \mathrm{A}_{\mathrm{g}, \mathrm{x}+1 / 2}^{\mathrm{n}}} \\
& E_{x y z}=-\left[A T_{z}+A_{y}+A W_{x}+A_{z}+A_{y}+A E_{x}+\left(\frac{V_{p}^{n} C_{t}^{n} p^{n}}{\Delta t}\right)_{x y z}\right] \\
& B_{x y z}=-\left[Q O W G+\left(\frac{V_{p}^{n} C_{t}^{n} p^{n}}{\Delta t}\right)_{x y z}\right] \\
& \text { QOWG }=\left(B_{o}-B_{g} R_{s o}\right)_{x y z}^{n}\left(G C O T-q_{o}\right)_{x y z}+ \\
& \left(B_{w}-B_{g} R_{s w}\right)_{x y z}^{n}\left(G C W T-q_{w}\right)_{x y z}+B_{g, x y z}^{n}\left(G C G T-q_{g}\right)_{x y z}
\end{aligned}
$$

Phase transmissibilities between blocks $\mathrm{x}$ and $\mathrm{x}-1$ or blocks $\mathrm{x}$ and $\mathrm{x}+1$ are defined as: 


$$
A_{\ell, x \pm 1 / 2}=T_{x \pm 1 / 2} M_{\ell, x \pm 1 / 2}, \quad \ell=0, w, g
$$

The geometrical part of the phase transmissibilities is considered as a harmonic average:

$$
T_{x \pm 1 / 2}=\left(\frac{K A}{\Delta X}\right)_{x \pm 1 / 2}=\frac{2(K A)_{x}(K A)_{x \pm 1}}{(\Delta X)_{x}(K A)_{x \pm 1}+(\Delta X)_{x \pm 1}(K A)_{x}}
$$

where, $\mathrm{K}$ is absolute permeability; $\mathrm{A}$ is cross-sectional area, $\Delta \mathrm{X}$ is grid block size in the $\mathrm{X}$ direction. The mobility part of the phase transmissibilities is given:

$$
\mathbf{M}_{\ell, \mathrm{x} \pm 1 / 2}=\left(\frac{\mathrm{K}_{\mathrm{r} \ell}}{\mu_{\ell} \mathrm{B}_{\ell}}\right)_{\mathrm{x} \pm 1 / 2}=\left(\frac{\mathrm{K}_{\mathrm{r} \ell}}{\mu_{\ell} \mathrm{B}_{\ell}}\right)_{\text {upstream }}
$$

Both the pressure and saturation dependent functions in the mobility term are evaluated using one-point upstream weighting. For example, the relative permeability of phase $\ell$ at the boundary between block $(x, y, z)$ and block $(x+1, y, z)$ is defined by:

$$
\begin{aligned}
& \mathrm{K}_{\mathrm{r} \ell \mathrm{x}+1 / 2}=\mathrm{K}_{\mathrm{r} \ell, \mathrm{x}} \quad \text { if flow is from } \mathrm{x} \text { to } \mathrm{x}+1 \\
& \mathrm{~K}_{\mathrm{r} \ell, \mathrm{x}+1 / 2}=\mathrm{K}_{\mathrm{r} \ell, \mathrm{x}+1} \quad \text { if flow is from } \mathrm{x}+1 \text { to } \mathrm{x}
\end{aligned}
$$

Phase transmissibilities in the $\mathrm{Y}$ - and Z-directions can be defined similarly using the above notations. 
Once the new time level pressures are determined implicitly from equations (6.9) and (6.10), the oil, water, and gas saturations can be explicitly found by discretizing equations (5.73) to (5.75) in both spatial and temporal variables:

$$
\begin{aligned}
& S_{0, x y z}^{n+1}=\left(\frac{B_{o}}{V_{p}}\right)_{x y z}^{n+1}\left[\left(V_{p} \frac{S_{o}}{B_{o}}\right)^{n}+\Delta t\left(\Delta A_{o} \Delta p^{n+1}+G \operatorname{COT}-q_{o}\right)\right]_{x y z} \\
& S_{w, x y z}^{n+1}=\left(\frac{B_{w}}{V_{p}}\right)_{x y z}^{n+1}\left[\left(V_{p} \frac{S_{w}}{B_{w}}\right)^{n}+\Delta t\left(\Delta A_{w} \Delta p^{n+1}+G C O T-q_{w}\right)\right]_{x y z} \\
& S_{g, x y z}^{n+1}=1-S_{o, x y z}^{n+1}-S_{w, x y z}^{n+1}
\end{aligned}
$$

\subsection{Component Equation Approximation}

For components such as metabolic products and substrates, the mass transport equations can be written as:

$$
\frac{\partial}{\partial t}\left(\frac{\phi S_{w}}{B_{w}} C_{k}+\phi C_{k s}\right)=-\nabla\left(\frac{\vec{u}_{w}}{B_{w}} C_{k}\right)+\nabla\left(\frac{\phi S_{w}}{B_{w}} \overrightarrow{\vec{D}}_{k w} \nabla C_{k}\right)-\frac{q_{w}}{V_{b}} C_{k}+\frac{\phi S_{w}}{B_{w}} R_{k}
$$

Since adsorption concentrations for products and substrates are described by Langmuir isotherms, adsorption rates can be expressed as:

$$
\frac{\partial \mathrm{C}_{\mathrm{ks}}}{\partial \mathrm{t}}=\frac{\mathrm{a}_{\mathrm{k}}}{\left(1+\mathrm{b}_{\mathrm{k}} \mathrm{C}_{\mathrm{k}}\right)^{2}} \frac{\partial \mathrm{C}_{\mathrm{k}}}{\partial \mathrm{t}}
$$


where, $a_{k}$ and $b_{k}$ are Langmuir adsorption constants.

Assuming that changes in porosity $(\phi)$, phase saturation $\left(\mathrm{S}_{\mathrm{L}}\right)$, and fluid formation volume factor $\left(B_{L}\right)$ with time are smaller than changes in component concentrations $\left(C_{k}\right)$ with time, the transport equation for component $\mathrm{k}$ can be rewritten as:

$$
\frac{\partial C_{k}}{\partial t}=\frac{1}{D_{s}}\left[-\nabla\left(\frac{\vec{u}_{w}}{B_{w}} C_{k}\right)+\nabla\left(\frac{\phi S_{w}}{B_{w}} \overrightarrow{\bar{D}}_{k w} \nabla C_{k}\right)-\frac{q_{w}}{V_{b}} C_{k}+\frac{\phi S_{w}}{B_{w}} R_{k}\right]
$$

where

$$
D_{s}=\frac{\phi S_{w}}{B_{w}}+\frac{\phi a_{k}}{\left(1+b_{k} C_{k}\right)^{2}}
$$

The component transport equation is discretized in the spatial variables while the temporal solution is kept continuous. At grid block ( $\mathrm{x}, \mathrm{y}, \mathrm{z}), \mathrm{Eq}$ (6.32) is expressed as:

$$
\left(\frac{\partial C_{k}}{\partial t}\right)_{x y z}=\left\{\frac{1}{D_{s}}\left[-\nabla\left(\frac{\vec{u}_{w}}{B_{w}} C_{k}\right)+\nabla\left(\frac{\phi S_{w}}{B_{w}} \overrightarrow{\vec{D}}_{k w} \nabla C_{k}\right)-\frac{q_{w}}{V_{b}} C_{k}+\frac{\phi S_{w}}{B_{w}} R_{k}\right]\right\}_{x y z}
$$

The convection term in Eq (6.34) can be expanded as:

$$
\left[\nabla\left(\frac{\vec{u}_{w}}{B_{w}} C_{k}\right)\right]_{x y z}=\left[\frac{\partial}{\partial x}\left(\frac{u_{w x}}{B_{w}} C_{k}\right)+\frac{\partial}{\partial y}\left(\frac{u_{w y}}{B_{w}} C_{k}\right)+\frac{\partial}{\partial z}\left(\frac{u_{w z}}{B_{w}} C_{k}\right)\right]_{x y z}
$$

The convection term in the $\mathrm{X}$-direction is replaced by the finite difference equation: 


$$
\left[\frac{\partial}{\partial X}\left(\frac{u_{w x}}{B_{w}} C_{k}\right)\right]_{x y z}=\frac{1}{\Delta X_{x}}\left[\left(\frac{u_{w x}}{B_{w}}\right)_{x+1 / 2} C_{k, x+1 / 2}-\left(\frac{u_{w x}}{B_{w}}\right)_{x-1 / 2} C_{k, x-1 / 2}\right]
$$

Leonard's third-order upstream formula with a modification for variable grid sizes is employed to approximate the concentrations for component $\mathrm{k}$ in Eq.(6.36):30,33

$$
\begin{aligned}
& \text { for } \Phi_{\mathrm{w}, \mathrm{x}-1}>\Phi_{\mathrm{w}, \mathrm{x}} \\
& \qquad \mathrm{C}_{k, x-1 / 2}=\mathrm{C}_{\mathrm{k}, \mathrm{x}-1}+\mathrm{A}_{\mathrm{x}-1}\left(\mathrm{C}_{\mathrm{k}, \mathrm{x}-1}-\mathrm{C}_{\mathrm{k}, \mathrm{x}-2}\right)+2 \mathrm{~B}_{\mathrm{x}-1}\left(\mathrm{C}_{\mathrm{k}, \mathrm{x}}-\mathrm{C}_{\mathrm{k}, \mathrm{x}-1}\right)
\end{aligned}
$$

for $\Phi_{\mathrm{w}, \mathrm{x}}>\boldsymbol{\Phi}_{\mathrm{w}, \mathrm{x}+1}$

$$
C_{k, x+1 / 2}=C_{k, x}+A_{x}\left(C_{k, x}-C_{k, x-1}\right)+2 B_{x}\left(C_{k, x+1}-C_{k, x}\right)
$$

for $\Phi_{\mathrm{w}, \mathrm{x}-1}<\boldsymbol{\Phi}_{\mathrm{w}, \mathrm{x}}$

$$
C_{k, x-1 / 2}=C_{k, x}+2 A_{x}\left(C_{k, x-1}-C_{k, x}\right)+B_{x}\left(C_{k, x}-C_{k, x+1}\right)
$$

for $\Phi_{\mathrm{w}, \mathbf{x}}<\boldsymbol{\Phi}_{\mathrm{w}, \mathbf{x}+1}$

$$
C_{k, x+1 / 2}=C_{k, x+1}+2 A_{x+1}\left(C_{k, x}-C_{k, x+1}\right)+B_{x+1}\left(C_{k, x+1}-C_{k, x+2}\right)
$$

where, $\boldsymbol{\Phi}_{\mathrm{w}, \mathrm{x}}$ is water phase potential in $\mathrm{x}$-direction; and $\mathrm{A}_{\mathrm{x}}$ and $\mathrm{B}_{\mathrm{x}}$ are defined as

$$
\mathrm{A}_{\mathrm{x}}=\frac{\Delta \mathrm{X}_{\mathrm{x}}}{3\left(\Delta \mathrm{X}_{\mathrm{x}}+\Delta \mathrm{X}_{\mathrm{x}-1}\right)}, \quad \mathrm{B}_{\mathrm{x}}=\frac{\Delta \mathrm{X}_{\mathrm{x}}}{3\left(\Delta \mathrm{X}_{\mathrm{x}+1}+\Delta \mathrm{X}_{\mathrm{x}}\right)}
$$


Convection terms in the $\mathrm{Y}$ - and Z-directions can be similarly approximated. In implementing the high-order method, an one-point upstream formula is employed whenever a grid block is located outside the reservoir boundary.

Since a full tensor is used to describe the physical dispersion in component transport processes, the dispersion term in Eq (4.34) can be expanded as:

$$
\begin{aligned}
& {\left[\nabla\left(\frac{\phi S_{w}}{B_{w}} \overrightarrow{\vec{D}}_{k w} \nabla C_{k}\right)\right]_{x y z}=} \\
& \quad \frac{\partial}{\partial X}\left[\frac{\phi S_{w}}{B_{w}}\left(D_{k w, x x} \frac{\partial C_{k}}{\partial X}+D_{k w, x y} \frac{\partial C_{k}}{\partial Y}+D_{k w, x z} \frac{\partial C_{k}}{\partial Z}\right)\right]_{x y z}+ \\
& \frac{\partial}{\partial Y}\left[\frac{\phi S_{w}}{B_{w}}\left(D_{k w, y x} \frac{\partial C_{k}}{\partial X}+D_{k w, y y} \frac{\partial C_{k}}{\partial Y}+D_{k w, y z} \frac{\partial C_{k}}{\partial Z}\right)\right]_{x y z}+ \\
& \frac{\partial}{\partial Z}\left[\frac{\phi S_{w}}{B_{w}}\left(D_{k w, z x} \frac{\partial C_{k}}{\partial X}+D_{k w, z y} \frac{\partial C_{k}}{\partial Y}+D_{k w, z z} \frac{\partial C_{k}}{\partial Z}\right)\right]_{x y z}
\end{aligned}
$$

Replacing the spatial derivatives with central finite differences, the dispersion term with differencing carried out in the X-direction can be approximated as: ${ }^{31}$

$$
\begin{gathered}
\frac{\partial}{\partial X}\left[\frac{\phi S_{w}}{B_{w}}\left(D_{k w, x x} \frac{\partial C_{k}}{\partial X}+D_{k w, x y} \frac{\partial C_{k}}{\partial Y}+D_{k w, x z} \frac{\partial C_{k}}{\partial Z}+\right]_{x y z}=\frac{1}{\Delta X_{x}}\{\right. \\
{\left[\left(\frac{\phi S_{w} D_{k w, x x}}{B_{w}}\right)_{x+1 / 2} \frac{C_{k, x+1}-C_{k, x}}{\Delta X_{x+1 / 2}}-\left(\frac{\phi S_{w} D_{k w, x x}}{B_{w}}\right)_{x-1 / 2} \frac{C_{k, x}-C_{k, x-1}}{\Delta X_{x-1 / 2}}\right]+}
\end{gathered}
$$




$$
\begin{aligned}
& {\left[\left(\frac{\phi S_{w} D_{k w, x y}}{B_{w}}\right)_{x+1 / 2} \frac{\left(C_{k, y+1}-C_{k, y-1}\right)_{x+1 / 2}}{\Delta Y_{y+1 / 2}+\Delta Y_{y-1 / 2}}-\left(\frac{\phi S_{w} D_{k w, x y}}{B_{w}}\right)_{x-1 / 2} \frac{\left(C_{k, y+1}-C_{k, y-1}\right)_{x-1 / 2}}{\Delta Y_{y+1 / 2}+\Delta Y_{y-1 / 2}}\right]+} \\
& \left.\left[\left(\frac{\phi S_{w} D_{k w, x z}}{B_{w}}\right)_{x+1 / 2} \frac{\left(C_{k, z+1}-C_{k, z-1}\right)_{x+1 / 2}}{\Delta Z_{z+1 / 2}+\Delta Z_{z-1 / 2}}-\left(\frac{\phi S_{w} D_{k w, x z}}{B_{w}}\right)_{x-1 / 2} \frac{\left(C_{k, z+1}-C_{k, z-1}\right)_{x-1 / 2}}{\Delta Z_{z+1 / 2}+\Delta Z_{z-1 / 2}}\right]\right\}
\end{aligned}
$$

where

$$
\begin{aligned}
& \Delta X_{x \pm 1 / 2}=\frac{\Delta X_{x}+\Delta X_{x \pm 1}}{2} \\
& \Delta Y_{y \pm 1 / 2}=\frac{\Delta Y_{y}+\Delta Y_{y \pm 1}}{2} \\
& \Delta Z_{z \pm 1 / 2}=\frac{\Delta Z_{z}+\Delta Z_{z \pm 1}}{2}
\end{aligned}
$$

The dispersion terms with differencing in the $\mathrm{Y}$ - and Z-directions are replaced by similar finite difference formulae.

A first-order upstream formula is used to approximate the concentrations with subscript of $x+1 / 2$ in Eq (6.43):31

$$
\begin{array}{ll}
\left(C_{k, y \pm 1}\right)_{x \pm 1 / 2}=\left(C_{k, y \pm 1}\right)_{x \pm 1} & \text { for }\left(\Phi_{w}\right)_{x \pm 1}>\left(\Phi_{w}\right)_{x} \\
\left(C_{k, z \pm 1}\right)_{x \pm 1 / 2}=\left(C_{k, z \pm 1}\right)_{x \pm 1} & \text { for }\left(\Phi_{w}\right)_{x \pm 1}>\left(\Phi_{w}\right)_{x}
\end{array}
$$




$$
\begin{array}{ll}
\left(C_{k, y \pm 1}\right)_{x \pm 1 / 2}=\left(C_{k, y \pm 1}\right)_{x} & \text { for }\left(\Phi_{w}\right)_{x \pm 1}<\left(\Phi_{w}\right)_{x} \\
\left(C_{k, z \pm 1}\right)_{x \pm 1 / 2}=\left(C_{k, z \pm 1}\right)_{x} & \text { for }\left(\Phi_{w}\right)_{x \pm 1}<\left(\Phi_{w}\right)_{x}
\end{array}
$$

Similar treatments can be made for the concentrations with subscripts of $y \pm 1 / 2$ and $z \pm 1 / 2$ in dispersion terms with differencing in the $\mathrm{Y}$ - and $\mathrm{Z}$-directions.

The coefficient products of the physical dispersion terms in Eq (6.43) are computed from the following discrete formulae:

$$
\begin{aligned}
& \left(\frac{\phi S_{w} D_{k w, x x}}{B_{w}}\right)_{x \pm 1 / 2}=\frac{D_{k}}{\tau}\left(\frac{\phi S_{w}}{B_{w}}\right)_{x \pm 1 / 2}+\frac{\left(\alpha_{l w}-\alpha_{t w}\right)}{B_{w, x \pm 1 / 2}} \frac{\left(u_{w z}^{2}\right)_{x \pm 1 / 2}}{\left|\vec{u}_{w}\right|_{x \pm 1 / 2}}+\frac{\alpha_{t w}\left|\vec{u}_{w}\right|_{x \pm 1 / 2}}{B_{w, x \pm 1 / 2}} \\
& \left(\frac{\phi S_{w} D_{k w, x y}}{B_{w}}\right)_{x \pm 1 / 2}=\frac{\left(\alpha_{1 w}-\alpha_{t w}\right)}{B_{w, x \pm 1 / 2}\left|\vec{u}_{w}\right|_{x \pm 1 / 2}}\left|u_{w x} u_{w y}\right|_{x \pm 1 / 2} \\
& \left(\frac{\phi S_{w} D_{k w, x z}}{B_{w}}\right)_{x \pm 1 / 2}=\frac{\left(\alpha_{l w}-\alpha_{t w}\right)}{B_{w, x \pm 1 / 2}\left|\vec{u}_{w}\right|_{x \pm 1 / 2}}\left|u_{w x} u_{w z}\right|_{x \pm 1 / 2}
\end{aligned}
$$

where

$$
\left|\vec{u}_{w}\right|_{x \pm 1 / 2}=\sqrt{\left(u_{w x}\right)_{x \pm 1 / 2}^{2}+\left(u_{w y}\right)_{x \pm 1 / 2}^{2}+\left(u_{w z}\right)_{x \pm 1 / 2}^{2}}
$$

Darcy velocities such as $\left(u_{w y}\right)_{x+1 / 2}$ and $\left(u_{w z}\right)_{x+1 / 2}$ in Eqs. (6.52) to (6.54) are replaced by the average, first-order upstream velocities: ${ }^{31}$ 
$\left(6 S^{\circ} 9\right)$

$$
\begin{aligned}
& { }^{\mathrm{I}} \mathrm{y} \frac{{ }^{M} \mathrm{~g}}{{ }^{M} S \phi}+{ }^{\mathrm{l}} \mathrm{D} \frac{{ }^{\mathrm{q}} \Lambda}{{ }^{M} b}-
\end{aligned}
$$

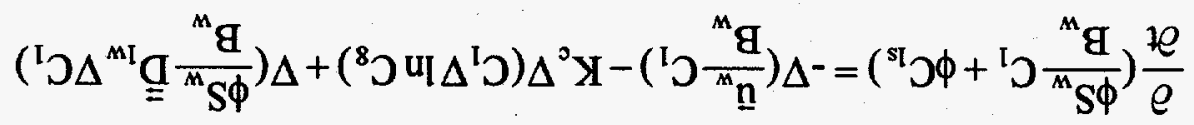

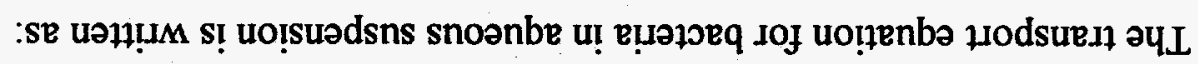

suọpui!xoIdde әч†

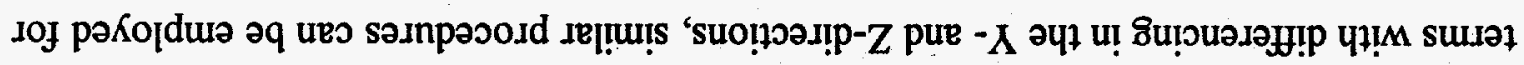

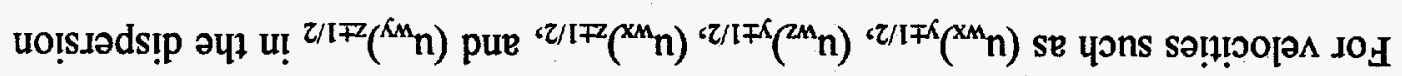

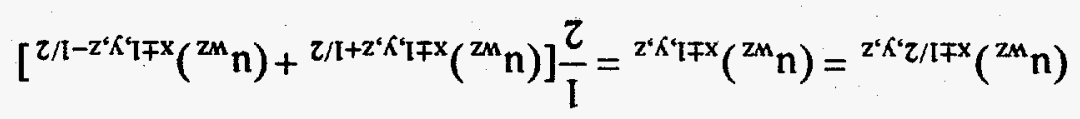

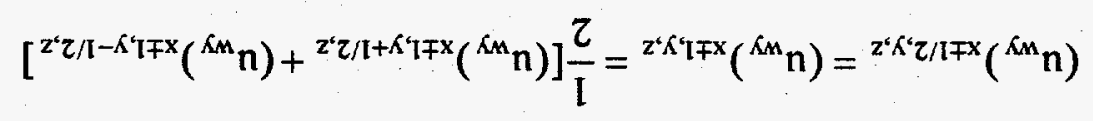

$$
{ }^{I F x}\left({ }^{M} \Phi\right)>{ }^{x}\left({ }^{M} \Phi\right) \text { 10J }
$$

$\left(9 \varsigma^{9} 9\right)$

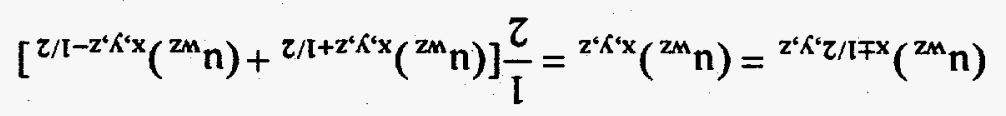

$\left(\varsigma \varsigma^{\circ} 9\right)$

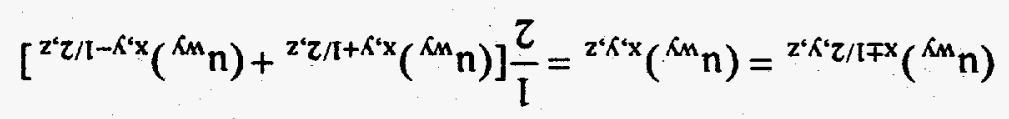

$$
{ }^{[+x}\left({ }^{m} \Phi\right)<{ }^{x}\left({ }^{m} \Phi\right) \text { IOf }
$$


where, $C_{1}$ is the concentration of the flowing bacteria and $C_{8}$ is the concentration of the carbon-source nutrient. Adsorption of cells on pore surfaces is considered as a dynamic adsorption process. The adsorption rate is expressed as:

$$
\frac{\partial \mathbf{C}_{1 \mathbf{s}}}{\partial \mathrm{t}}=\mathbf{R}_{\mathbf{r}}-\mathbf{R}_{\mathbf{d}}
$$

where, $R_{r}$ and $R_{d}$ are rates of bacterial retention and detachment. For simplicity, the bacterial transport equation (6.59) is rewritten as:

$$
\begin{aligned}
\frac{\partial C_{1}}{\partial t}= & \frac{1}{D_{s}}\left[-\nabla\left(\frac{\vec{u}_{w}}{B_{w}} C_{1}\right)-K_{c} \nabla\left(C_{1} \nabla \ln C_{8}\right)+\nabla\left(\frac{\phi S_{w}}{B_{w}} \overrightarrow{\bar{D}}_{1 w} \nabla C_{1}\right)\right. \\
& \left.-\frac{q_{w}}{V_{b}} C_{1}+\frac{\phi S_{w}}{B_{w}} R_{1}+\phi\left(R_{d}-R_{r}\right)\right]
\end{aligned}
$$

where

$$
D_{s}=\frac{\phi S_{w}}{B_{w}}
$$

Discretization of the bacterial transport equation (6.61) in the spatial variable is essentially the same as that of equation (6.34) for product and substrate, except that the chemotaxis term in equation (6.61) needs to be treated with special care. The chemotaxis term can be further expanded as: 


$$
\begin{aligned}
\mathrm{K}_{\mathrm{c}} \nabla\left(\mathrm{C}_{1} \nabla \ln \mathrm{C}_{8}\right) & =\mathrm{K}_{\mathrm{c}}\left[\frac{\partial}{\partial \mathrm{X}}\left(\mathrm{C}_{1} \frac{\partial \ln \mathrm{C}_{8}}{\partial \mathrm{X}}\right)+\frac{\partial}{\partial \mathrm{Y}}\left(\mathrm{C}_{1} \frac{\partial \ln \mathrm{C}_{8}}{\partial \mathrm{Y}}\right)+\frac{\partial}{\partial \mathrm{Z}}\left(\mathrm{C}_{1} \frac{\partial \ln \mathrm{C}_{8}}{\partial \mathrm{Z}}\right)\right] \\
& =\mathrm{K}_{\mathrm{c}}\left[\frac{\partial}{\partial \mathrm{X}}\left(\frac{1}{\mathrm{C}_{8}} \frac{\partial \mathrm{C}_{8}}{\partial \mathrm{X}} \mathrm{C}_{1}\right)+\frac{\partial}{\partial \mathrm{Y}}\left(\frac{1}{\mathrm{C}_{8}} \frac{\partial \mathrm{C}_{8}}{\partial \mathrm{Y}} \mathrm{C}_{1}\right)+\frac{\partial}{\partial \mathrm{Z}}\left(\frac{1}{\mathrm{C}_{8}} \frac{\partial \mathrm{C}_{8}}{\partial \mathrm{Z}} \mathrm{C}_{1}\right)\right]
\end{aligned}
$$

The X-direction component of the chemotaxis term is approximated as:

$$
\left[\frac{\partial}{\partial \mathrm{X}}\left(\frac{1}{\mathrm{C}_{8}} \frac{\partial \mathrm{C}_{8}}{\partial \mathrm{X}} \mathrm{C}_{1}\right)\right]_{\mathrm{xyz}}=\frac{1}{\Delta \mathrm{X}_{\mathrm{x}}}\left[\left(\frac{1}{\mathrm{C}_{8}} \frac{\partial \mathrm{C}_{8}}{\partial \mathrm{X}} \mathrm{C}_{1}\right)_{\mathrm{x}+1 / 2}-\left(\frac{1}{\mathrm{C}_{8}} \frac{\partial \mathrm{C}_{8}}{\partial \mathrm{X}} \mathrm{C}_{1}\right)_{\mathrm{x}-1 / 2}\right]
$$

where,

$$
\left(\frac{1}{C_{8}} \frac{\partial C_{8}}{\partial X}\right)_{x \pm 1 / 2}=\frac{C_{8, x \pm 1}-C_{8, x}}{\left(C_{8} \Delta X\right)_{x \pm 1 / 2}}=\frac{4\left(C_{8, x \pm 1}-C_{8, x}\right)}{\left(C_{8, x}+C_{8, x \pm 1}\right)\left(\Delta X_{x}+\Delta X_{x \pm 1}\right)}
$$

Again, Leonard's third-order upstream formula with a modification for variable grid sizes is used to approximate the bacterial concentrations in Eq. (6.64):

$$
\begin{aligned}
& \text { for } C_{8, x-1}>C_{8, x} \\
& \qquad C_{1, x-1 / 2}=C_{1, x-1}+A_{x-1}\left(C_{1, x-1}-C_{1, x-2}\right)+2 B_{x-1}\left(C_{1, x}-C_{1, x-1}\right) \\
& \text { for } C_{8, x}>C_{8, x+1}
\end{aligned}
$$




$$
\begin{aligned}
& C_{1, x+1 / 2}=C_{1, x}+A_{x}\left(C_{1, x}-C_{1, x-1}\right)+2 B_{x}\left(C_{1, x+1}-C_{1, x}\right) \\
& \text { for } C_{8, x-1}<C_{8, x} \\
& C_{1, x-1 / 2}=C_{1, x}+2 A_{x}\left(C_{1, x-1}-C_{1, x}\right)+B_{x}\left(C_{1, x}-C_{1, x+1}\right) \\
& \text { for } C_{8, x}<C_{8, x+1} \\
& C_{1, x+1 / 2}=C_{1, x+1}+2 A_{x+1}\left(C_{1, x}-C_{1, x+1}\right)+B_{x+1}\left(C_{1, x+1}-C_{1, x+2}\right)
\end{aligned}
$$

\subsection{Well Model}

In this section, well inflow performance is discussed. Wells, either producers or injectors, are treated as source/sink terms in the numerical simulator. Basically, constraints of either constant flow rate or constant flowing bottomhole pressure can be imposed on wells. From Darcy's law, the well volumetric flow rate for phase $\ell$ is proportional to the pressure difference between the gridblock pressure and flowing bottomhole pressure:

$$
\mathrm{q}_{\ell}=\mathrm{PI}_{\ell}\left(\mathrm{p}-\mathrm{p}_{\mathrm{wf}}\right)
$$

where, $\mathrm{p}$ is the gridblock pressure; $\mathrm{p}_{\mathrm{wf}}$ is the flowing bottomhole pressure; $\mathrm{PI}_{\ell}$ is productivity index for phase $\ell$, which is defined as:

$$
\mathrm{PI}_{\ell}=\mathrm{T}_{\mathrm{w}} \frac{\lambda_{\ell}}{\mathrm{B}_{\ell}}
$$


where, $\lambda_{\ell}$ and $\mathrm{B}_{\ell}$ are mobility and formation volume factor for phase $\ell ; \mathrm{T}_{\mathrm{w}}$ is defined as well transmissivity to connect flow between wellbore and gridblock:

$$
T_{w}=\frac{\Delta Z \sqrt{K_{x} K_{y}}}{\ln \left(\frac{r_{0}}{r_{w}}\right)+S}
$$

where, $K_{x}$ and $K_{y}$ are permeabilities in the $X$ - and $Y$-directions; $\Delta Z$ is gridblock size in the $Z$-direction; $r_{w}$ is wellbore radius; $S$ is skin factor; The pressure equivalent radius of the gridblock $\left(r_{o}\right)$ is computed using Peaceman's formula: ${ }^{34}$

$$
r_{o}=\frac{\left[\left(\frac{K_{y}}{K_{x}}\right)^{1 / 2} \Delta X^{2}+\left(\frac{K_{x}}{K_{y}}\right)^{1 / 2} \Delta Y^{2}\right]^{1 / 2}}{\left(\frac{K_{y}}{K_{x}}\right)^{1 / 4}+\left(\frac{K_{x}}{K_{y}}\right)^{1 / 4}}
$$

Next, well constraints such as flow rates and flowing bottomhole pressures will be discussed.

\subsubsection{Constant Oil Production Rate}

If the oil production rate is specified as $q_{0}$ for a well, the oil, water, and gas production rates from layer $\mathrm{z}$ in this well can be computed by: 


$$
\begin{aligned}
& q_{o, z}=q_{o} \frac{\left(P I_{L}\right)_{z}}{\sum_{z=1}^{n z}\left(P I_{L}\right)_{z}} \\
& q_{w, z}=q_{o, z}\left(\frac{\lambda_{w} / B_{w}}{\lambda_{o} / B_{o}}\right)_{z} \\
& q_{g, z}=q_{o, z}\left(\frac{\lambda_{g} / B_{g}}{\lambda_{o} / B_{o}}\right)_{z}+q_{o, z} R_{s o, z}+q_{w, z} R_{s w, z}
\end{aligned}
$$

where, $\mathrm{nz}$ is total number of completion intervals.

\subsubsection{Constant Total Liquid Production Rate}

Total oil and water mobility ratios are expressed as:

$$
\begin{aligned}
& \alpha_{o t}=\sum_{z=1}^{n z}\left(\frac{\lambda_{o} / B_{o}}{\lambda_{o} / B_{o}+\lambda_{w} / B_{w}}\right)_{z} \\
& \alpha_{w t}=\sum_{z=1}^{n z}\left(\frac{\lambda_{w} / B_{w}}{\lambda_{o} / B_{o}+\lambda_{w} / B_{w}}\right)_{z}
\end{aligned}
$$

If the total liquid production rate at surface condition is assumed to be $q_{t}$, total oil rate is calculated by: 


$$
q_{o}=\left(\frac{\alpha_{o t}}{\alpha_{o t}+\alpha_{o t}}\right) q_{t}
$$

If the total oil production rate is known, the oil, water, and gas rates for each layer can be calculated using Eqs (6.74) through (6.76).

\subsubsection{Constant Water or Gas Injection Rates}

Total water or gas injection rates are specified as $q_{w}$ or $q_{g}$. The water or gas injection rates for each layer are computed based on total mobilities instead of only injected fluid mobility:

$$
\begin{aligned}
& q_{w, z}=q_{w} \frac{\left[T_{w}\left(\lambda_{o}+\lambda_{w}+\lambda_{g}\right)\right]_{z}}{\sum_{z=1}^{n z}\left[T_{w}\left(\lambda_{o}+\lambda_{w}+\lambda_{g}\right)\right]_{z}} \\
& q_{g, z}=q_{g} \frac{\left[T_{w}\left(\lambda_{o}+\lambda_{w}+\lambda_{g}\right)\right]_{z}}{\sum_{z=1}^{n z}\left[T_{w}\left(\lambda_{o}+\lambda_{w}+\lambda_{g}\right)\right]_{z}}
\end{aligned}
$$

\subsubsection{Constant Bottom-Hole Pressure for Producer}

In this simulator it is assumed that the flowing bottom-hole pressure (BHP) at the top layer is specified for the producer. The flowing BHP at lower layers are computed by: 


$$
\mathrm{p}_{\mathrm{wf}, \mathrm{z}}=\mathrm{p}_{\mathrm{wf}, \mathrm{z}-1}+0.5\left(\bar{\gamma}_{\mathrm{z}} \Delta \mathrm{Z}_{\mathrm{z}}+\bar{\gamma}_{\mathrm{z}-1} \Delta \mathrm{Z}_{\mathrm{z}-1}\right)
$$

where, the average specific weight of wellbore fluids is defined as:

$$
\bar{\gamma}_{z}=\frac{\sum_{\ell=0, w, g}\left(\gamma_{\ell} \mathrm{PI}_{\ell}\right)_{z}}{\sum_{\ell=0, w, g}\left(\mathrm{PI}_{\ell}\right)_{z}}
$$

\subsubsection{Constant Bottom-Hole Pressure for Injector}

Similarly, the bottom-hole pressure at the top layer can be specified for an injection. The injection BHP for the lower layers are calculated as follows:

$$
\mathrm{p}_{\mathrm{wf}, \mathrm{z}}=\mathrm{p}_{\mathrm{wf}, \mathrm{z}-1}+0.5\left(\gamma_{\mathrm{inj}, \mathrm{z}} \Delta \mathrm{Z}_{\mathrm{z}}+\gamma_{\mathrm{inj}, \mathrm{z}-1} \Delta \mathrm{Z}_{\mathrm{z}-1}\right)
$$

where, $\gamma_{\text {inj, } z}$ is specific weight for the injected fluid at layer $z$.

\subsubsection{Implicit Pressure Constraints}

For constant bottom-hole pressure wells, production or injection rates for phase $\ell$ at layer $\mathrm{z}$ can be expressed as:

$$
\mathrm{q}_{\ell, \mathrm{z}}=\left(\mathrm{PI}_{\ell}\right)_{\mathrm{z}}\left(\mathrm{p}^{\mathrm{n}+1}-\mathrm{p}_{\mathrm{wf}}\right)_{\mathrm{z}}
$$

The above equation is substituted into the pressure equation (6.3) so that pressures can be solved implicitly. The calculated block pressure $\mathrm{p}^{\mathrm{n}+1}$ is then used to determine the 
phase flow rate $\mathrm{q}_{\ell, \mathrm{z}}$. This implicit pressure procedure requires that the original coefficients $\left(E_{x y z}\right.$ and $\left.B_{x y z}\right)$ of the pressure equation be redefined as:

$$
\begin{aligned}
& E_{x y z}^{\text {new }}=E_{x y z}^{\text {old }}-\beta_{t, x y z} \\
& B_{x y z}^{\text {new }}=B_{x y z}^{\text {old }}-\beta_{t, x y z} p_{w f, x y z} \\
& \hat{B}_{x y z}^{\text {new }}=\hat{B}_{x y z}^{\text {old }}-\beta_{t, x y z}\left(p_{w f, x y z}-p_{x y z}^{n}\right) \quad \text { for the perturbation method }
\end{aligned}
$$

where

$$
\beta_{t, x y z}=\left[\left(B_{o}-B_{g} R_{s o}\right) P I_{o}+\left(B_{w}-B_{g} R_{s w}\right) P I_{w}+B_{g} P I_{g}\right]_{x y z}
$$

\subsection{Time Step Selection}

An automatic time step selector is incorporated in the simulator to avoid numerical instability and to save computational time.

First, the relative changes in primary dependent variables (pressures, saturations, and concentrations) over a time step are calculated for each grid block:

$$
(\Delta p)_{m}=\frac{\left|p_{m}^{n+1}-p_{m}^{n}\right|}{p_{m}^{n+1}}
$$




$$
\begin{aligned}
& \left(\Delta S_{\ell}\right)_{m}=\frac{\left|\left(S_{\ell}\right)_{m}^{n+1}-\left(S_{\ell}\right)_{m}^{n}\right|}{\left(S_{\ell}\right)_{m}^{n+1}} \\
& \left(\Delta C_{k}\right)_{m}=\frac{\left|\left(C_{k}\right)_{m}^{n+1}-\left(C_{k}\right)_{m}^{n}\right|}{\left(C_{k}\right)_{m}^{n+1}}
\end{aligned}
$$

where, $\mathrm{m}, \ell$, and $\mathrm{k}$ are numbers for grid blocks, phases, and components, respectively. Next, maximum relative changes are determined for each variable:

$$
\begin{aligned}
& (\Delta \mathrm{p})_{\max }=\max _{\mathrm{m}}\left[(\Delta \mathrm{p})_{\mathrm{m}}\right] \\
& (\Delta \mathrm{S})_{\max }=\max _{\ell}\left\{\max _{\mathrm{m}}\left[\left(\Delta \mathrm{S}_{\ell}\right)_{\mathrm{m}}\right]\right\} \\
& (\Delta \mathrm{C})_{\max }=\max _{\mathrm{k}}\left\{\max _{\mathrm{m}}\left[\left(\Delta \mathrm{C}_{\mathrm{k}}\right)_{\mathrm{m}}\right]\right\}
\end{aligned}
$$

Finally, to check upper-limit violation, the following criteria are established:

$$
(\Delta \mathrm{p})_{\max } \leq(\Delta \mathrm{p})_{\lim } \quad(\Delta \mathrm{S})_{\max } \leq(\Delta \mathrm{S})_{\lim } \quad(\Delta \mathrm{C})_{\max } \leq(\Delta \mathrm{C})_{\lim }
$$

where, $(\Delta \mathrm{p})_{\lim },(\Delta S)_{\lim }$, and $(\Delta C)_{\text {lim }}$ are upper limits specified for relative changes in pressures, saturations, and concentrations, respectively.

If all the criteria in Eq.(6.96) are satisfied, time step can be increased by multiplying the factor $F_{\text {ine }}$, otherwise, the time step is reduced by the factor $F_{\text {dec }}$ :

$$
\Delta \mathrm{t}^{\mathrm{n}+1}=\mathrm{F}_{\mathrm{inc}} \Delta \mathrm{t}^{\mathrm{n}}
$$




$$
\Delta t^{n+1}=F_{\text {dec }} \Delta t^{n}
$$

However, the new time step should be limited by:

$$
\Delta t_{\text {min }} \leq \Delta t^{n+1} \leq \Delta t_{\text {max }}
$$

where, $\Delta t_{\min }$ and $\Delta t_{\max }$ are specified lower and upper limits for time step size.

\subsection{Vectorization}

All variables are vectorized so that the variables are stored in one-dimensional arrays following the order of grid-block numbering. This offers advantage and flexibility in computation.

In one form of natural ordering, gridblocks are numbered so that:

$$
\begin{aligned}
& \text { for } z=1,2, \ldots N_{z} \\
& y=1, \quad x=1,2, \ldots . ., N_{x} \\
& y=2, \quad x=1,2, \ldots ., N_{x} \\
& \begin{array}{l}
y . . . \\
y=N_{y}, \quad x=1,2, \ldots \ldots, N_{x}
\end{array}
\end{aligned}
$$


where, $N_{x}, N_{y}, N_{z}$ are total block numbers in the $X-, Y-$, and Z-directions. Thus, a relationship between block ordering number $\left\{n_{b}\right\}$ and block coordinate $\{x, y, z\}$ can be established:

$$
n_{b}=x+(y-1) N_{x}+(z-1) N_{x} N_{y}, \quad n_{b}=1,2,3, \ldots \ldots, N
$$

where, $\mathrm{N}$ is total block number for the grid system:

$$
\mathrm{N}=\mathrm{N}_{\mathbf{x}} \mathrm{N}_{\mathbf{y}} \mathrm{N}_{\mathbf{z}}
$$

Therefore, the following equivalent relationships hold:

$$
\begin{aligned}
& \{x \pm 1\} \Leftrightarrow\left\{n_{b} \pm 1\right\} \\
& \{y \pm 1\} \Leftrightarrow\left\{n_{b} \pm N_{x}\right\} \\
& \{z \pm 1\} \Leftrightarrow\left\{n_{b} \pm N_{x} N_{y}\right\} \\
& \{x \pm 2\} \Leftrightarrow\left\{n_{b} \pm 2\right\} \\
& \{y \pm 2\} \Leftrightarrow\left\{n_{b} \pm 2 N_{x}\right\} \\
& \{z \pm 2\} \Leftrightarrow\left\{n_{b} \pm 2 N_{x} N_{y}\right\} \\
& \{x \pm 1, y \pm 1\} \Leftrightarrow\left\{n_{b} \pm 1 \pm N_{x}\right\}
\end{aligned}
$$




$$
\begin{aligned}
& \{x \pm 1, z \pm 1\} \Leftrightarrow\left\{n_{b} \pm 1 \pm N_{x} N_{y}\right\} \\
& \{y \pm 1, z \pm 1\} \Leftrightarrow\left\{n_{b} \pm N_{x} \pm N_{x} N_{y}\right\} \\
& \left\{x \pm n_{x}, y \pm n_{y}, z \pm n_{z}\right\} \Leftrightarrow\left\{n_{b} \pm n_{x} \pm n_{y} N_{x} \pm n_{z} N_{x} N_{y}\right\}
\end{aligned}
$$

where

$$
1 \leq n_{x} \leq N_{x}, \quad 1 \leq n_{y} \leq N_{y}, \quad 1 \leq n_{z} \leq N_{z}
$$

\subsection{Computational Procedure}

The numerical solutions for mathematical models involves several steps. First the pressure distributions are solved implicitly. Second the phase saturations are calculated explicitly. Third the Darcy fluxes for the aqueous phase are computed. Finally, this is followed by the explicit solution of the convection-dispersion equations for components.

The pressure equation is solved using LSOR algorithm. ${ }^{35,36}$ Solutions for the component equations are obtained using method of lines (MOL) ${ }^{37}$ and the fourth-order Runge-Kutta-Fehlberg (RKF) formula. ${ }^{38}$

Finite difference formulae for the black oil model and component transport equations are summarized in Tables 6.1 and 6.2 . 
Table 6.1 Finite Difference Equations for Block Oil Model

\begin{tabular}{|c|c|}
\hline Variables & Equations \\
\hline Pressure & $\begin{array}{l}\mathrm{AT}_{\mathrm{z}} \mathrm{p}_{\mathrm{z}-1}^{\mathrm{n}+1}+\mathrm{AS}_{\mathrm{y}} \mathrm{p}_{\mathrm{y}-1}^{\mathrm{n}+1}+\mathrm{AW}_{\mathrm{x}} \mathrm{p}_{\mathrm{x}-1}^{\mathrm{n}+1}+\mathrm{AB}_{\mathrm{z}} \mathrm{p}_{\mathrm{z}+1}^{\mathrm{n}+1}+ \\
\mathrm{AN}_{\mathrm{y}} \mathrm{p}_{\mathrm{y}+1}^{\mathrm{n}+1}+\mathrm{AE}_{\mathrm{x}} \mathrm{p}_{\mathrm{x}+1}^{\mathrm{n}+1}+\mathrm{E}_{\mathrm{xyz}} \mathrm{p}_{\mathrm{xyz}}^{\mathrm{n}+1}=\mathrm{B}_{\mathrm{xyz}}\end{array}$ \\
\hline Saturations & $\begin{array}{l}S_{o, x y z}^{n+1}=\left(\frac{B_{o}}{V_{p}}\right)_{x y z}^{n+1}\left[\left(V_{p} \frac{S_{o}}{B_{o}}\right)^{n}+\Delta t\left(\Delta A_{o} \Delta p^{n+1}+G C O T-q_{o}\right)\right]_{x y z} \\
S_{w, x y z}^{n+1}=\left(\frac{B_{w}}{V_{p}}\right)_{x y z}^{n+1}\left[\left(V_{p} \frac{S_{w}}{B_{w}}\right)^{n}+\Delta t\left(\Delta A_{w} \Delta p^{n+1}+G C O T-q_{w}\right)\right]_{x y z} \\
S_{g, x y z}^{n+1}=1-S_{o, x y z}^{n+1}-S_{w, x y z}^{n+1}\end{array}$ \\
\hline
\end{tabular}


Table 6.2 Finite Difference Equations for Component Transport

\begin{tabular}{|c|c|}
\hline Variables & Equations \\
\hline $\begin{array}{l}\text { Flowing } \\
\text { Bacteria }\end{array}$ & $\begin{array}{l}\left(\frac{\partial C_{1}}{\partial t}\right)_{x y z}=\left\{\frac{1}{D_{s}}\left[-\nabla\left(\frac{\vec{u}_{w}}{B_{w}} C_{1}\right)-K_{c} \nabla\left(C_{1} \nabla \ln C_{8}\right)+\nabla\left(\frac{\phi S_{w}}{B_{w}} \overrightarrow{\bar{D}}_{1 w} \nabla C_{1}\right)-\right.\right. \\
\left.\left.\qquad \frac{q_{w}}{V_{b}} C_{1}+\frac{\phi S_{w}}{B_{w}} R_{1}+\phi\left(R_{d}-R_{r}\right)\right]\right\}_{x y z} \\
\text { where, } D_{s}=\frac{\phi S_{w}}{B_{w}}\end{array}$ \\
\hline $\begin{array}{l}\text { Products } \\
\text { and } \\
\text { Nutrients }\end{array}$ & $\begin{aligned} &\left(\frac{\partial C_{k}}{\partial t}\right)_{x y z}= \frac{1}{D_{s}}\left[-\nabla\left(\frac{\vec{u}_{w}}{B_{w}} C_{k}\right)+\nabla\left(\frac{\phi S_{w}}{B_{w}} \overline{\bar{D}}_{k w} \nabla C_{k}\right)-\right. \\
&\left.\left.\frac{q_{w}}{V_{b}} C_{k}+\frac{\phi S_{w}}{B_{w}} R_{k}\right]\right\}_{x y z} \quad k=2,3, \ldots .10 \\
& \text { where, } D_{s}=\frac{\phi S_{w}}{B_{w}}+\frac{\phi a_{k}}{\left(1+b_{k} C_{k}\right)^{2}}\end{aligned}$ \\
\hline $\begin{array}{c}\text { Sessile } \\
\text { Bacteria }\end{array}$ & $\left(\frac{\partial \sigma}{\partial \mathrm{t}}\right)_{\mathrm{xyz}}=\left(\frac{\mathbf{R}_{\mathrm{d}}-\mathbf{R}_{\mathrm{r}}+\mathbf{R}_{\mathrm{ls}}}{\rho_{\mathrm{lsc}}}\right)_{\mathrm{xyz}}$ \\
\hline
\end{tabular}




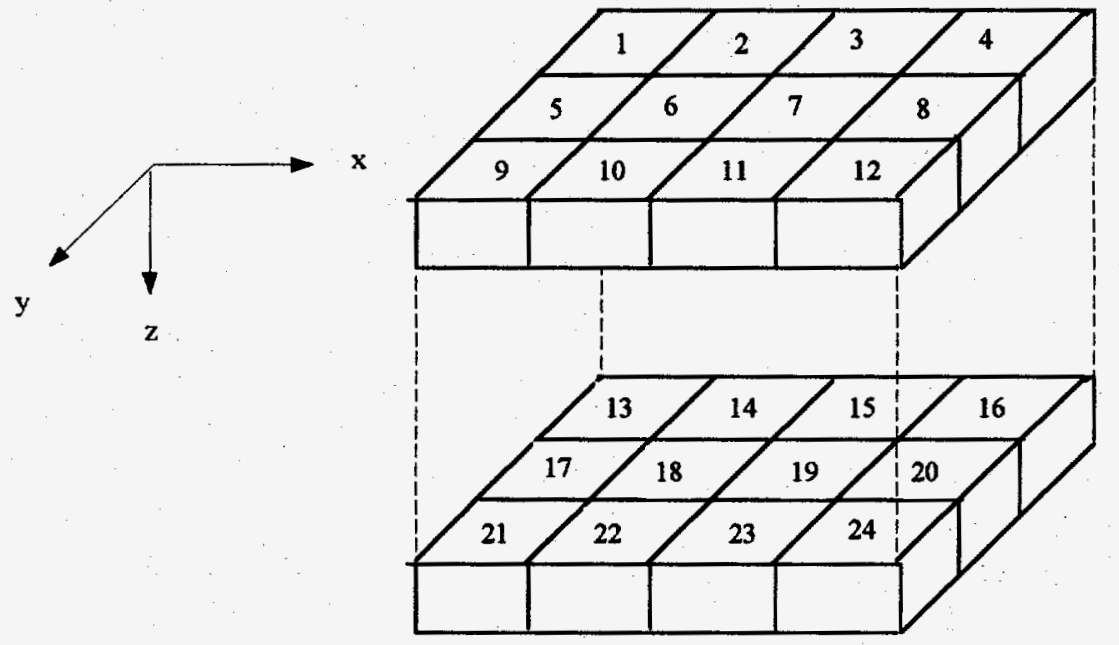

Fig. 6.1 Block Numbering for $4 \times 3 \times 2$ Grid System 


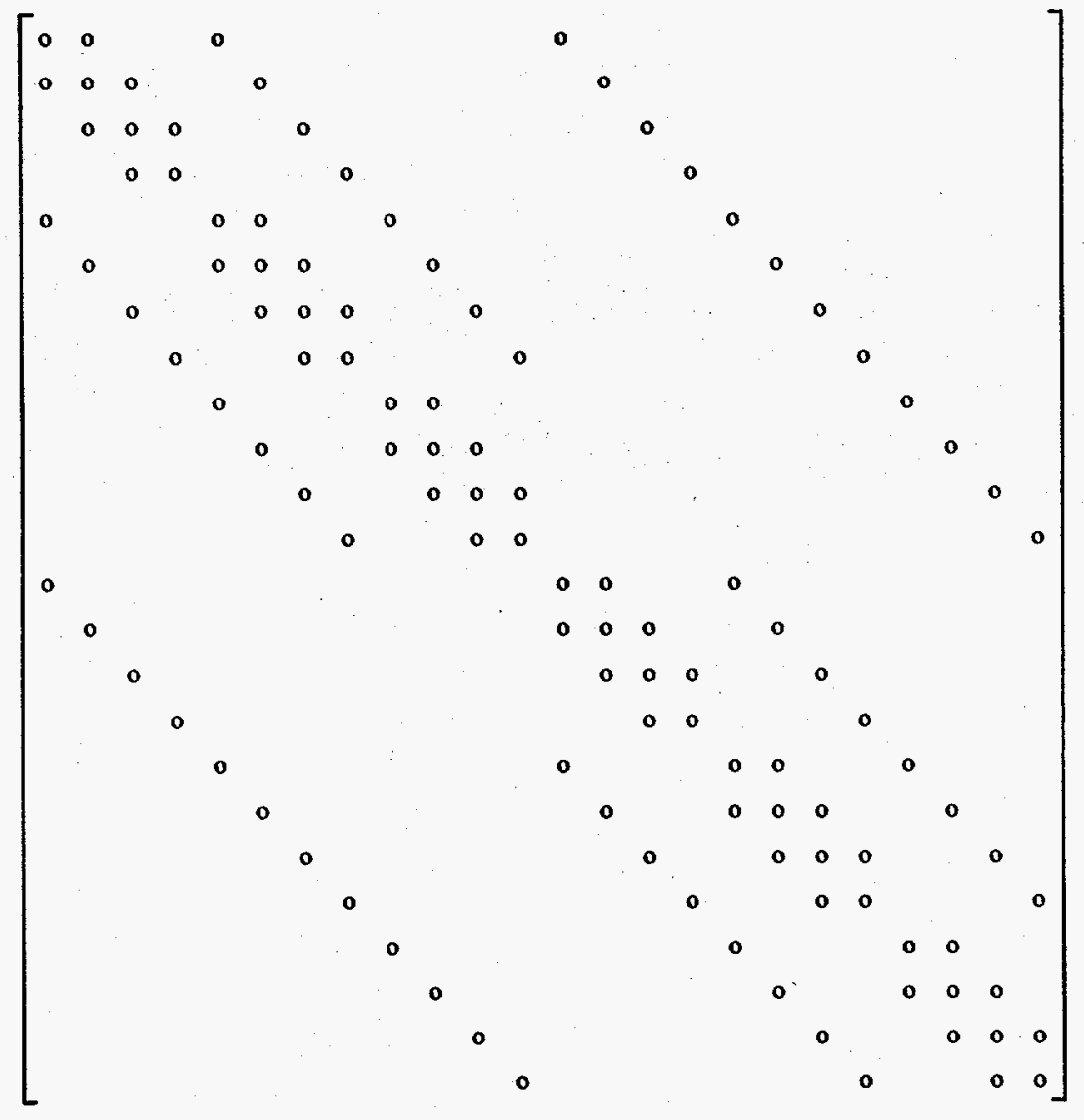

Fig. 6.2 Coefficient Matrix of Pressure Equation for $4 \times 3 \times 2$ Grid System 


\section{SIMULATOR VALIDATION AND APPLICATIONS}

The mathematical formulation of MEOR processes developed in Chapter 5, and the numerical techniques used to solve the MEOR model, described in Chapter 6 were verified using analytical solutions and other simulators. Special cases regarding growth inhibition, chemotaxis, microbial plugging, biopolymer, biosurfactant, biogases were used to test the simulator and investigate the mechanisms involved in MEOR processes. The validation and case studies were necessary to ensure the correctness of the proposed models and program coding. Finally, the simulator was used to model MEOR experiments conducted in the laboratory.

\subsection{Verification with Analytical Solutions}

In this section, the numerical results were compared with analytical solutions for a one-dimensional immiscible displacement, a one-dimensional convection and dispersion, and a two-dimensional ideal tracer flow.

\subsubsection{One-Dimensional Waterflood}

By neglecting capillary pressure and gravity effects, an analytical solution is available for the linear incompressible, immiscible waterflood case known as the BuckleyLeverett problem. ${ }^{39}$ Table 7.1 contains the input data necessary for an one-dimensional numerical solution. The 100-, 50-, and 25-block grid systems were used to test the model. Figure 7.1 shows the water saturation profiles after 40 days of water injection. Numerical solutions for various grid systems were stable. The finer grid system gave better 
agreement between simulation results and the analytical solution except at the displacing front where small numerical smearing occurred.

\subsubsection{Linear Convection-Dispersion Equation}

This sample problem was designed to test the Leonard's third-order upwinding formula $^{33}$ incorporated in the MEOR simulator. Compared with the first- and secondorder convective differencing formulae, the third-order scheme gave less oscillation and more accurate results. ${ }^{40} \mathrm{~A}$ one-dimensional miscible flow was simulated. The injected fluid was identical to the resident fluid in properties. The simulation was run at a Peclet number of 500 and with grid systems containing 100, 50, and 25 blocks. The input data are given in Table 7.2. The computed concentration profile at 0.5 pore volume injected is compared with the analytical solution of the one-dimensional convection-dispersion equation, as shown in Figure 7.2. No oscillation was observed for any of the numerical results. Coarser grid systems gave solutions with more numerical dispersion. An excellent match between simulation results and analytical solution was achieved with the 100-block grid system.

\subsubsection{Ideal Tracer Flow in Five-Spot Pattern}

The tracer breakthrough curve (displacing fluid cut versus pore volume injected) for different Peclet numbers and flow patterns has been obtained by application of mixing theory. ${ }^{41}$ The analytical solution for an ideal tracer flow with a unit mobility ratio in a homogeneous five-spot pattern was selected for solution comparison. A $20 \times 20 \times 1$ grid system was employed to model the flow of a $2 \%$ pore volume tracer slug with a longitudinal dispersivity of $0.2 \mathrm{ft}$ in one-quarter of five-spot pattern with sides of $100 \mathrm{ft}$ 
(Table.7.3). Figure 7.3 shows a comparison of simulation results and analytical solution. The calculated results obtained from the MEOR simulator were close to analytical solution. The observed discrepancy could be explained to be due to numerical dispersion since there were only 28 blocks along diagonal direction for the $20 \times 20 \times 1$ grid system. The numerical solution could be improved if a finer grid pattern was used.

\subsection{Comparison with ECLIPSE Simulator}

A two-dimensional waterflood case was chosen to test the MEOR simulator by comparison with the ECLIPSE simulator, a commercial three-phase, three-dimensional black oil model.

\subsubsection{Waterflood in Five-Spot Pattern}

The immiscible displacement of oil by water in a homogeneous one-quarter of a five-spot well pattern was selected to verify the black oil model portion of the MEOR simulator. Input data are listed in Table 7.4. A grid system of $10 \times 10 \times 1$ was used. Figures 7.4 to 7.9 show comparisons of the MEOR simulator with the ECLIPSE simulator for oil production rate, water cut, water saturation at a specified block $(5,5,1)$, average reservoir pressure, and bottom-hole pressures (BHP) for the injector and producer. In general, agreement between the two simulators was good. However, the MEOR simulator predicted a little lower injection BHP and higher production BHP than those did the ECLIPSE simulator. This might be due to slightly different well models incorporated into the two simulators. 


\subsection{Case Studies for MEOR Processes}

Mechanisms involved in MEOR techniques were investigated through simulation of processes regarding growth inhibition, chemotaxis, microbial plugging, mobility control by biopolymers, interfacial tension reduction by biosurfactants, and biogas effects. The following hypothetical cases were designed for numerical simulation.

\subsubsection{Growth Inhibition by End Products}

Bacterial growth can be inhibited by metabolic products such as alcohol. This may become important when the concentrations of inhibitors increase significantly at the later stages of growth and metabolism. A case of cell growth inhibition by alcohol in liquid cultures was selected for simulation. Necessary input data are given in Table 7.5. When terms were included to account for the inhibition of growth by metabolic end products, the duration of the exponential phase of growth was shorter and less biomass was produced compared to the case where no inhibition of growth by metabolic end products occurs (Figure 7.10).

\subsubsection{Chemotactic Migration of Cells}

Mechanisms by which bacteria can penetrate porous material under static conditions include growth, mobility, chemotaxis, or a combination of these modes of locomotion. The movement of microorganisms by self-propulsion in subsurface formation could be an important issue for environmental problems. Experimental results ${ }^{42}$ show that chemotactic strains move through the core in a bank-like fashion while migration of 
nonchemotactic strains appears dispersive. A numerical study was conducted to investigate chemotactic movement of motile bacteria under static conditions. Input data are given in Table 7.6. A six-inch core with a diameter of two inches was partitioned lengthwise into 100 grid blocks. Initially, nutrient was distributed uniformly throughout the core and bacterial cells were introduced into the first 10 blocks. This duplicated the actual experimental protocal. ${ }^{42}$ The core was sealed for the duration of the experiment. Figures 7.11 and 7.12 show profiles for biomass and glucose concentrations after 50 hours of growth. In this study, cell mobility was modeled by effective diffusion including Brownian motion and tumbling. Diffusion phenomenon was a random process. Compared to the case where cell migration was due to diffusion, chemotactic migration of bacteria in porous media appeared band-like. The results were expected since microbial chemotaxis is a systematical process where the net movement of cells is towards a higher nutrient concentration.

\subsubsection{Microbial Plugging}

A two-layer cross section system was chosen to simulate selective plugging of porous media by bacterial cells. Table 7.7 defines the grid system and presents a list of all pertinent data. The top layer of the system is a high-permeability zone and the bottom layer is a low-permeability zone. The MEOR treatment began with the injection of 0.3 pore volumes of biomass and a nutrient solution after waterflood breakthrough. This was followed by incubation and a subsequent waterflood. As shown in Figure 7.13, the permeability decreased by $60 \%$ near the wellbore in the top layer, but only about $5 \%$ reduction in permeability was observed in the bottom layer. This was expected since the high-permeability zone should receive a larger portion of the injected cells and nutrients 
than the low-permeability zone. Selective plugging of the top layer caused a diversion of injected water into the low-permeability zone. Additional oil was recovered as results of improvement in volumetric sweep efficiency. Figures 7.14 and 7.15 give comparisons between the conventional waterflood and waterflood after microbial plugging for oil production rates and oil recovery factors.

\subsubsection{Mobility Control by Biopolymer}

The sweep efficiency of a displacement process may be improved by mobility control that reduces viscous fingering. This can be done by increasing the viscosity of the displacing fluid with biopolymer. A scenario was designed to test the effects of mobility control by in situ biopolymer production. Injection of $10 \%$ pore volumes of biomass and nutrient solution into the core along with the waterflood was followed by an incubation period to allow biopolymer production. This was followed by post MEOR waterflood for oil recovery. The fluid and microbial data are given in Table 7.8. The proposed viscosity model (Eq. 5.86) was used to adjust the viscosity of the biopolymer solution to the level of the oil viscosity. This resulted in a unit viscosity ratio which was favorable for the displacement process. Figure 7.16 shows a post waterflood process after microbial growth occurred in the core. In this process the biopolymer solution slug with the same viscosity as the oil displaced the oil more efficiently than did a conventional waterflood without the biopolymer. This is shown by the fact that the waterflood with the biopolymer solution gave the steep water saturation front while the conventional waterflood had a relatively flat front. Therefore, oil recovery was enhanced through the process of mobility control caused by biopolymer production, as shown in Figures 7.17 and 7.18 . 


\subsubsection{Interfacial Tension Reduction by Biosurfactants}

Biosurfactants produced during the growth and metabolism of bacteria may reduce interfacial tension (IFT) between the oil and water phases. This leads to mobilization and solubilization of residual oil trapped in porous media. Additional oil recovery is expected from this process. A linear core system was selected for simulation of this MEOR mechanism (Table 7.9). The core was assumed to have been flooded to residual oil saturation prior to the MEOR treatment. The simulated MEOR treatment involved nutrient and biomass injection, incubation, and post-incubation brine flood. After microbial growth and metabolism occurred in the core, biosurfactant was produced which significantly decreased the interfacial tension between the oleic and brine phases. Figures 7.19 and 7.20 show the changes in oil production rate, interfacial tension, recovery factor, and capillary number during post-incubation brine flood. It is noted that the oil production rate kept relatively constant and the recovery factor increased linearly as the biosurfactantrich solution displaced the residual oil where interfacial tension was low and capillary number was high. However, once fresh brine breakthrough occurred, oil production droped dramatically since the IFT between the fresh brine and the residual oil was quite high.

\subsubsection{Effects of Biogases}

Gases produced during growth and metabolism include carbon dioxide, nitrogen, and hydrogen. These gases may increase reservoir pressure, swell the oil phase, and reduce oil viscosity so that additional oil may be recovered. A simulation study was conducted based on a $\mathrm{CO}_{2}$-producing bacterium and a linear core system (Table 7.10). As 
shown in Figure 7.21, the growth and metabolism of bacteria in a core flooded with a nutrient solution (111 m moles per liter of glucose) resulted in production of $200 \mathrm{~m}$ moles per liter of carbon dioxide which caused about a 250 psig increase in the pore pressure. It is interesting that the increase in pore pressure showed a trend similar to an exponential bacterial growth curve (Figure 7.22). However, during post brine flush, $80 \%$ of the carbon dioxide was produced and no oil was recovered, as shown in Figure 7.23. Based on the data given in Table 7.10, a solution gas-oil ratio can be estimated as $10 \mathrm{scc} / \mathrm{scc}(55$ scf/stb). At this solution gas-oil ratio, the oil swelling factor is about 1.04. It appears that the amount of gases produced from MEOR processes are not likely sufficient to recover residual oil.

\subsection{Simulation of Experiments}

In this section the MEOR numerical simulator was used to simulate laboratory experiments. The experiments to be simulated included the movement of chemotactic and nonchemotactic bacterial strains of $E$. coli in static sand-packed cores, and Berea sandstone core-flooding experiments using gas- or surfactant-producing bacteria.

\subsubsection{Core Flooding with Indigenous Bacteria}

Experiments were conducted to study mechanisms involved in MEOR processes. ${ }^{43}$ Data from these experiments were used earlier to test the prediction of our onedimensional model ${ }^{13}$ and were reported in our first annual report. ${ }^{49}$ Indigenous bacterial strains and nutrients (glucose and ammonium nitrate) were injected into Berea sandstone core \#6 (6 inches in length and 2 inches in diameter) and the core was then incubated to 
allow time for microbial growth and metabolism. After MEOR treatments permeability reduction and residual oil recovery were observed. End products detected in effluents of the core include acetate, carbon dioxide, and nitrogen. Table 7.11 gives the input data used for numerical simulation. Figures 7.24 to 7.28 show comparisons of simulation solutions with the experimental results for effluent acetate concentration, total gas production, glucose consumption, nitrate consumption, and permeability reduction. No significant metabolic products were observed during the first four treatments. This was probably because cell populations were too low to result in detectable production of metabolities during this time. A good match between experimental data and simulation results was achieved for total gases production which included $\mathrm{CO}_{2}$ and $\mathrm{N}_{2}$. The predicted consumption of glucose and nitrate was very close to that actually measured in the experiment. The surface retention and pore-throat plugging model (Eq.5.23) gave a good agreement for permeability reduction between experimental data and simulation results.

\subsubsection{Chemotactic and Nonchemotactic Strains}

The importance of chemotaxis was investigated in the laboratory experiments using strains of $E$. coli. ${ }^{42}$ These data were previously reported in our first annual report. ${ }^{49}$ A 10-cm-long, sand-packed core was useed. The core was divided into 5 sections of equal length in order to monitor the bacterial transport along the length of the core. The core was filled with mobility growth medium (MGM) ${ }^{42}$ The motile nonchemotactic strain PR5232 and its parental chemotactic strain, RP437, were each inoculated to the first section of separate cores. The cores were then placed in a horizontal position inside the anaerobic chamber for incubation. The concentrations of these strains were determined along the length of MGM-saturated cores with time. ${ }^{42,49}$ Input data for the numerical 
study are listed in Tables 7.12 and 7.13. For simulation, the core was divided lengthwise into 50 grid blocks. Nutrients were distributed uniformly throughout the core and the first 10 blocks were inoculated with bacteria. Figures 7.29 and 7.30 show comparisons between experimental data and simulation results for the concentration profiles of the chemotactic and nonchemotactic strains along the length of the core. The overall matches was good. The chemotactic strain (RP437) grew and moved through cores in a band-like fashion with a high-concentration of cells in the moving front $\left(10^{7} \mathrm{cel} / \mathrm{ml}\right)$ which was accurately predicted by the MEOR simulator. The cells of the nonchemotactic strain (RP5323) moved through cores in a more diffusive manner with a low-concentration cells in the moving front $\left(10^{3} \mathrm{cell} / \mathrm{ml}\right)$. This was also simulated by the model.

\subsubsection{Core Flooding with Clostridium acetobutylicum}

Clostridium acetobutylicum was used for a MEOR core flooding experiment. This organism produces a mixture of acids, solvents, and gases from glucose. A mineral salts medium with glucose and yeast extract was used..$^{42}$ Core \#1, with dimensions of $113 / 16$ inches in length and 2 inches in diameter, was cut from a block of Berea sandstone. Petrophysical properties of this core are listed in Table 7.14. The experimental involved bacterial and nutrient injection, incubation under high pressures (500-1000 psig), and brine flush. Metabolic products that were produced included acetate, butyrate, ethanol, butanol, and carbon dioxide. The experimental data are summarized in Table 7.15. For computational convenience, the acid component represents the sum of acetate and butyrate while the alcohol component represents the sum of ethanol and butanol. A 50block grid system was used for simulating the experiment conducted with core \#1. Table 7.16 gives the necessary input data. The results from numerical solution along with the 
experimental data are plotted in Figures 7.31 to 7.35 . The MEOR simulator predicted lower acid and alcohol production than obtained in the experiment. Good agreement was

observed for $\mathrm{CO}_{2}$ production. Simulation results showed a consumption of about $90 \%$ of the glucose during treatments 2 to 5 , which was much higher than the experimental glucose consumption. High concentration of the unused glucose in the effluent was probably due to desorption of glucose which was sorbed in the rock during nutrient injection.

\subsubsection{Core Flooding with Bacillus Strain JF-2}

MEOR treatments with Bacillus strain JF-2 were conducted in Berea core \#4. Bacillus strain JF-2 produces a biosurfactant which reduces the interfacial tension between oil and water phases. After the core was saturated with brine, it was flooded to connate water saturation with oil, and then flooded to residual oil saturation with brine. The initial core data are shown in Table 7.17. Experimental processes included injection of bacteria and nutrients, incubation of the core to allow time for microbial growth and metabolism, and a post-incubation flush with brine to recover oil and metabolic endproducts. Recovery of $23 \%$ of the residual oil after five treatments was observed. The experimental results are summarized in Table 7.18. To simulate this experiment, a 50 block grid was used. The simulation input data are given in Table 7.19. As seen in Figures 7.36 to 7.38 , simulation results showed that oil recovery was proportional to biosurfactant production. However, the simulator did not predict any increase in permeability as was observed during early treatments (Figure 7.39). Overall matches was reasonable. 
Table 7.1 Input Data for One-Dimensional Waterflood Run

\begin{tabular}{|l|l||}
\hline \multicolumn{1}{|c|}{ Variables } & \multicolumn{1}{|c|}{ Values } \\
\hline Reservoir Dimension: NX $\times \mathrm{NY} \times \mathrm{NZ}$ & $25,50,100 \times 1 \times 1$ \\
\hline Grid Block Size: $\Delta \mathrm{X} \times \Delta \mathrm{Y} \times \Delta Z$ & $40,20,10 \times 100 \times 10 \mathrm{ft}$ \\
\hline Absolute Permeabilities & $\mathrm{K}_{\mathrm{x}}=\mathrm{K}_{\mathrm{y}}=\mathrm{K}_{\mathrm{z}}=100 \mathrm{md}$. \\
\hline Porosity & $20 \%$ \\
\hline Reservoir Top & $8000 \mathrm{ft}$. \\
\hline Pirson's Model ${ }^{44}$ for \\
Oil Relative Permeability & $\mathrm{K}_{\mathrm{ro}}=\left(\frac{1-\mathrm{S}_{\mathrm{w}}-\mathrm{S}_{\mathrm{or}}}{1-\mathrm{S}_{\mathrm{wc}}-\mathrm{S}_{\mathrm{or}}}\right.$ \\
\hline Pirson's Model ${ }^{44}$ for \\
Water Relative Permeability & $\mathrm{K}_{\mathrm{rw}}=\mathrm{S}_{\mathrm{w}}^{3}\left(\frac{\mathrm{S}_{\mathrm{w}}-\mathrm{S}_{\mathrm{wc}}}{1-\mathrm{S}_{\mathrm{wc}}}\right)^{0.5}$ \\
\hline Residual Phase Saturations & $\mathrm{S}_{\mathrm{or}}=30 ; \mathrm{S}_{\mathrm{wc}}=20 \%$ \\
\hline Phase Viscosities & $\mu_{\mathrm{o}}=1.4 ; \mu_{\mathrm{w}}=0.6 \mathrm{cp}$ \\
\hline Phase Densities at Surface Conditions & $\mathrm{Pos}_{\mathrm{os}}=46.244 ; \rho_{\mathrm{ws}}=62.238 \mathrm{lb} / \mathrm{ft}^{3}$ \\
\hline Rock Compressibility & $5 \times 10^{-6} \mathrm{psia}^{-1}$ \\
\hline Initial Reservoir Pressure & $4000 \mathrm{psia}$ \\
\hline Initial Oil Saturation & $70 \%$ \\
\hline Injection Rate & $200 \mathrm{stb} / \mathrm{d}$ \\
\hline
\end{tabular}


Table 7.2 Input Data for One-Dimensional Tracer Flow Run

\begin{tabular}{|l|l||}
\hline \multicolumn{1}{|c|}{ Variables } & \multicolumn{1}{c|}{ Values } \\
\hline \hline Reservoir Dimension: NX x NY x NZ & $25,50,100 \times 1 \times 1$ \\
\hline Grid Block Size: $\Delta \mathrm{X} \times \Delta \mathrm{Y} \times \Delta \mathrm{Z}$ & $20,10,5 \times 50 \times 10 \mathrm{ft}$ \\
\hline Absolute Permeabilities & $\mathrm{K}_{\mathrm{x}}=\mathrm{K}_{\mathrm{y}}=\mathrm{K}_{\mathrm{z}}=100 \mathrm{md}$ \\
\hline Porosity & $20 \%$ \\
\hline Reservoir Top & $8000 \mathrm{ft}$. \\
\hline Longitudinal Dispersivity & $1 \mathrm{ft}$. \\
\hline Tortuosity & 1.4 \\
\hline Molecular Diffusion Coefficient & 0. \\
\hline Water Viscosity & $1 \mathrm{cp}$ \\
\hline Water Density at Surface Condition & $62.238 \mathrm{lb} / \mathrm{ft}^{3}$ \\
\hline Rock Compressibility & $5 \times 10^{-6} \mathrm{psia}^{-1}$ \\
\hline Initial Pressure & $4000 \mathrm{psia}^{-1}$ \\
\hline Injection Rate & $100 \mathrm{stb} / \mathrm{d}$ \\
\hline
\end{tabular}


Table 7.3 Input Data for Two-Dimensional Tracer Flow Run

\begin{tabular}{|l|l|}
\hline \multicolumn{1}{|c|}{ Variables } & \\
\hline Reservoir Dimension: $\mathrm{NX} \times \mathrm{NY} \times \mathrm{NZ}$ & $20 \times 20 \times 1$ \\
\hline Grid Block Size: $\Delta \mathrm{X} \times \Delta \mathrm{Y} \times \Delta \mathrm{Z}$ & $5 \times 5 \times 10 \mathrm{ft}$. \\
\hline Absolute Permeabilities & $\mathrm{K}_{\mathrm{x}}=\mathrm{K}_{\mathrm{y}}=100 \mathrm{md}$; $\mathrm{K}_{\mathrm{z}}=50 \mathrm{md}$ \\
\hline Porosity & $20 \%$ \\
\hline Longitudinal Dispersivity & $0.2 \mathrm{ft}$. \\
\hline Tortuosity & 1.4 \\
\hline Molecular Diffusion Coefficient & 0. \\
\hline Water Viscosity & $0.6 \mathrm{cp}$ \\
\hline Water Density at Surface Condition & $62.238 \mathrm{lb} / \mathrm{ft}^{3}$ \\
\hline Rock Compressibility & $3 \times 10^{-6} \mathrm{psia}^{-1}$ \\
\hline Initial Pressure & $4000 \mathrm{psia}$ \\
\hline Tracer Slug Size & $0.02 \mathrm{PV}$ \\
\hline Injection Rate & $200 \mathrm{stb} / \mathrm{d}$ \\
\hline
\end{tabular}


Table 7.4 Input Data for Two-Dimensional Waterflood Run

\begin{tabular}{|l|l|}
\hline \multicolumn{1}{|c||}{ Variables } & \multicolumn{1}{|c|}{ Values } \\
\hline Reservoir Dimension: $\mathrm{NX} \times \mathrm{NY} \times \mathrm{NZ}$ & $10 \times 10 \times 1$ \\
\hline Grid Block Size: $\Delta \mathrm{X} \times \Delta \mathrm{Y} \times \Delta \mathrm{Z}$ & $100 \times 100 \times 20 \mathrm{ft}$ \\
\hline Absolute Permeabilities & $\mathrm{K}_{\mathrm{x}}=\mathrm{K}_{\mathrm{y}}=200 \mathrm{md} ; \mathrm{K}_{\mathrm{z}}=20 \mathrm{md}$ \\
\hline Porosity & $20 \%$ \\
\hline Reservoir Top & $8000 \mathrm{ft}$. \\
\hline Residual Oil Saturation & $30 \%$ \\
\hline Connate Water Saturation & $20 \%$ \\
\hline Endpoints for Phase Relative Permeabilities & $\mathrm{K}_{\mathrm{ro}}^{0}=1 ; \mathrm{K}_{\mathrm{rw}}^{0}=0.5$ \\
\hline Phase Viscosities & $\mu_{\mathrm{o}}=2 ; \mu_{\mathrm{w}}=1 \mathrm{cp}$ \\
\hline Phase Densities at Surface Condition & $\rho_{\mathrm{os}}=46.244 ; \mathrm{pws}_{\mathrm{w}}=62.238 \mathrm{lb} / \mathrm{ft}^{3}$ \\
\hline Rock Compressibility & $3 \times 10^{-6} \mathrm{psia}$ \\
\hline Initial Reservoir Pressure & $4000 \mathrm{psia}$ \\
\hline Initial Oil Saturation & $70 \%$ \\
\hline Injection Rate & $200 \mathrm{stb} / \mathrm{d}$ \\
\hline Production Rate & $200 \mathrm{stb} / \mathrm{d}$ \\
\hline
\end{tabular}


Table 7.5 Input Data for Alcohol Inhibition Test Run

\begin{tabular}{|l|l||}
\hline \multicolumn{1}{|c|}{ Variables } & \multicolumn{1}{|c|}{ Values } \\
\hline Cell Yield from Glucose & $0.8202 \mathrm{mg} / \mathrm{mg}$ \\
\hline Cell Yield from Ammonium & $6.8246 \mathrm{mg} / \mathrm{mg}$ \\
\hline Carbon Dioxide Yield from Glucose & $0.4885 \mathrm{mg} / \mathrm{mg}$ \\
\hline Nitrogen Yield from Nitrate & $0.2259 \mathrm{mg} / \mathrm{mg}$ \\
\hline Acid Yield from Glucose & $0.6555 \mathrm{mg} / \mathrm{mg}$ \\
\hline Alcohol Yield from Glucose & $0.5115 \mathrm{mg} / \mathrm{mg}$ \\
\hline Constant for Alcohol Inhibition & $0.05 \mathrm{mg} / \mathrm{ml}$ \\
\hline Initial Biomass & $2.94 \times 10^{4} \mathrm{cell} / \mathrm{ml}$ \\
\hline Initial Glucose Concentration & $27 \mathrm{mM}$ \\
\hline Initial Ammonium Concentration & $35 \mathrm{mM}$ \\
\hline Initial Nitrate Concentration & $35 \mathrm{mM}$ \\
\hline Biomass Growth Rate & $0.6017 \mathrm{hr}{ }^{-1}$ \\
\hline
\end{tabular}


Table 7.6 Input Data for Chemotaxis Test Run

\begin{tabular}{|l|l|}
\hline \multicolumn{1}{|c|}{ Variables } & \multicolumn{1}{c|}{ Values } \\
\hline \hline Core Dimension: NX x NY x NZ & $100 \times 1 \times 1$ \\
\hline Grid Block Size: $\Delta \mathrm{X} \times \Delta \mathrm{Y} \times \Delta Z$ & $0.1524 \times 4.502 \times 4.502 \mathrm{~cm}$ \\
\hline Porosity & 0.2 \\
\hline Molecular Diffusion Coefficient & $0.05 \mathrm{~cm}^{2} / \mathrm{hr}$ \\
\hline Tortuosity & 1.4 \\
\hline Chemotactic Coefficient & $0.15 \mathrm{~cm}^{2} / \mathrm{hr}$ \\
\hline Cell Yield from Glucose & $0.8202 \mathrm{mg} / \mathrm{mg}$ \\
\hline Cell Yield from Ammonium & $6.8246 \mathrm{mg} / \mathrm{mg}$ \\
\hline Carbon Dioxide Yield from Glucose & $0.4885 \mathrm{mg} / \mathrm{mg}$ \\
\hline Nitrogen Yield from Nitrate & $0.2259 \mathrm{mg} / \mathrm{mg}$ \\
\hline Acid Yield from Glucose & $0.6555 \mathrm{mg} / \mathrm{mg}$ \\
\hline Initial Biomass & $2.94 \times 10^{4} \mathrm{cell} / \mathrm{ml}$ \\
\hline Initial Glucose Concentration & $27 \mathrm{mM}$ \\
\hline Initial Ammonium Concentration & $35 \mathrm{mM}$ \\
\hline Initial Nitrate Concentration & $35 \mathrm{mM}$ \\
\hline
\end{tabular}


Table 7.7 Input Data for Two-Layer Microbial Plugging Test Run

\begin{tabular}{|c|c|}
\hline Variables & Values \\
\hline System Dimension: NX x NY x NZ & $25 \times 1 \times 2$ \\
\hline Grid Block Size in Layer 1: $\Delta \mathrm{X} \times \Delta \mathrm{Y} \times \Delta \mathrm{Z}$ & $4 \times 10 \times 10 \mathrm{~cm}$ \\
\hline Grid Block Size in Layer 2: $\Delta \mathrm{X} \times \Delta \mathrm{Y} \times \Delta \mathrm{Z}$ & $4 \times 10 \times 5 \mathrm{~cm}$ \\
\hline Absolute Permeabilities in layers 1 and 2 & $K_{1}=1000 ; K_{2}=100 \mathrm{md}$ \\
\hline Porosity & $20 \%$ \\
\hline $\begin{array}{l}\text { Corey's Model }{ }^{45} \text { for } \\
\text { Oil and Water Relative Permeabilities }\end{array}$ & $\mathrm{K}_{\mathrm{rp}}=\mathrm{K}_{\mathrm{rp}}^{0}\left(\frac{\mathrm{S}_{\mathrm{p}}-\mathrm{S}_{\mathrm{pr}}}{1-\sum \mathrm{S}_{\mathrm{pr}}}\right)^{\mathrm{e}_{\mathrm{p}}}$ \\
\hline Endpoints of Phase Relative Permeabilities & $\mathrm{K}_{\mathrm{ro}}^{0}=0.65 ; \quad \mathrm{K}_{\mathrm{rw}}^{0}=0.2$ \\
\hline Exponents of Phase Relative Permeabilities & $e_{0}=2.5 ; e_{w}=2.1$ \\
\hline Residual Phase Saturations & $\mathrm{S}_{\mathrm{or}}=30 ; \mathrm{S}_{\mathrm{wr}}=30 \%$ \\
\hline Phase Viscosities & $\mu_{\mathrm{o}}=2 ; \mu_{\mathrm{w}}=1 \mathrm{cp}$ \\
\hline Phase Densities at Surface Condition & $\rho_{o s}=741 ; \rho_{w s}=997 \mathrm{mg} / \mathrm{ml}$ \\
\hline Rock Compressibility & $5 \times 10^{-6} \mathrm{psia}^{-1}$ \\
\hline Molecular Diffusion Coefficients & $0.044 \mathrm{~cm}^{2} / \mathrm{hr}$ \\
\hline Tortuosity & 1.4 \\
\hline Longitudinal Dispersivity & $0.2 \mathrm{~cm}$ \\
\hline Cell Yield from Glucose & $0.8 \mathrm{mg} / \mathrm{mg}$ \\
\hline Maximum Specific Growth Rate & $0.6 \mathrm{hr}^{-1}$ \\
\hline Injected Glucose Concentration & $20 \mathrm{mg} / \mathrm{ml}$ \\
\hline Injected Biomass & $1 \times 10^{8} \mathrm{cell} / \mathrm{ml}$ \\
\hline Parameters for Bimodal Distribution & $e_{1}=1 ; e_{2}=4 ; m_{1}=2 ; m_{2}=5 ; w=0.8$ \\
\hline Min. and Max. Pore-Throat, and Cell Sizes & $x_{\min }=1 ; x_{\max }=10 ; x_{p}=1 \mu \mathrm{m}$ \\
\hline Initial Pressure & $14.7 \mathrm{psia}$ \\
\hline Initial Oil Saturation & $70 \%$ \\
\hline Water Injection Rate & $100 \mathrm{scc} / \mathrm{hr}$ \\
\hline
\end{tabular}


Table 7.8 Input Data for Biopolymer Test Run

\begin{tabular}{|c|c|}
\hline Variables & Values \\
\hline System Dimension: NX x NY x NZ & $50 \times 1 \times 1$ \\
\hline Grid Block Size: $\Delta \mathrm{X} \times \Delta \mathrm{Y} \times \Delta \mathrm{Z}$ & $3.048 \times 9.004 \times 9.004 \mathrm{~cm}$ \\
\hline Absolute Permeabilities & $K_{x}=K_{y}=K_{z}=200 \mathrm{md}$ \\
\hline Porosity & $20 \%$ \\
\hline Oil and Water Relative Permeabilities & Corey's Model ${ }^{45}$ \\
\hline Endpoints of Phase Relative Permeabilities & $\mathrm{K}_{\mathrm{ro}}^{0}=0.65 ; \quad \mathrm{K}_{\mathrm{rw}}^{0}=0.2$ \\
\hline Exponents of Phase Relative Permeabilities & $e_{0}=2.5 ; e_{w}=2.1$ \\
\hline Residual Phase Saturations & $\mathrm{S}_{\mathrm{or}}=30 ; \mathrm{S}_{\mathrm{wr}}=30 \%$ \\
\hline Phase Viscosities & $\mu_{\mathrm{o}}=4 ; \mu_{\mathrm{w}}=1 \mathrm{cp}$ \\
\hline Phase Densities at Surface Condition & $\rho_{\mathrm{os}}=741 ; \rho_{\mathrm{ws}}=997 \mathrm{mg} / \mathrm{ml}$ \\
\hline Rock Compressibility & $5 \times 10^{-6}$ psia $^{-1}$ \\
\hline Molecular Diffusion Coefficients & $0.044 \mathrm{~cm}^{2} / \mathrm{hr}$ \\
\hline Tortuosity & 1.4 \\
\hline Longitudinal Dispersivity & $1 \mathrm{~cm}$ \\
\hline Cell Yield from Glucose & $0.5 \mathrm{mg} / \mathrm{mg}$ \\
\hline Biopolymer Yield from Glucose & $0.5 \mathrm{mg} / \mathrm{mg}$ \\
\hline Maximum Specific Growth Rate & $0.5 \mathrm{hr}^{-1}$ \\
\hline Injected Glucose Concentration & $10 \mathrm{mg} / \mathrm{ml}$ \\
\hline Injected Biomass & $1 \times 10^{4} \mathrm{cell} / \mathrm{ml}$ \\
\hline Initial Pressure & 100 psia \\
\hline Initial Oil Saturation & $70 \%$ \\
\hline Water Injection Rate & $150 \mathrm{scc} / \mathrm{hr}$ \\
\hline
\end{tabular}


Table 7.9 Input Data for Biosurfactant Test Run

\begin{tabular}{|c|c|}
\hline Variables & Values \\
\hline System Dimension: NX x NY x NZ & $50 \times 1 \times 1$ \\
\hline Grid Block Size: $\Delta \mathrm{X} \times \Delta \mathrm{Y} \times \Delta \mathrm{Z}$ & $3.048 \times 9.004 \times 9.004 \mathrm{~cm}$ \\
\hline Absolute Permeabilities & $K_{x}=K_{y}=K_{z}=200 \mathrm{md}$ \\
\hline Porosity & $20 \%$ \\
\hline Oil and Water Relative Permeabilities & Corey's Model ${ }^{45}$ \\
\hline Endpoints of Phase Relative Permeabilities & $\mathrm{K}_{\mathrm{ro}}^{0}=0.65 ; \quad \mathrm{K}_{\mathrm{rw}}^{0}=0.2$ \\
\hline Exponents of Phase Relative Permeabilities & $e_{o}=2.5 ; e_{w}=2.1$ \\
\hline Residual Phase Saturations & $S_{\mathrm{or}}=30 ; S_{\mathrm{wr}}=30 \%$ \\
\hline Phase Viscosities & $\mu_{\mathrm{o}}=2 ; \mu_{\mathrm{w}}=1 \mathrm{cp}$ \\
\hline Phase Densities at Surface Condition & $\rho_{o s}=741 ; \rho_{w s}=997 \mathrm{mg} / \mathrm{ml}$ \\
\hline Rock Compressibility & $5 \times 10^{-6} \mathrm{psia}^{-1}$ \\
\hline Molecular Diffusion Coefficients & $0.044 \mathrm{~cm}^{2} / \mathrm{hr}$ \\
\hline Tortuosity & 1.4 \\
\hline Longitudinal Dispersivity & $1 \mathrm{~cm}$ \\
\hline Cell Yield from Glucose & $0.8202 \mathrm{mg} / \mathrm{mg}$ \\
\hline Biosurfactant Yield from Glucose & $0.8333 \mathrm{mg} / \mathrm{mg}$ \\
\hline Maximum Specific Growth Rate & $0.5 \mathrm{hr}^{-1}$ \\
\hline Injected Glucose Concentration & $10 \mathrm{mg} / \mathrm{ml}$ \\
\hline Injected Biomass & $1 \times 10^{4} \mathrm{cell} / \mathrm{ml}$ \\
\hline Min. and Max Surfactant Concentrations & $\mathrm{C}_{6, \min }=0.1 ; \mathrm{C}_{6, \max }=7.6 \mathrm{mg} / \mathrm{ml}$ \\
\hline Min. and Max. Interfacial Tensions & $\sigma_{\min }=0.1 ; \sigma_{\max }=30 \mathrm{mN} / \mathrm{m}$ \\
\hline Low and High Capillary Numbers for Oil & $\mathrm{N}_{\mathrm{co}}^{\mathrm{w}}=1 \times 10^{-4} ; \quad \mathrm{N}_{\mathrm{co}}^{\mathrm{h}}=1 \times 10^{-2}$ \\
\hline Low and High Capillary Numbers for water & $N_{c w}^{w}=1 \times 10^{-3} ; N_{c w}^{h}=1 \times 10^{-1}$ \\
\hline Initial Pressure & 100 psia \\
\hline Initial Oil Saturation & $70 \%$ \\
\hline Water Injection Rate & $150 \mathrm{scc} / \mathrm{hr}$ \\
\hline
\end{tabular}


Table 7.10 Input Data for Carbon Dioxide Test Run

\begin{tabular}{|c|c|}
\hline Variables & Values \\
\hline System Dimension: NX x NY x NZ & $50 \times 1 \times 1$ \\
\hline Grid Block Size: $\Delta \mathrm{X} \times \Delta \mathrm{Y} \times \Delta \mathrm{Z}$ & $3.048 \times 9.004 \times 9.004 \mathrm{~cm}$ \\
\hline Absolute Permeabilities & $\mathrm{K}_{\mathrm{x}}=\mathrm{K}_{\mathrm{y}}=\mathrm{K}_{\mathrm{z}}=200 \mathrm{md}$ \\
\hline Porosity & $20 \%$ \\
\hline Oil and Water Relative Permeabilities & Corey's Model ${ }^{45}$ \\
\hline Endpoints of Phase Relative Permeabilities & $\mathrm{K}_{\mathrm{ro}}^{0}=0.65 ; \mathrm{K}_{\mathrm{rw}}^{0}=0.2 ; \mathrm{K}_{\mathrm{rg}}^{0}=0.1$ \\
\hline Exponents of Phase Relative Permeabilities & $\mathrm{e}_{\mathrm{o}}=2.5 ; \mathrm{e}_{\mathrm{w}}=2.1 ; \mathrm{e}_{\mathrm{g}}=2.1$ \\
\hline Residual Phase Saturations & $\mathrm{S}_{\mathrm{or}}=30 ; \mathrm{S}_{\mathrm{wr}}=30 ; \mathrm{S}_{\mathrm{gr}}=5 \%$ \\
\hline Oil PVT Data & Correlations $\mathbf{S}^{46,47}$ \\
\hline Water PVT Data & $\mathrm{R}_{\mathrm{sw}}=0 ; \mathrm{B}_{\mathrm{w}}=1 ; \mu_{\mathrm{w}}=1 \mathrm{cp}$ \\
\hline Gas PVT Data & Correlations ${ }^{48}$ \\
\hline Phase Densities at Surface Condition & $\rho_{o s}=741 ; \rho_{w s}=997 ; \rho_{g s}=1.04 \mathrm{mg} / \mathrm{ml}$ \\
\hline Rock Compressibility & $5 \times 10^{-6} \mathrm{psia}^{-1}$ \\
\hline Molecular Diffusion Coefficients & $0.044 \mathrm{~cm}^{2} / \mathrm{hr}$ \\
\hline Tortuosity & 1.4 \\
\hline Longitudinal Dispersivity & $1 \mathrm{~cm}$ \\
\hline Cell Yield from Glucose & $0.2051 \mathrm{mg} / \mathrm{mg}$ \\
\hline Carbon Dioxide Yield from Glucose & $0.4886 \mathrm{mg} / \mathrm{mg}$ \\
\hline Maximum Specific Growth Rate & $0.5 \mathrm{hr}^{-1}$ \\
\hline Injected Glucose Concentration & $20 \mathrm{mg} / \mathrm{ml}$ \\
\hline Injected Biomass Concentration & $1 \times 10^{4} \mathrm{cell} / \mathrm{ml}$ \\
\hline Initial Pressure & $14.7 \mathrm{psia}$ \\
\hline Initial Bubble Point Pressure & 14.7 psia \\
\hline Initial Oil Saturation & $30 \%$ \\
\hline Water Injection Rate & $150 \mathrm{scc} / \mathrm{hr}$ \\
\hline
\end{tabular}


Table 7.11 Input Data for Core \#6 a

\begin{tabular}{|c|c|}
\hline Variables & Values \\
\hline System Dimension: NX x NY x NZ & $50 \times 1 \times 1$ \\
\hline Grid Block Size: $\Delta \mathrm{X} \times \Delta \mathrm{Y} \times \Delta \mathrm{Z}$ & $0.304 \times 4.52 \times 4.52 \mathrm{~cm}$ \\
\hline Absolute Permeabilities and Porosity & $\mathrm{K}_{\mathrm{x}}=\mathrm{K}_{\mathrm{y}}=\mathrm{K}_{\mathrm{z}}=526 \mathrm{md} ; \phi=22 \%$ \\
\hline Oil and Water Relative Permeabilities & Corey's Model 45 \\
\hline Endpoints of Phase Relative Permeabilities & $\mathrm{K}_{\mathrm{ro}}^{0}=0.894 ; \mathrm{K}_{\mathrm{rw}}^{0}=0.105 ; \mathrm{K}_{\mathrm{rg}}^{0}=0.1$ \\
\hline Exponents of Phase Relative Permeabilities & $e_{o}=2.5 ; e_{w}=2.1 ; e_{g}=2.1$ \\
\hline Residual Phase Saturations & $S_{o r}=29.6 ; S_{w r}=27.4 ; S_{g r}=5 \%$ \\
\hline Oil PVT Data & Correlations ${ }^{46,47}$ \\
\hline Water PVT Data & $\mathbf{R}_{\mathrm{sw}}=0 ; \mathrm{B}_{\mathrm{w}}=1 ; \mu_{\mathrm{w}}=1.4 \mathrm{cp}$ \\
\hline Gas PVT Data & Correlations $^{48}$ \\
\hline Phase Densities at Surface Condition & $\rho_{\mathrm{os}}=850 ; \rho_{\mathrm{ws}}=1100 ; \rho_{\mathrm{gs}}=1.9 \mathrm{mg} / \mathrm{ml}$ \\
\hline Rock Compressibility & $5 \times 10^{-6} \mathrm{psia}^{-1}$ \\
\hline Molecular Diffusion Coefficients & $0.044 \mathrm{~cm}^{2} / \mathrm{hr}$ \\
\hline Tortuosity & 1.4 \\
\hline Longitudinal Dispersivity & $0.03 \mathrm{~cm}$ \\
\hline Cell Yield from Glucose & $0.8202 \mathrm{mg} / \mathrm{mg}$ \\
\hline Carbon Dioxide Yield from Glucose & $0.4885 \mathrm{mg} / \mathrm{mg}$ \\
\hline Nitrogen Yield from Nitrate & $0.2259 \mathrm{mg} / \mathrm{mg}$ \\
\hline Acetate Yield from Glucose & $0.6555 \mathrm{mg} / \mathrm{mg}$ \\
\hline Parameters for Bimodal Distribution & $e_{1}=1 ; e_{2}=4 ; m_{1}=2 ; m_{2}=5 ; w=0.8$ \\
\hline Min. and Max. Pore-Throat, and Cell Sizes & $x_{\min }=1 ; x_{\max }=10 ; x_{p}=1 \mu \mathrm{m}$ \\
\hline Injected Biomass Concentration & $9.0 \times 10^{8} \mathrm{cell} / \mathrm{ml}$ \\
\hline Injected Glucose Concentration & $59 \mathrm{mM}$ \\
\hline Injected Ammonium Concentration & $47.5 \mathrm{mM}$ \\
\hline Injected Nitrate Concentration & $37.5 \mathrm{mM}$ \\
\hline Water Injection Rate & $46.8 \mathrm{scc} / \mathrm{hr}$ \\
\hline
\end{tabular}

a: See reference 43 . 
Table 7.12 Input Data for Chemotactic Strain RP437

\begin{tabular}{|l|l|}
\hline \multicolumn{1}{|c|}{ Variables } & \multicolumn{1}{c|}{ Values } \\
\hline \hline Core Dimension: $\mathrm{NX} \times \mathrm{NY} \times \mathrm{NZ}$ & $50 \times 1 \times 1$ \\
\hline Grid Block Size: $\Delta \mathrm{X} \times \Delta \mathrm{Y} \times \Delta \mathrm{Z}$ & $0.2 \times 1.108 \times 1.108 \mathrm{~cm}$ \\
\hline Porosity & 0.387 \\
\hline Molecular Diffusion Coefficient & $0.06 \mathrm{~cm}^{2} / \mathrm{hr}$ \\
\hline Tortuosity & 1.4 \\
\hline Chemotactic Coefficient & $0.15 \mathrm{~cm}^{2} / \mathrm{hr}$ \\
\hline Cell Yield from Glucose & $0.8202 \mathrm{mg} / \mathrm{mg}$ \\
\hline Initial Biomass Concentration & $3.5 \times 10^{7} \mathrm{cell} / \mathrm{ml}$ \\
\hline Initial Glucose Concentration & $25 \mathrm{mM}$ \\
\hline
\end{tabular}


Table 7.13 Input Data for Nonhemotactic Strain RP5232

\begin{tabular}{|l||l||}
\hline \multicolumn{1}{|c|}{ Variables } & \multicolumn{1}{c|}{ Values } \\
\hline Core Dimension: NX x NY x NZ & $50 \times 1 \times 1$ \\
\hline Grid Block Size: $\Delta \mathrm{X} \times \Delta \mathrm{Y} \times \Delta Z$ & $0.2 \times 1.108 \times 1.108 \mathrm{~cm}$ \\
\hline Porosity & 0.387 \\
\hline Molecular Diffusion Coefficient & $0.025 \mathrm{~cm}^{2} / \mathrm{hr}$ \\
\hline Tortuosity & 1.4 \\
\hline Chemotactic Coefficient & $0 . \mathrm{cm}^{2} / \mathrm{hr}$ \\
\hline Cell Yield from Glucose & $0.8202 \mathrm{mg} / \mathrm{mg}$ \\
\hline Initial Biomass Concentration & $8 . \times 10^{7} \mathrm{cell} / \mathrm{ml}$ \\
\hline Initial Glucose Concentration & $25 \mathrm{mM}$ \\
\hline
\end{tabular}


Table 7.14 Petrophysical Properties for Core \#1

\begin{tabular}{|l|c|}
\hline \multicolumn{1}{|c|}{ Properties } & Values \\
\hline \hline Core Length & $28.42 \mathrm{~cm}$ \\
\hline Core Diameter & $5.08 \mathrm{~cm}$ \\
\hline Pore Volume & $106 \mathrm{ml}$ \\
\hline Porosity & $18.4 \%$ \\
\hline Absolute Permeability & $178 \mathrm{md}$ \\
\hline Permeability to Oil & $112 \mathrm{md}$ \\
\hline Permeability to Water & $42 \mathrm{md}$ \\
\hline Connate Water (saturation) & $33 \mathrm{ml} \mathrm{(31 \% )}$ \\
\hline Residual Oil (saturation) & $31 \mathrm{ml} \mathrm{(29 \% )}$ \\
\hline
\end{tabular}


Table 7.15 Experimental Results for Core \#1

\begin{tabular}{|c||c|c|c|c|c|c||}
\hline $\begin{array}{c}\text { Treatment } \\
\text { Number }\end{array}$ & $\begin{array}{c}\text { Produced } \\
\text { Oil } \\
(\mathrm{ml})\end{array}$ & $\begin{array}{c}\text { Produced } \\
\mathrm{CO}_{2} \mathbf{a} \\
(\mathrm{ml})\end{array}$ & $\begin{array}{c}\text { Produced } \\
\text { Acid } \mathbf{b} \\
(\mathrm{mg})\end{array}$ & $\begin{array}{c}\text { Produced } \\
\text { Alcohol } \mathrm{c} \\
(\mathrm{mg})\end{array}$ & $\begin{array}{c}\text { Unsued } \\
\text { Glucose } \mathbf{d} \\
(\mathrm{mg})\end{array}$ & $\begin{array}{c}\text { PRF } \\
(\%)\end{array}$ \\
\hline 1 & 1 & 2.6 & 221 & 34 & 3569 & 95 \\
\hline 2 & 1 & 17.2 & 448 & 83 & 1577 & 136 \\
\hline 3 & 0 & 9.7 & 198 & 18 & 567 & 131 \\
\hline 4 & 0 & 24.4 & 361 & 127 & 846 & 136 \\
\hline 5 & 3 & 19.6 & 197 & 64 & 63 & 29 \\
\hline
\end{tabular}
a: At Standard Condition;
b: Acid = Acetate + Butyrate;
c: Alcohol = Ethanol + Butanol;
d: Initial Glucose $=1528 \mathrm{mg}(20 \mathrm{mg} / \mathrm{ml})$. 
Table 7.16 Input Data for Core \#1

\begin{tabular}{|c|c|}
\hline Variables & Values \\
\hline System Dimension: NX x NY x NZ & $50 \times 1 \times 1$ \\
\hline Grid Block Size: $\Delta \mathrm{X} \times \Delta \mathrm{Y} \times \Delta \mathrm{Z}$ & $0.5684 \times 4.502 \times 4.502 \mathrm{~cm}$ \\
\hline Absolute Permeabilities & $\mathrm{K}_{\mathrm{x}}=\mathrm{K}_{\mathrm{y}}=\mathrm{K}_{\mathrm{z}}=178 \mathrm{md}$ \\
\hline Porosity & $18.4 \%$ \\
\hline Oil and Water Relative Permeabilities & Corey's Model ${ }^{45}$ \\
\hline Endpoints of Phase Relative Permeabilities & $\mathrm{K}_{\mathrm{ro}}^{0}=0.63 ; \mathrm{K}_{\mathrm{rw}}^{0}=0.24 ; \mathrm{K}_{\mathrm{rg}}^{0}=0.1$ \\
\hline Exponents of Phase Relative Permeabilities & $\mathrm{e}_{\mathrm{o}}=2.5 ; \mathrm{e}_{\mathrm{w}}=2.1 ; \mathrm{e}_{\mathrm{g}}=2.1$ \\
\hline Residual Phase Saturations & $\mathrm{S}_{\mathrm{or}}=29 ; \mathrm{S}_{\mathrm{wr}}=31 ; \mathrm{S}_{\mathrm{gr}}=5 \%$ \\
\hline Oil PVT Data & Correlations ${ }^{46,47}$ \\
\hline Water PVT Data & $R_{s w}=0 ; B_{w}=1 ; \mu_{w}=1.4 \mathrm{cp}$ \\
\hline Gas PVT Data & Correlations $^{48}$ \\
\hline Phase Densities at Surface Condition & $\rho_{o s}=850 ; \rho_{w s}=1100 ; \rho_{g s}=1.9 \mathrm{mg} / \mathrm{ml}$ \\
\hline Rock Compressibility & $5 \times 10^{-6} \mathrm{psia}^{-1}$ \\
\hline Molecular Diffusion Coefficients & $0.044 \mathrm{~cm}^{2} / \mathrm{hr}$ \\
\hline Tortuosity & 1.4 \\
\hline Longitudinal Dispersivity & $0.06 \mathrm{~cm}$ \\
\hline Cell Yield from Glucose & $0.8202 \mathrm{mg} / \mathrm{mg}$ \\
\hline Carbon Dioxide Yield from Glucose & $0.0707 \mathrm{mg} / \mathrm{mg}$ \\
\hline Acid Yield from Glucose & $0.6575 \mathrm{mg} / \mathrm{mg}$ \\
\hline Alcohol Yield from Glucose & $0.1862 \mathrm{mg} / \mathrm{mg}$ \\
\hline Parameters for Bimodal Distribution & $e_{1}=1 ; e_{2}=4 ; m_{1}=2 ; m_{2}=5 ; w=0.8$ \\
\hline Min. and Max. Pore-Throat, and Cell Sizes & $x_{\min }=1 ; x_{\max }=10 ; x_{p}=1 \mu \mathrm{m}$ \\
\hline Injected Biomass Concentration & $1 \times 10^{8} \mathrm{cell} / \mathrm{ml}$ \\
\hline Injected Glucose Concentration & $20 \mathrm{mg} / \mathrm{ml}$ \\
\hline Water Injection Rate & $50 \mathrm{scc} / \mathrm{hr}$ \\
\hline
\end{tabular}


Table 7.17 Petrophysical Properties for Core \#4

\begin{tabular}{|l|c|}
\hline \multicolumn{1}{|c|}{ Properties } & Values \\
\hline Core Length & $29.85 \mathrm{~cm}$ \\
\hline Core Diameter & $5.08 \mathrm{~cm}$ \\
\hline Pore Volume & $85 \mathrm{ml}$ \\
\hline Porosity & $14 \%$ \\
\hline Absolute Permeability & $106 \mathrm{md}$ \\
\hline Permeability to Oil & $74 \mathrm{md}$ \\
\hline Permeability to Water & $22 \mathrm{md}$ \\
\hline Connate Water (saturation) & $30 \mathrm{ml} \mathrm{(35 \% )}$ \\
\hline Residual Oil (saturation) & $26 \mathrm{ml} \mathrm{(31 \% )}$ \\
\hline
\end{tabular}


Table 7.18 Experimental Results for Core \#4

\begin{tabular}{|c|c|c|c|c|c|}
\hline $\begin{array}{c}\text { Treatment } \\
\text { Number }\end{array}$ & $\begin{array}{c}\text { Oil } \\
\text { Recovery } \\
\text { (ml) }\end{array}$ & $\begin{array}{c}\text { Gas } \\
\text { Recovery } \\
\text { (ml) }\end{array}$ & \multicolumn{2}{|c|}{$\begin{array}{l}\text { Surfactant } \\
\text { Produced } \\
\text { (unit) } \quad(\mathrm{mg})^{\mathrm{a}}\end{array}$} & $\begin{array}{l}\text { PRF } \\
(\%)\end{array}$ \\
\hline 1 & 1 & 0 & 132 & 0.121 & 105 \\
\hline 2 & 2 & 0 & 116 & 0.106 & 118 \\
\hline 3 & 2 & 0 & 79 & 0.072 & 109 \\
\hline 4 & 0.5 & 0 & 57 & 0.052 & 96 \\
\hline 5 & $<0.5$ & 0 & 46 & 0.042 & 91 \\
\hline
\end{tabular}

a: Conversion factor $=1092$ unit $/ \mathrm{mg}$. 
Table 7.19 Input Data for Core \#4

\begin{tabular}{|c|c|}
\hline Variables & Values \\
\hline System Dimension: NX x NY x NZ & $50 \times 1 \times 1$ \\
\hline Grid Block Size: $\Delta \mathrm{X} \times \Delta \mathrm{Y} \times \Delta \mathrm{Z}$ & $0.597 \times 4.502 \times 4.502 \mathrm{~cm}$ \\
\hline Absolute Permeabilities and Porosity & $\mathrm{K}_{\mathrm{x}}=\mathrm{K}_{\mathrm{y}}=\mathrm{K}_{\mathrm{z}}=106 \mathrm{md} ; \phi=14 \%$ \\
\hline Oil and Water Relative Permeabilities & Corey's Model ${ }^{45}$ \\
\hline Endpoints of Phase Relative Permeabilities & $\mathrm{K}_{\mathrm{ro}}^{0}=0.7 ; \quad \mathrm{K}_{\mathrm{rw}}^{0}=0.2$ \\
\hline Exponents of Phase Relative Permeabilities & $e_{0}=2.5 ; e_{w}=2.1$ \\
\hline Residual Phase Saturations & $S_{\text {or }}=31 ; S_{w r}=35 \%$ \\
\hline Phase Viscosities & $\mu_{\mathrm{o}}=5.8 ; \mu_{\mathrm{w}}=1.3 \mathrm{cp}$ \\
\hline Phase Densities at Surface Condition & $\rho_{o s}=741 ; \rho_{w s}=997 \mathrm{mg} / \mathrm{ml}$ \\
\hline Rock Compressibility & $5 \times 10^{-6} \mathrm{psia}^{-1}$ \\
\hline Molecular Diffusion Coefficients & $0.044 \mathrm{~cm}^{2} / \mathrm{hr}$ \\
\hline Tortuosity & 1.4 \\
\hline Longitudinal Dispersivity & $0.1 \mathrm{~cm}$ \\
\hline Cell Yield from Glucose & $0.8202 \mathrm{mg} / \mathrm{mg}$ \\
\hline Biosurfactant Yield from Glucose & $2.54 \times 10^{-4} \mathrm{mg} / \mathrm{mg}$ \\
\hline Maximum Specific Growth Rate & $0.6 \mathrm{hr}^{-1}$ \\
\hline Injected Glucose Concentration & $9 \mathrm{mg} / \mathrm{ml}$ \\
\hline Injected Biomass Concentration & $1 \times 10^{4} \mathrm{cell} / \mathrm{ml}$ \\
\hline Min. and Max Surfactant Concentrations & $C_{6, \min }=0 ; C_{6, \max }=2.1 \times 10^{-3} \mathrm{mg} / \mathrm{ml}$ \\
\hline Min. and Max. Interfacial Tensions & $\sigma_{\min }=0.1 ; \sigma_{\max }=30 \mathrm{mN} / \mathrm{m}$ \\
\hline Parameters for Bimodal Distribution & $e_{1}=1 ; e_{2}=4 ; m_{1}=2 ; m_{2}=5 ; w=0.8$ \\
\hline Min. and Max. Pore-Throat, and Cell Sizes & $x_{\min }=1 ; x_{\max }=20 ; x_{p}=1.32 \mu \mathrm{m}$ \\
\hline Water Injection Rate & $50 \mathrm{scc} / \mathrm{hr}$ \\
\hline
\end{tabular}




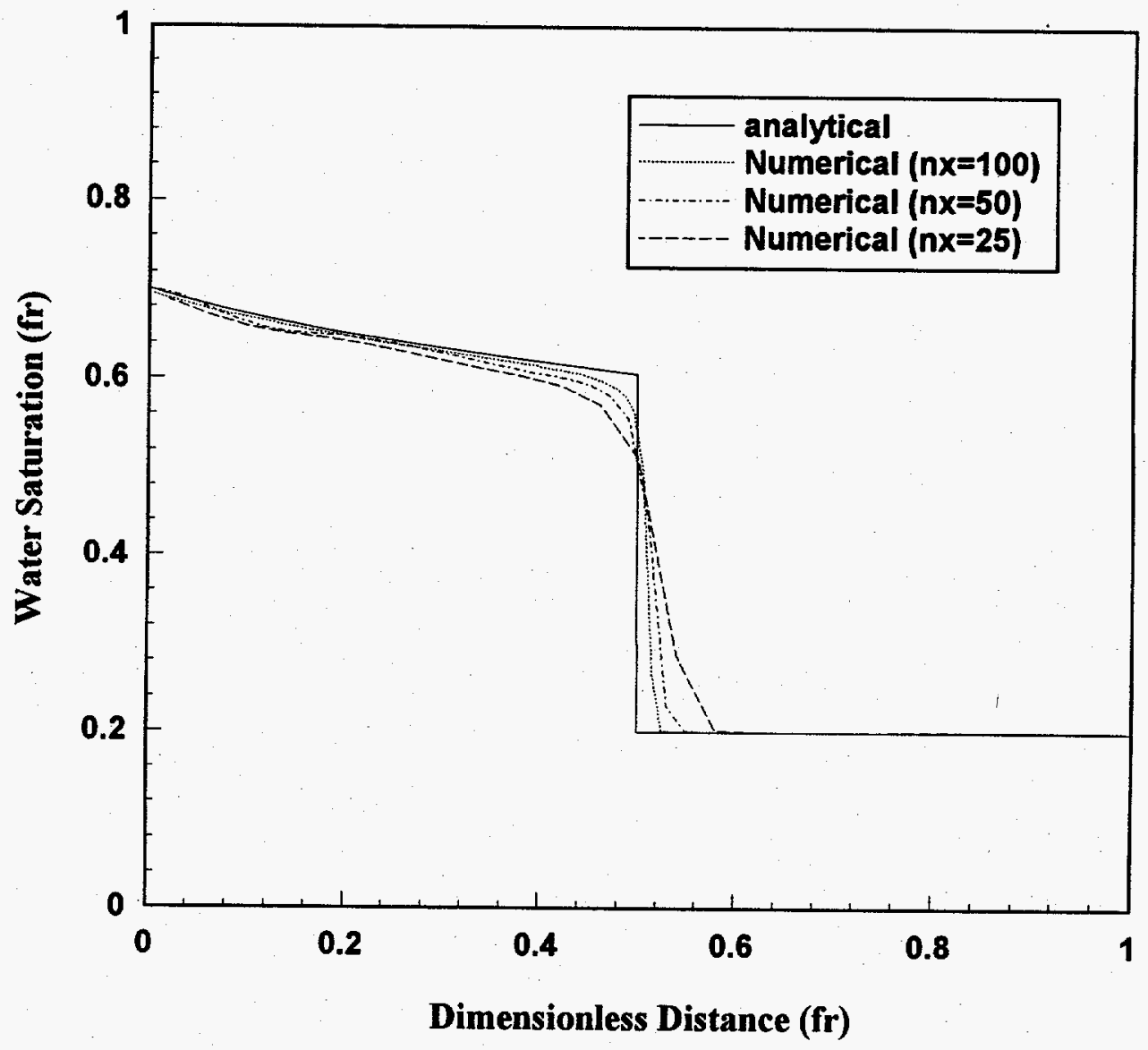

Figure 7.1: Comparison of Water Saturation Profiles after 40 Days of Injection Computed from Buckley-Leverett Equation and MEOR Simulator 


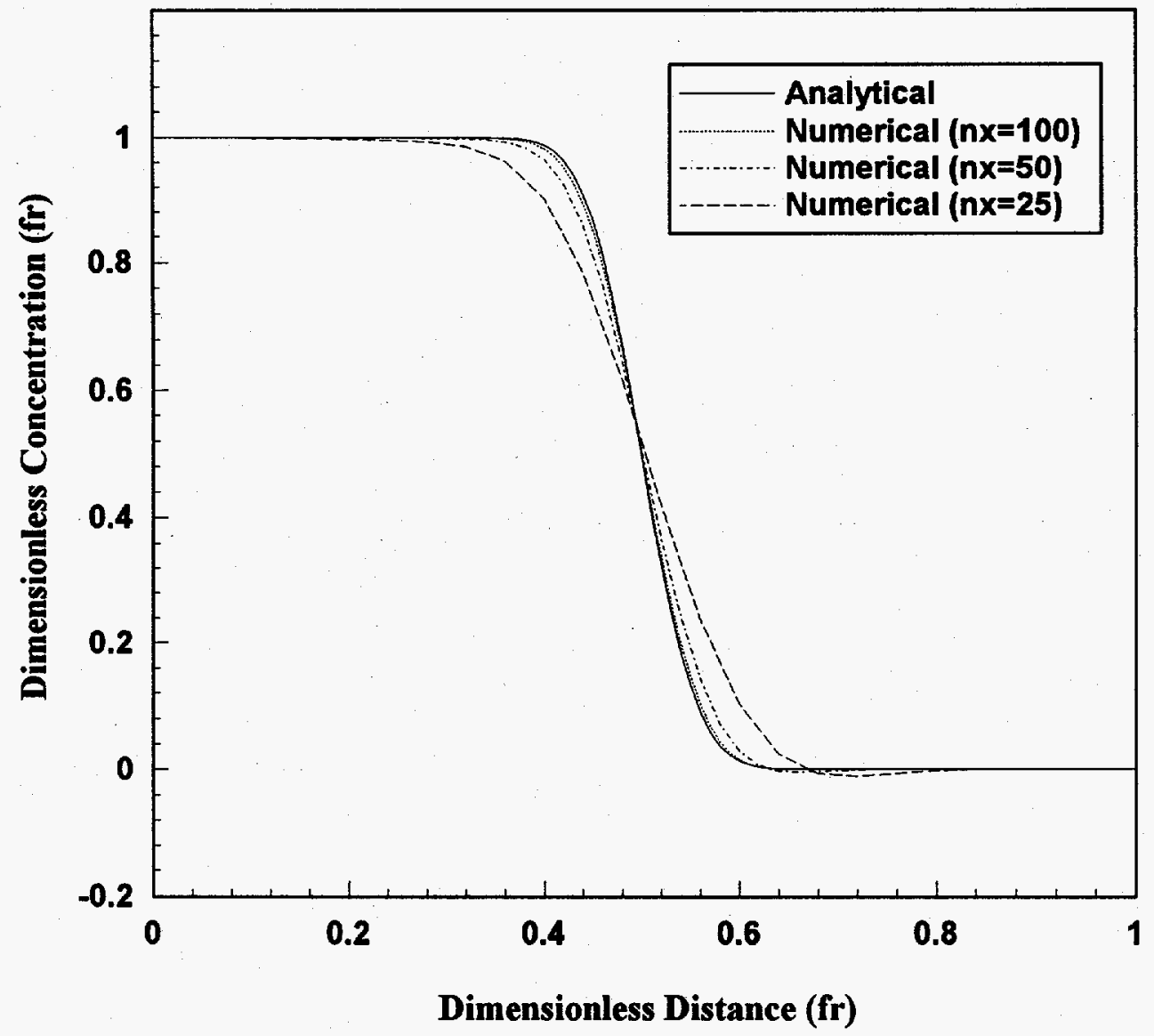

Figure 7.2: Comparison of Concentration Profiles after 50\% Pore Volume of Injection Computed from Analytical Equation and MEOR Simulator for Ideal Tracer Flow in an One-Dimensional Homogeneous Porous Medium 


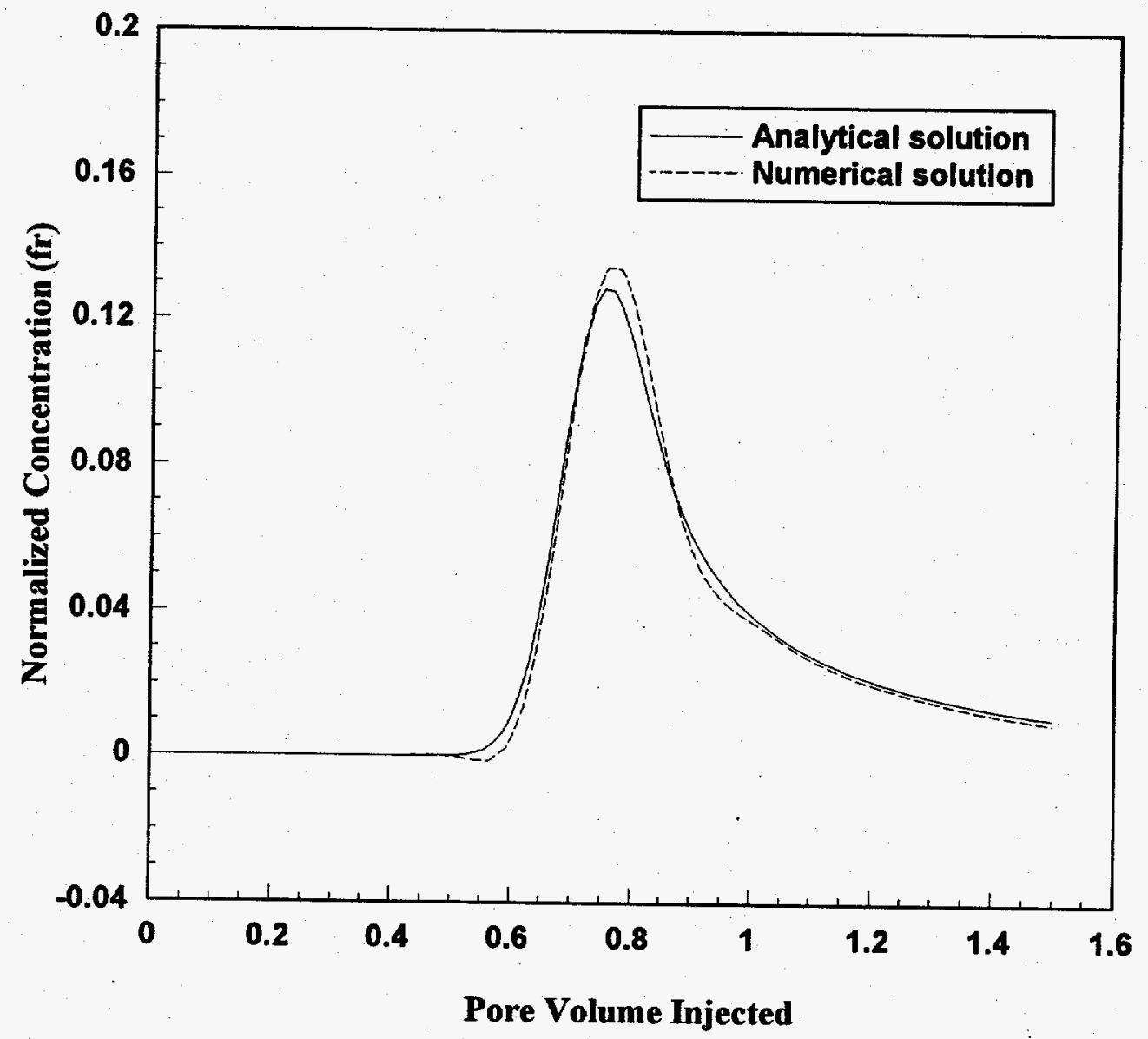

Figure 7.3: Comparison of Normalized Effluent Concentrations Computed from Analytical Equation and MEOR Simulator for Ideal Tracer Flow in a Homogeneous Five-Sport Well Pattern 


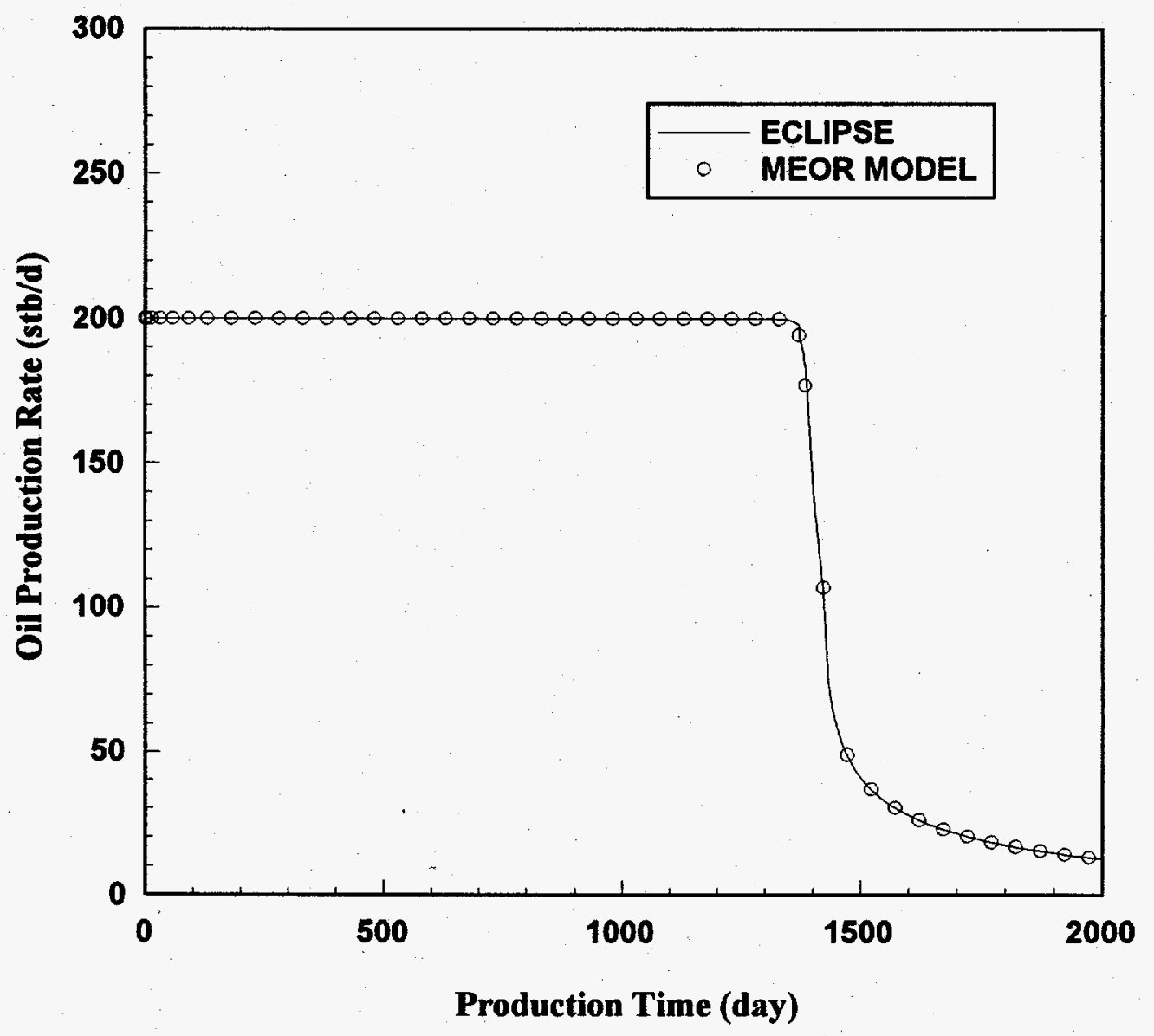

Figure 7.4: Comparison of Oil Production Rates Computed from ECLIPSE and MEOR Simulators for a Waterflooding Process in a Homogeneous Five-Spot Well Pattern 


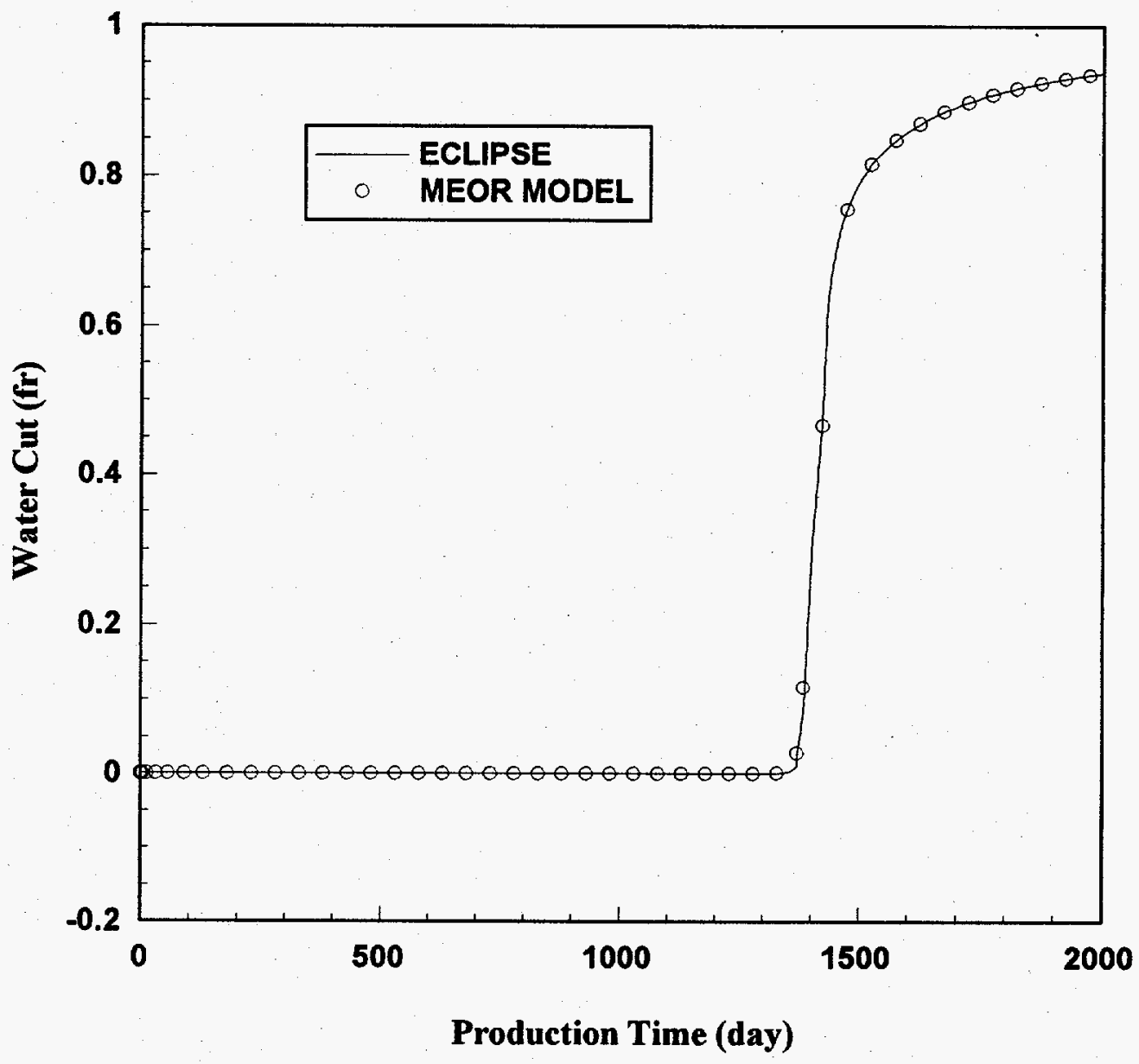

Figure 7.5: Comparison of Water Cuts Computed from ECLIPSE and MEOR Simulators for a Waterflooding Process in a Homogeneous Five-Spot Well Pattern 


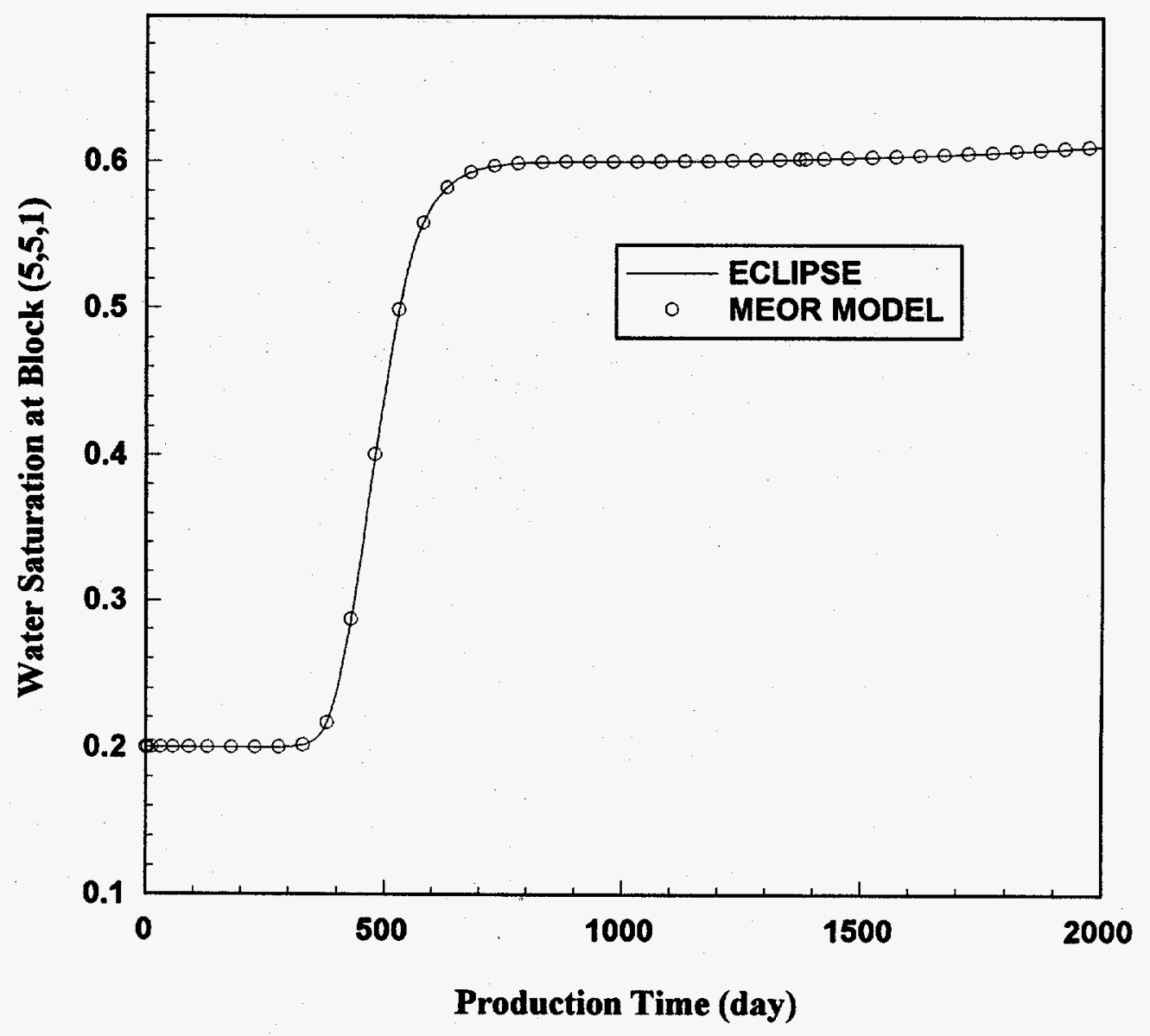

Figure 7.6: Comparison of Water Saturations at Block $(5,5,1)$ Computed from ECLIPSE and MEOR Simulators for a Waterflooding Process in a Homogeneous Five-Spot Well Pattern 


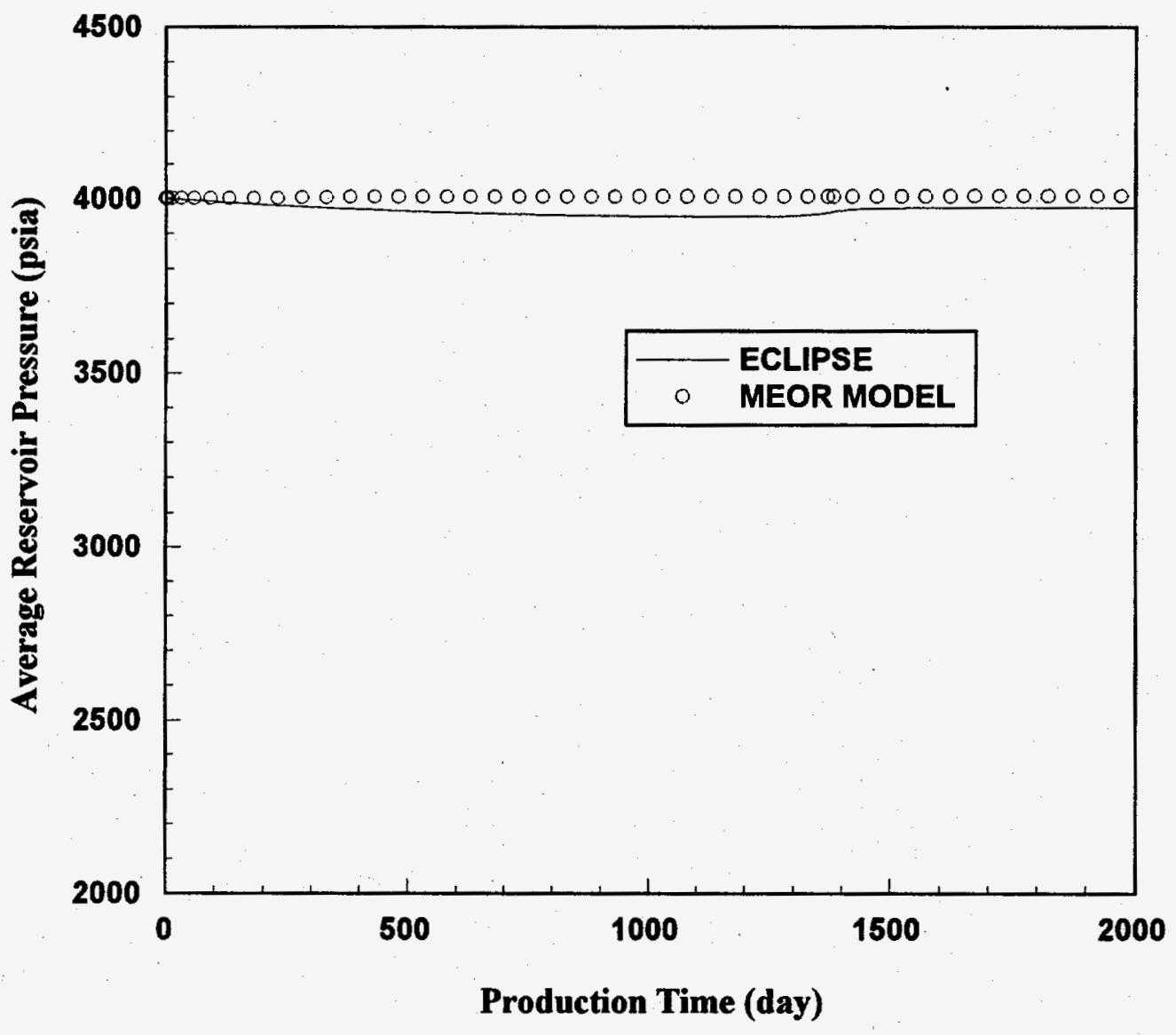

Figure 7.7: Comparison of Average Reservoir Pressures Computed from ECLIPSE and MEOR Simulators for a Waterflooding Process in a Homogeneous Five-Spot Well Pattern 


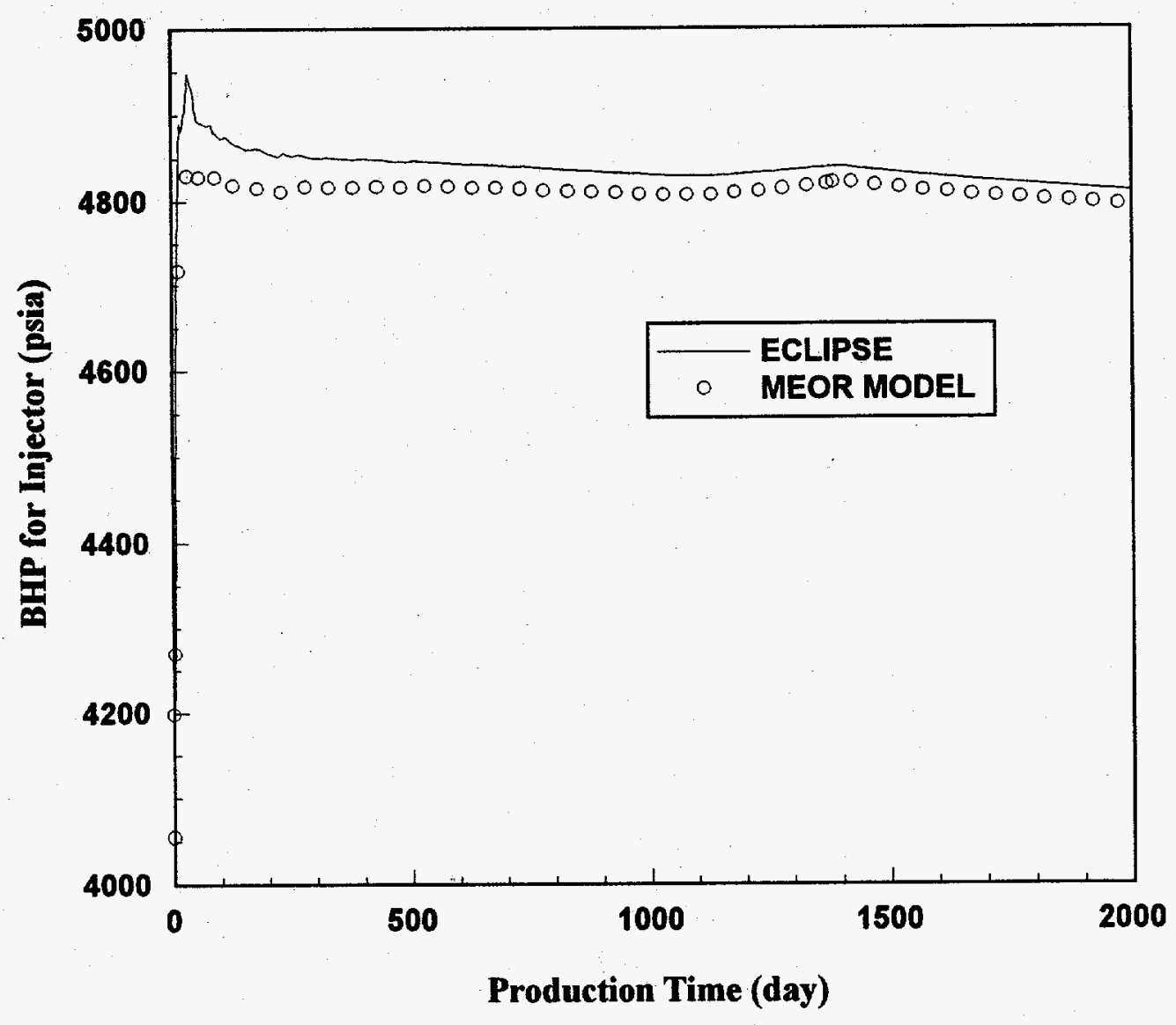

Figure 7.8: Comparison of Injection Bottomhole Pressures Computed from ECLIPSE and MEOR Simulators for a Waterflooding Process in a Homogeneous Five-Spot Well Pattern 


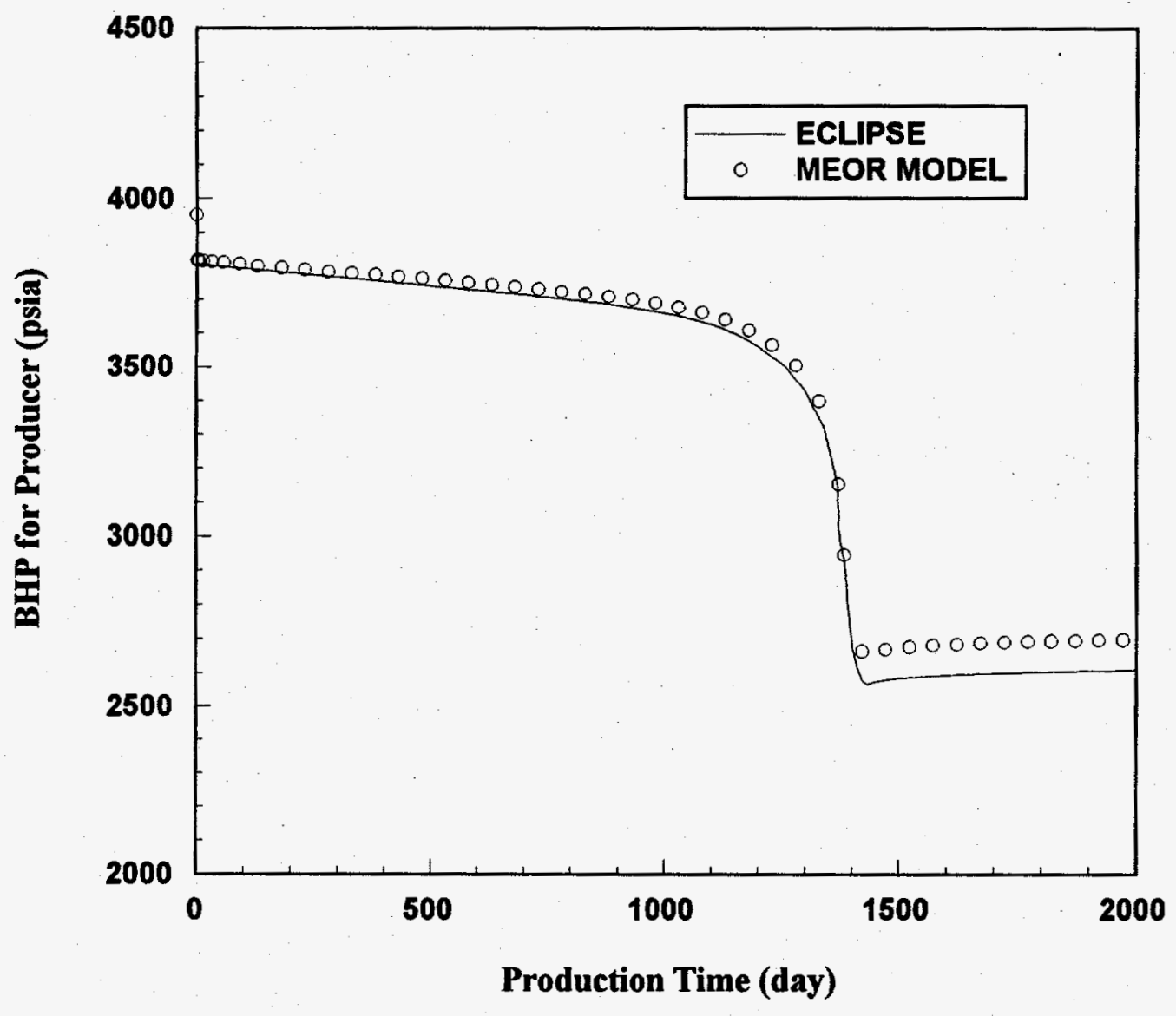

Figure 7.9: Comparison of Production Bottomhole Pressures Computed from ECLIPSE and MEOR Simulators for a Waterflooding Process in a Homogeneous Five-Spot Well Pattern 


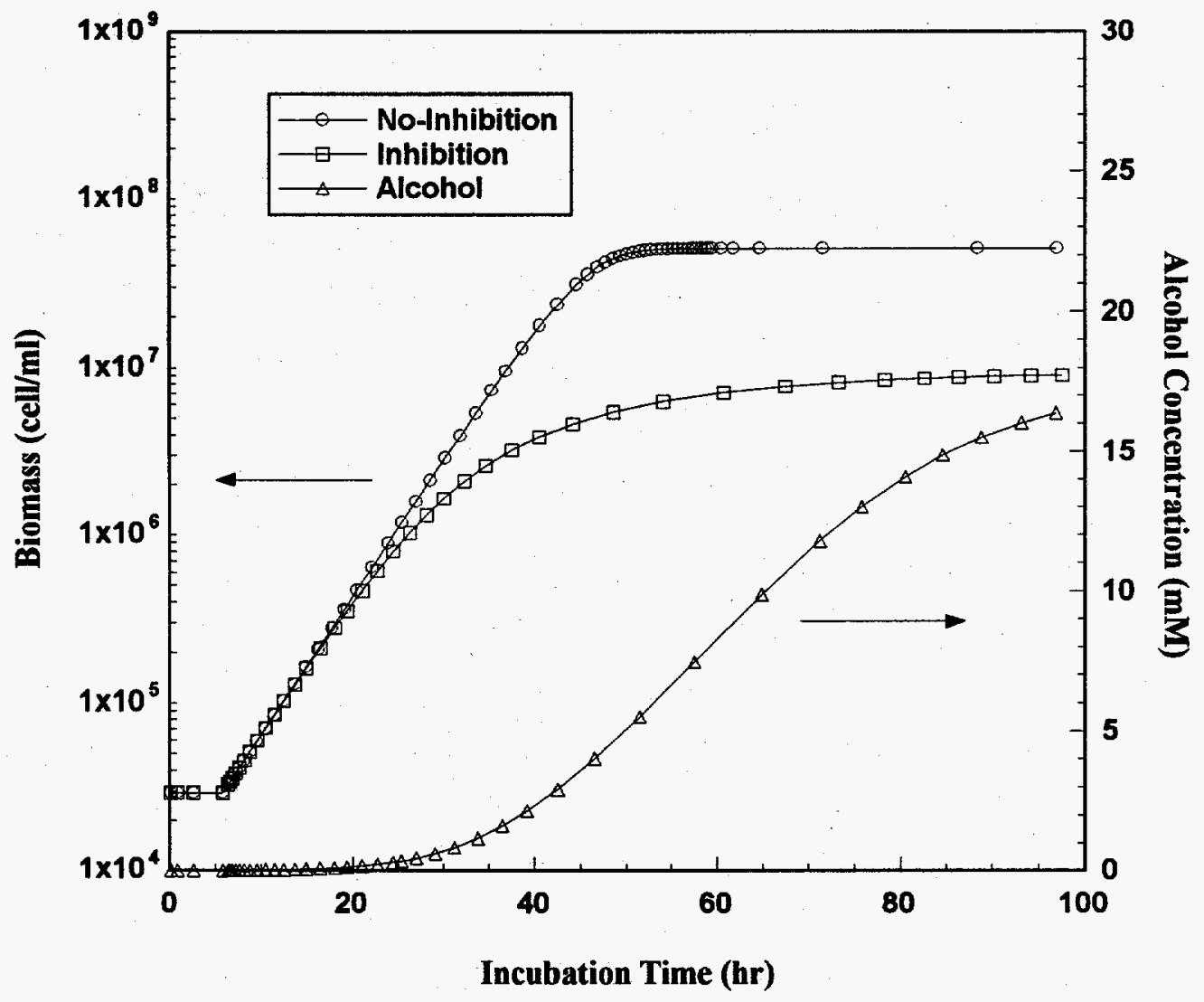

Figure 7.10: Effect of Alcohol Inhibition on Bacterial Growth 


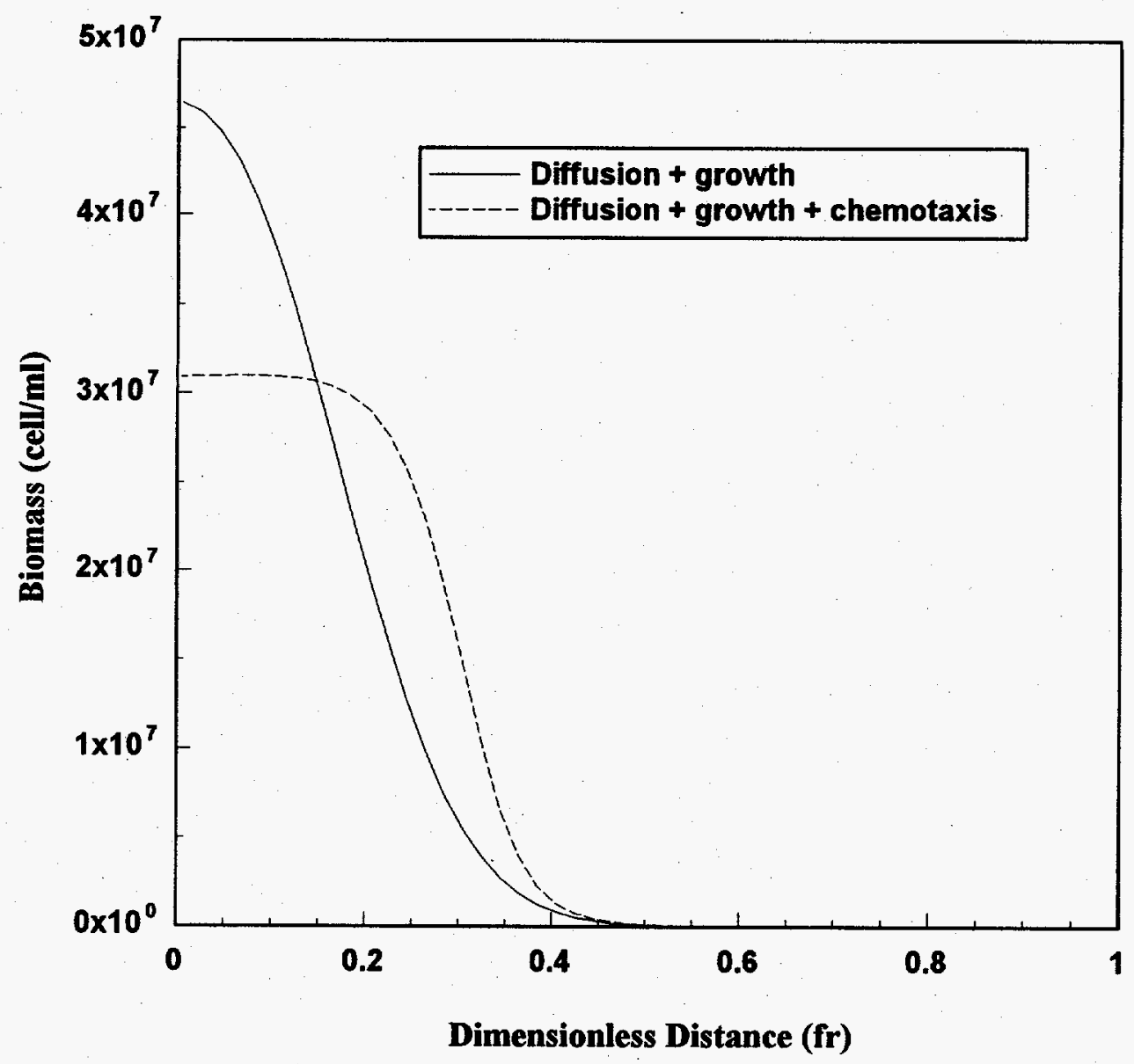

Figure 7.11: Comparison of Biomass Profiles after 50 Hours of Incubation for Chemotaxis Effects 


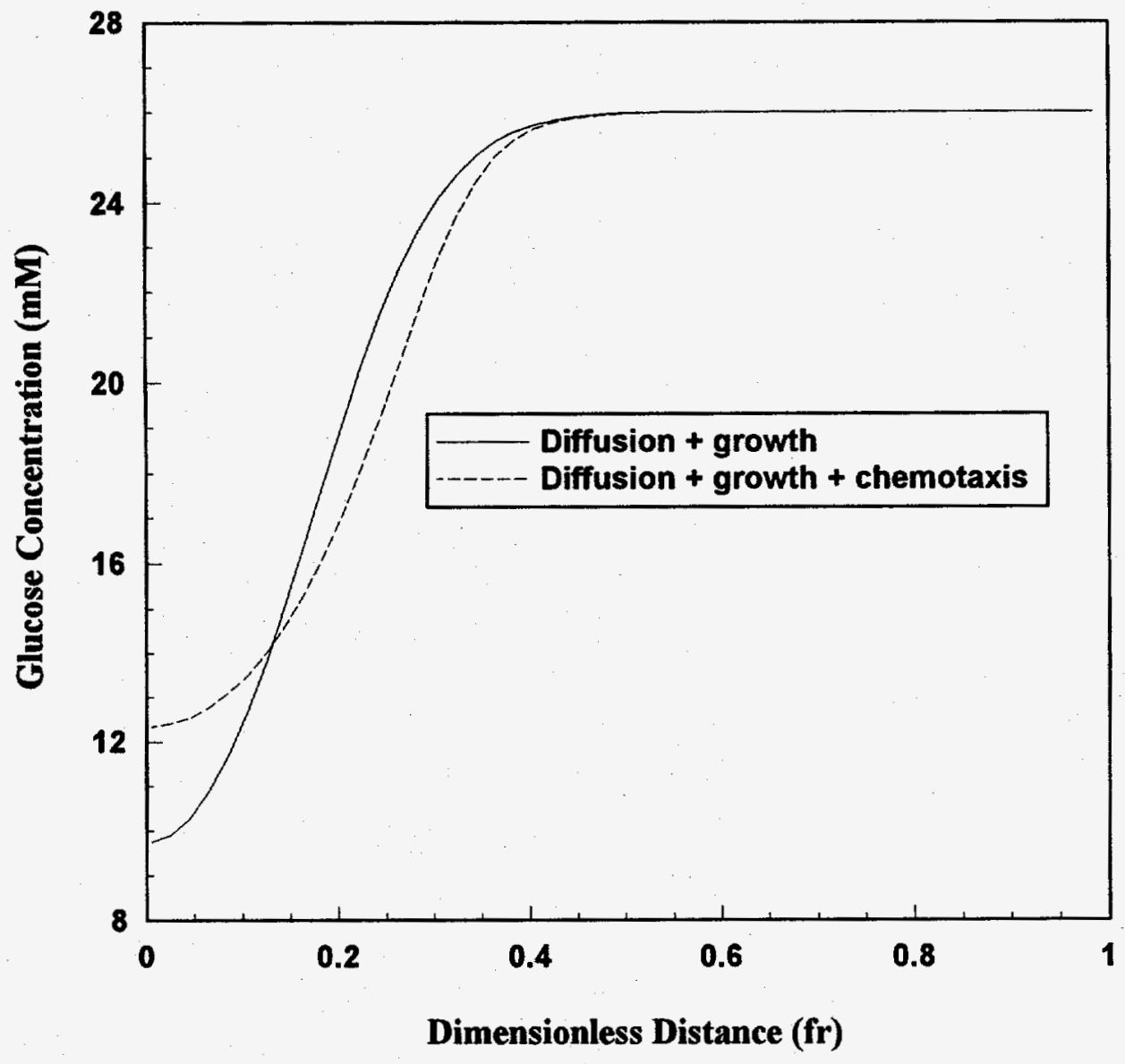

Figure 7.12: Comparison of Nutrient Profiles after 50 Hours of Incubation for Chemotaxis Effects 


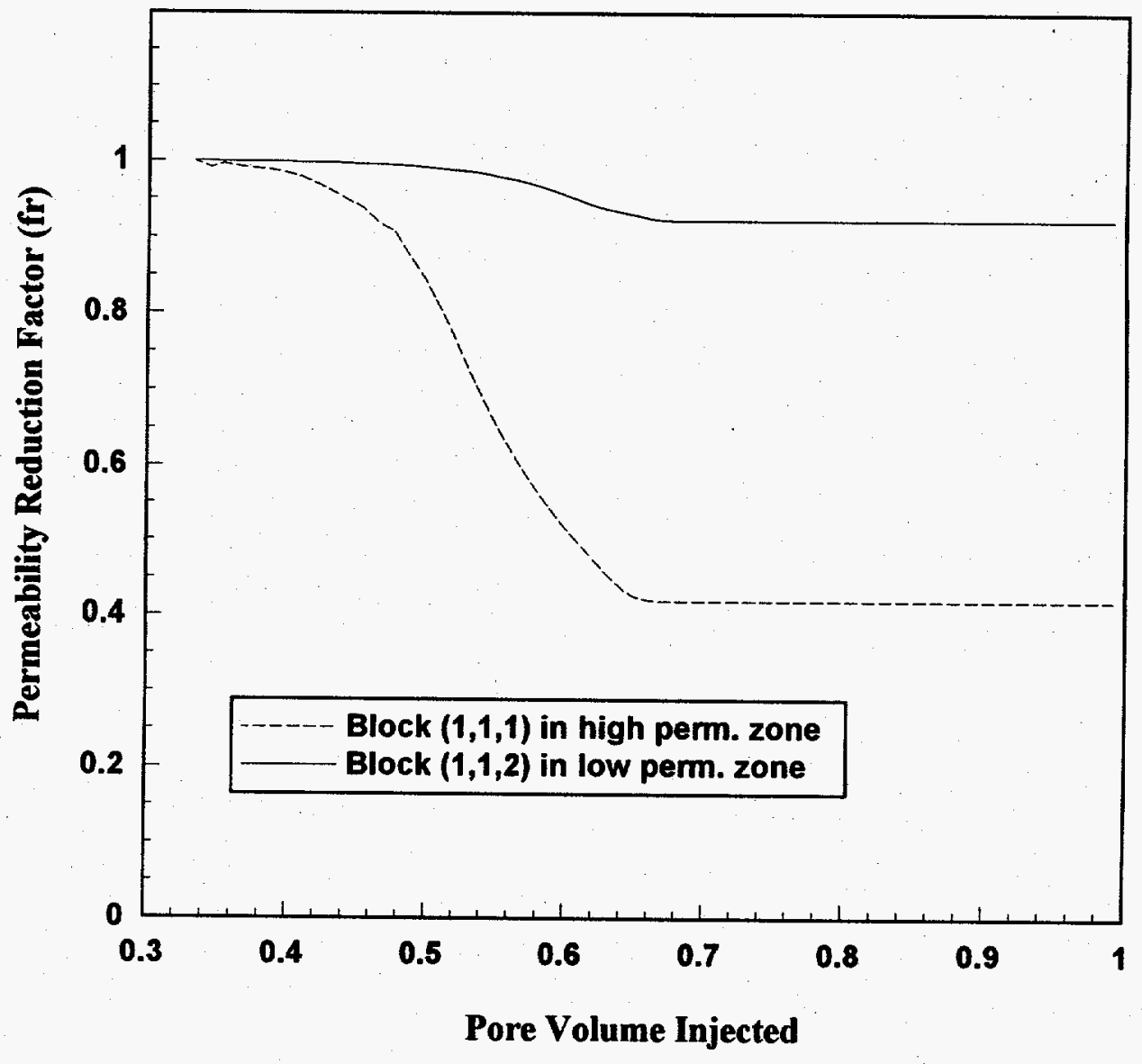

Figure 7.13: Comparison of Permeability Reduction Factors for Producing Blocks in High and Low Permeability Zones during Microbial Plugging Treatment 


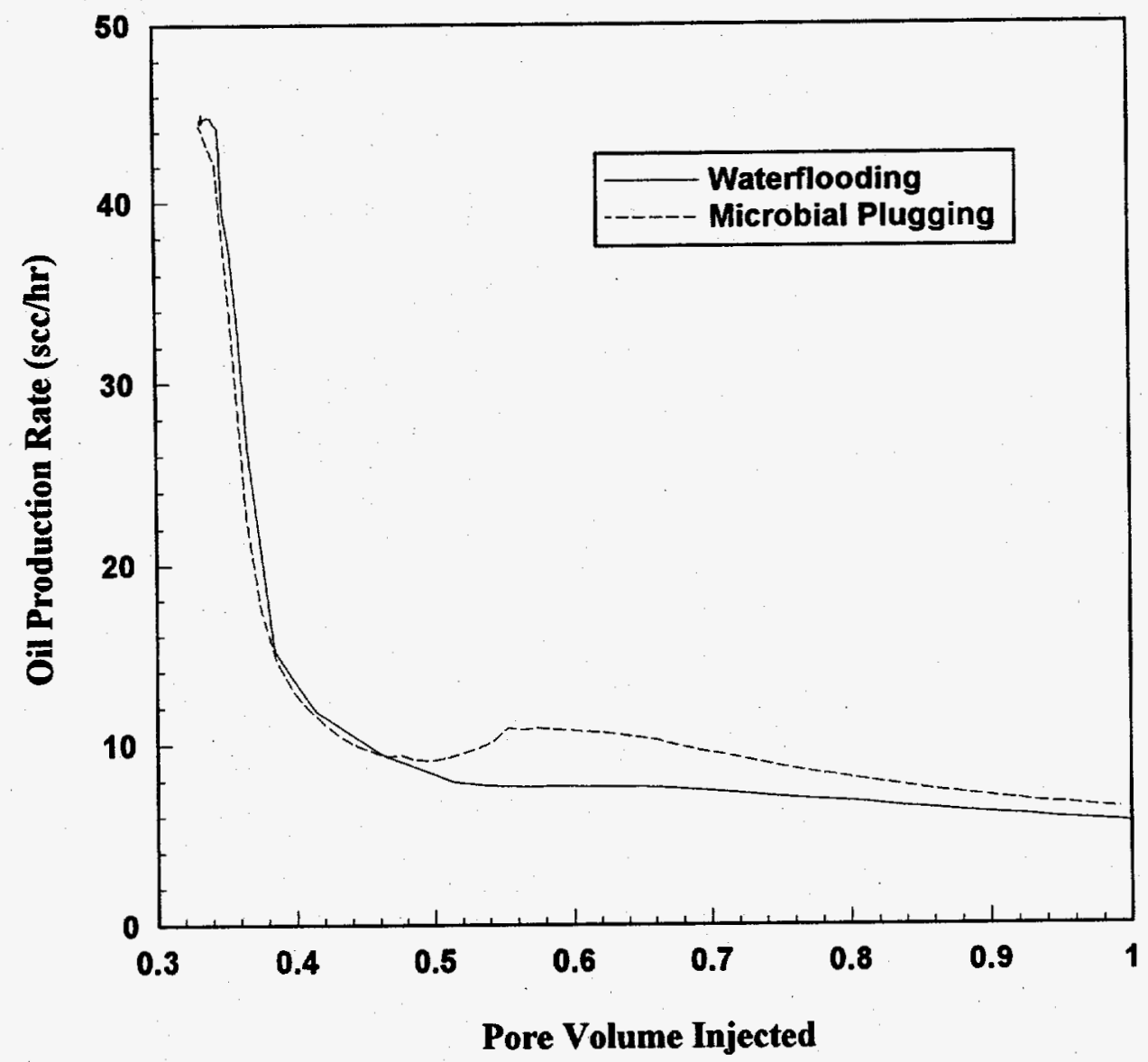

Figure 7.14: Comparison of Oil Production Rates after Water Breakthrough for Conventional Waterflood and Microbial Plugging Processes 


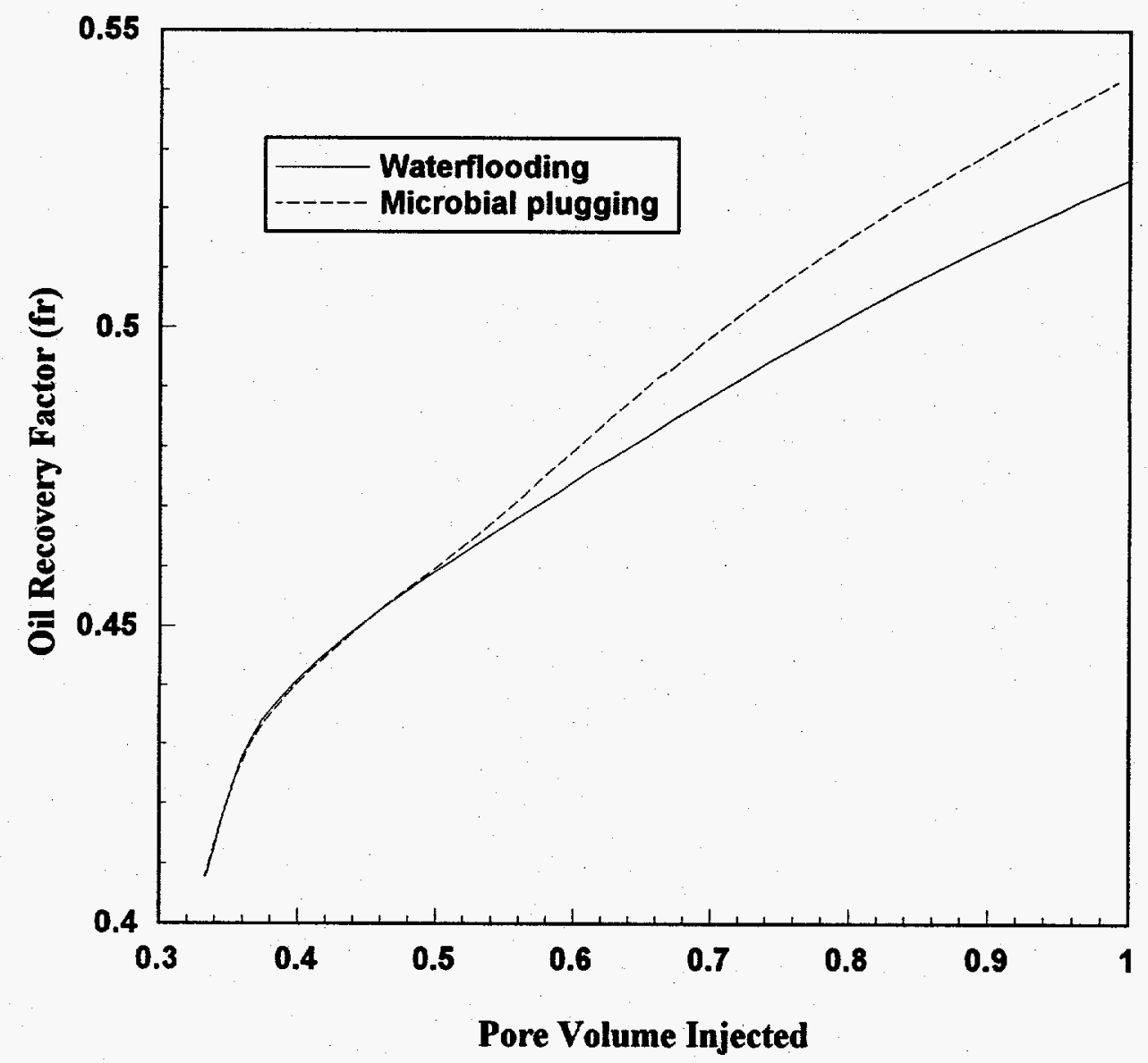

Figure 7.15: Comparison of Oil Recovery Factors after Water

Breakthrough for Conventional Waterflood and Microbial Plugging Processes 


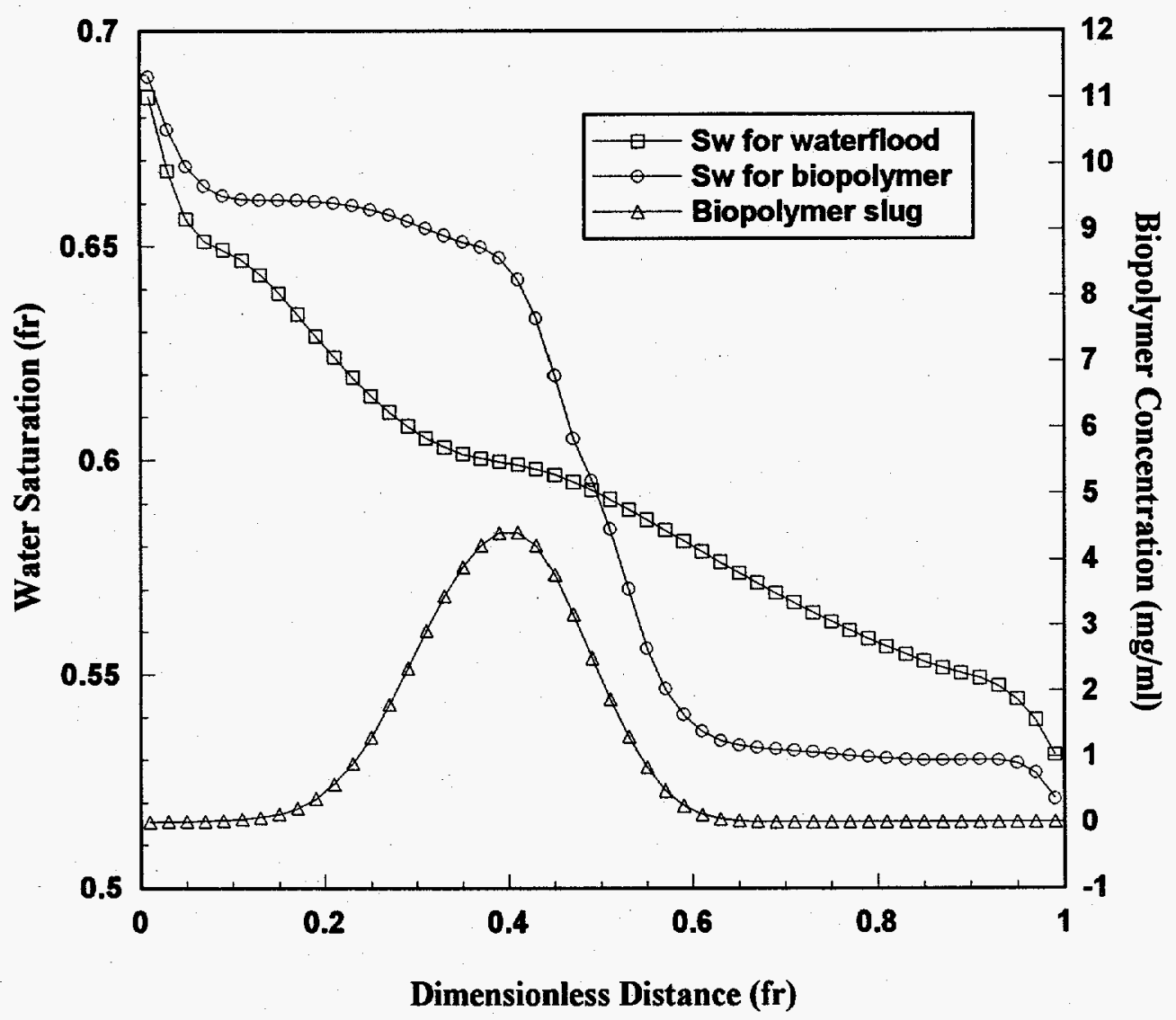

Figure 7.16: Comparison of Water Saturation Profiles after 0.3 Pore Volume of injection for Conventional Waterflood and Biopolymer-Producing BacteriumTreatment Processes 


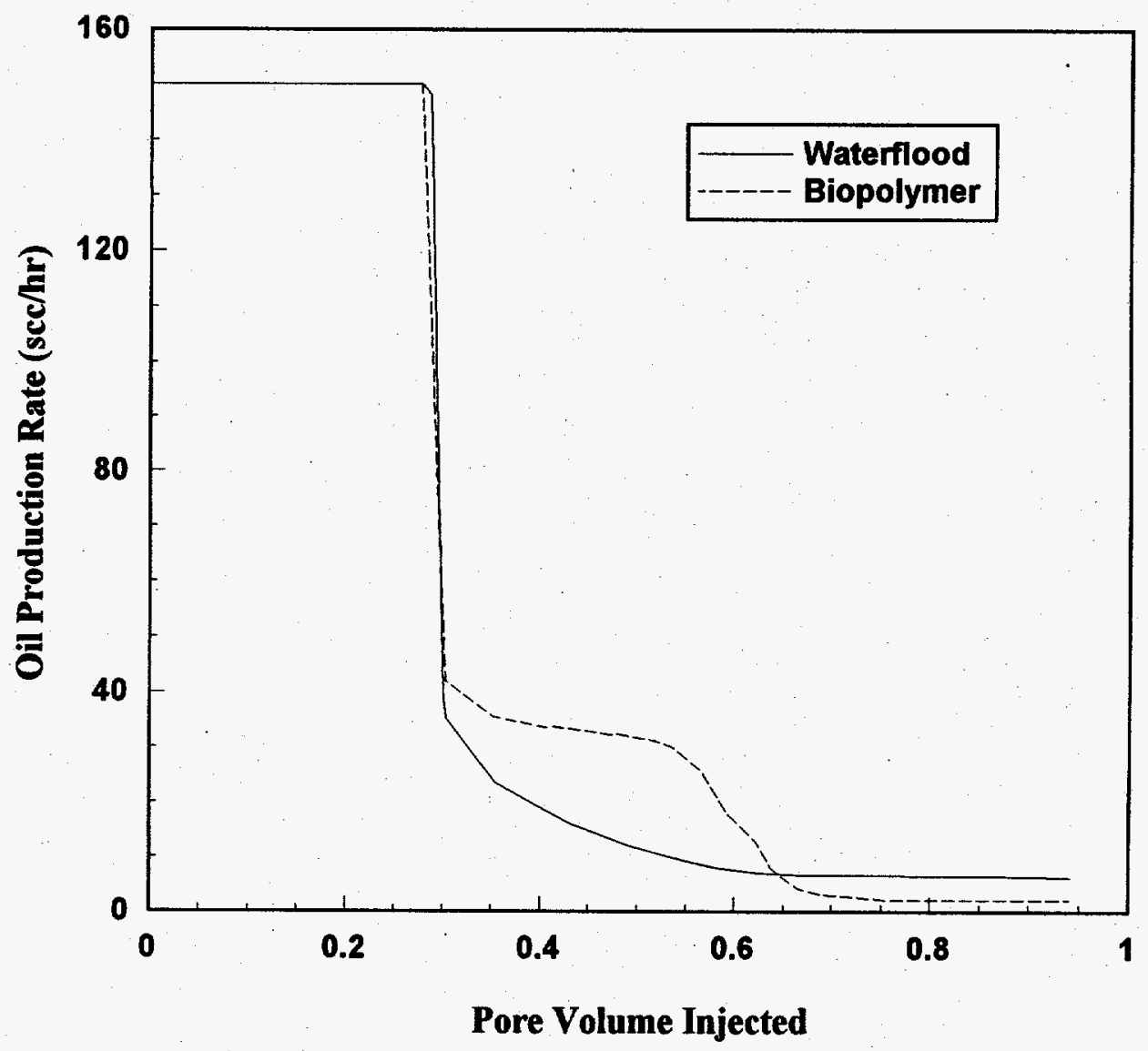

Figure 7.17: Comparison of Oil Production Rates for Conventional Waterflood and Biopolymer-Producing Bacterium Treatment Processes 


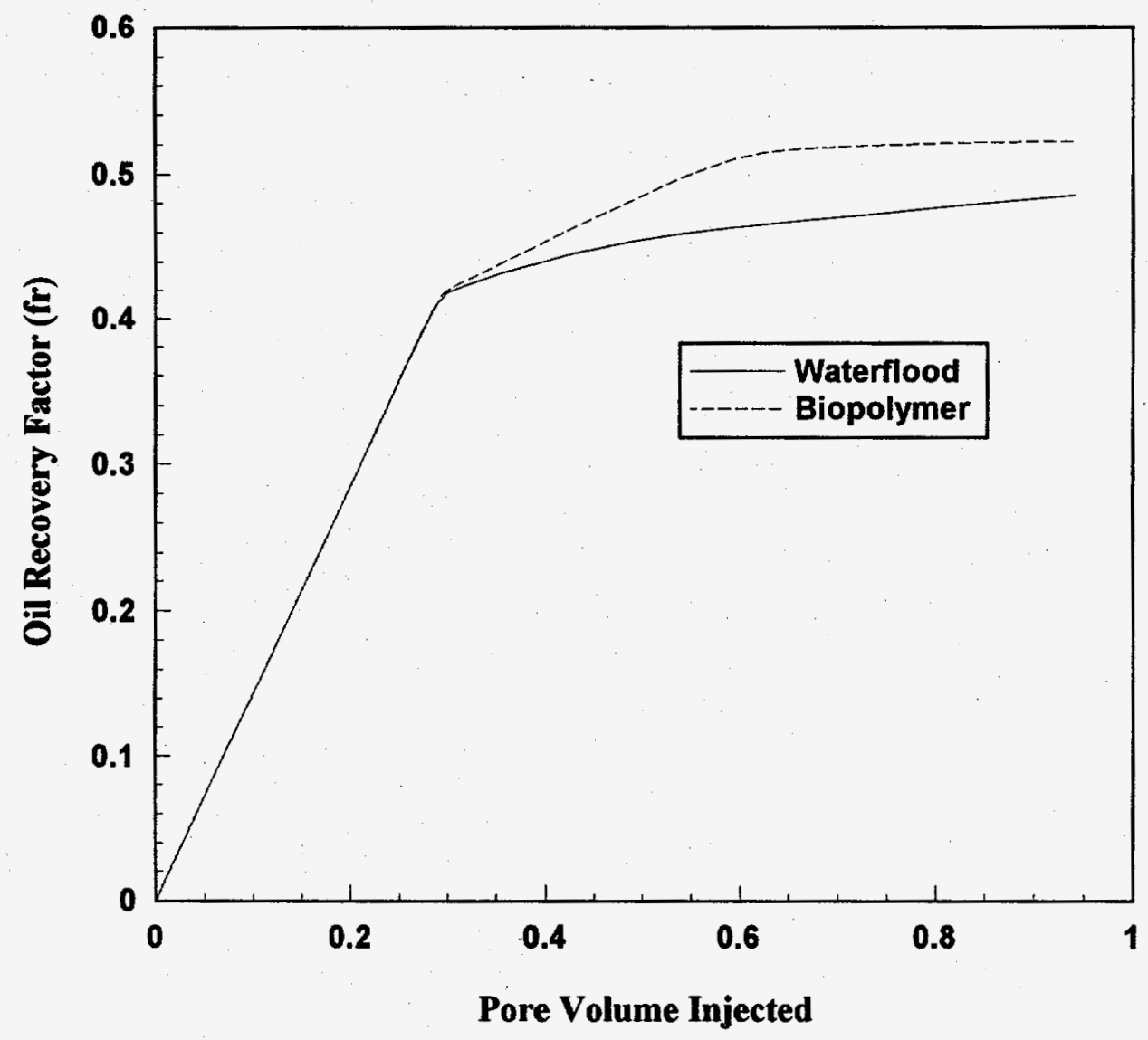

Figure 7.18: Comparison of Oil Recovery Factors for Conventional Waterflood and Biopolymer-Producing Bacterium Treatment Processes 


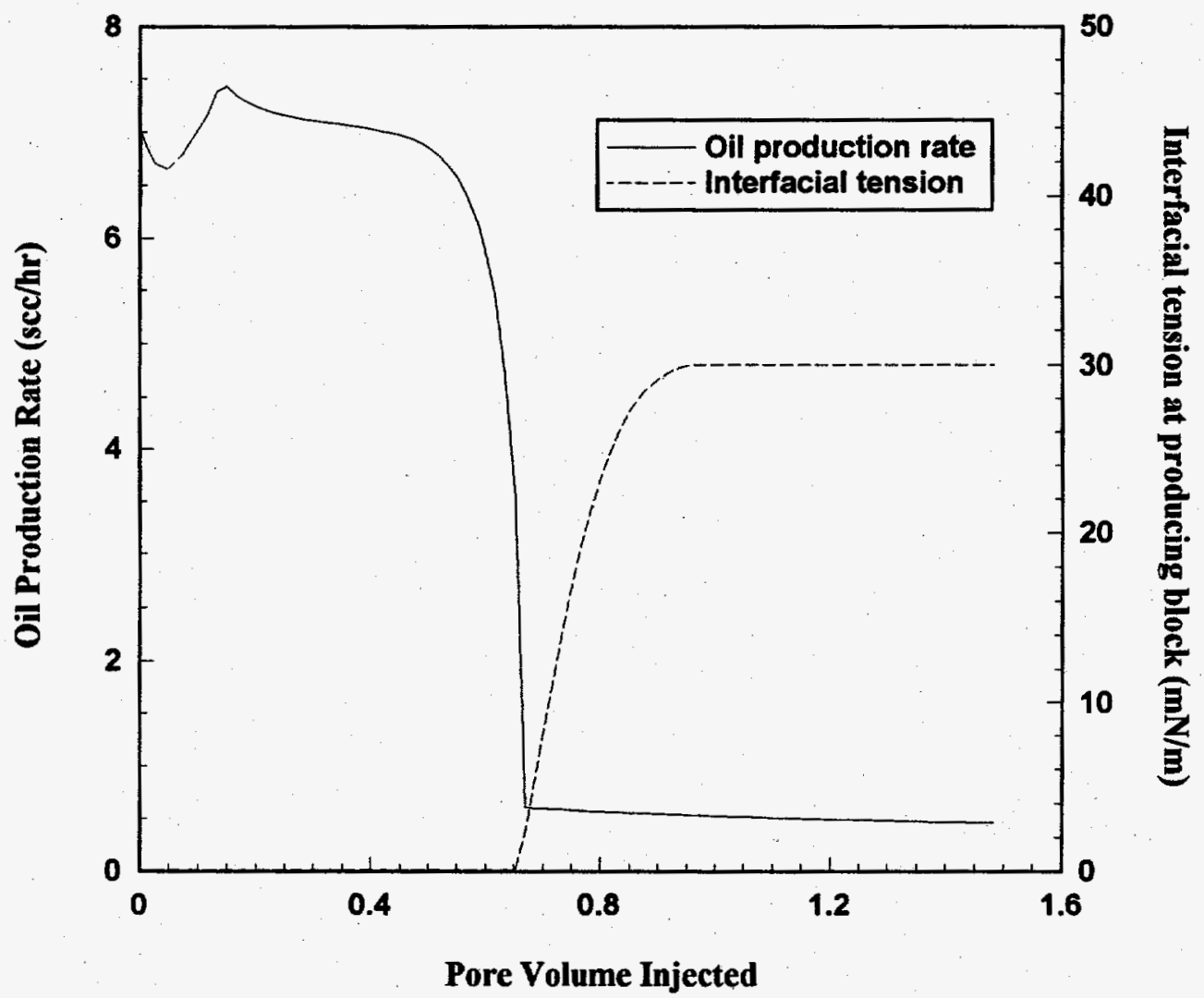

Figure 7.19: Computed Oil Production Rate and Interfacial Tension at the Producing Block during Post flushing for BiosurfactantProducing Bacterium Treatment Processes 


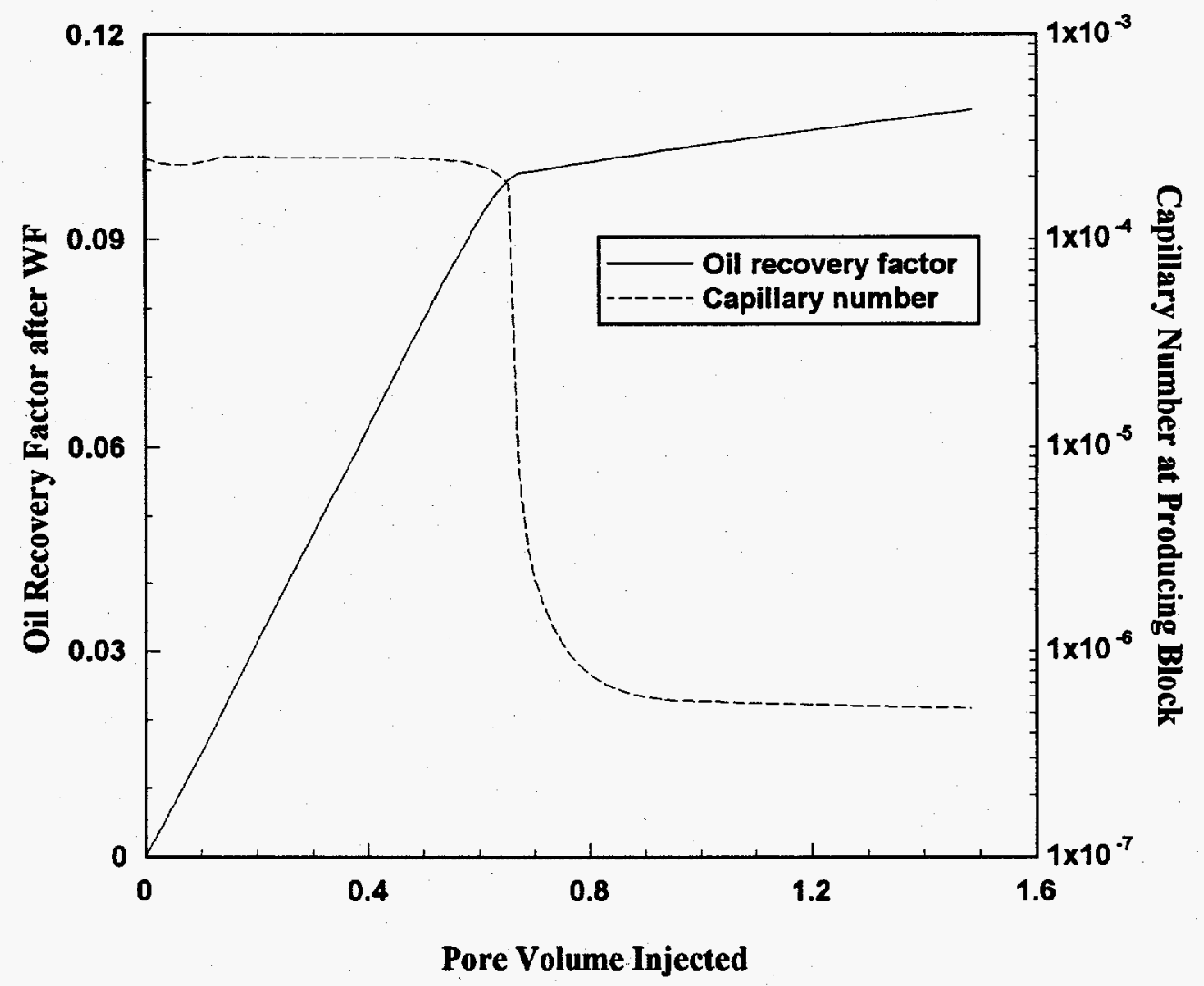

Figure 7.20: Computed Oil Recovery Factor and Capillary Number at the Producing Block during post flushing for BiosurfactantProducing Bacterium Treatment Processes 


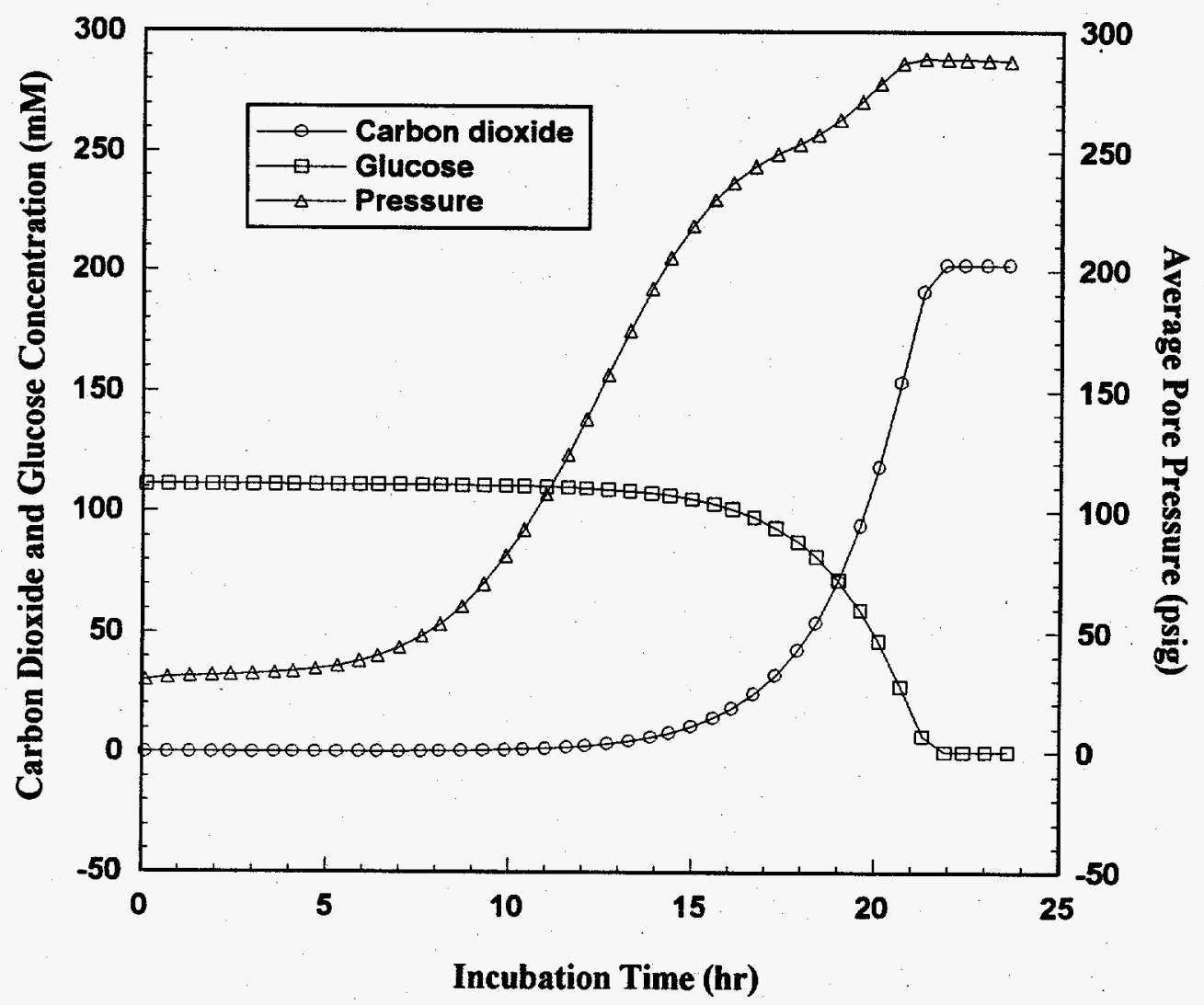

Figure 7.21: Computed $\mathrm{CO}_{2}$ Production, Glucose Consumption, and Pore Pressure Increase during Incubation for $\mathrm{CO}_{2}$-Producing Bacterium Treatment Processes 


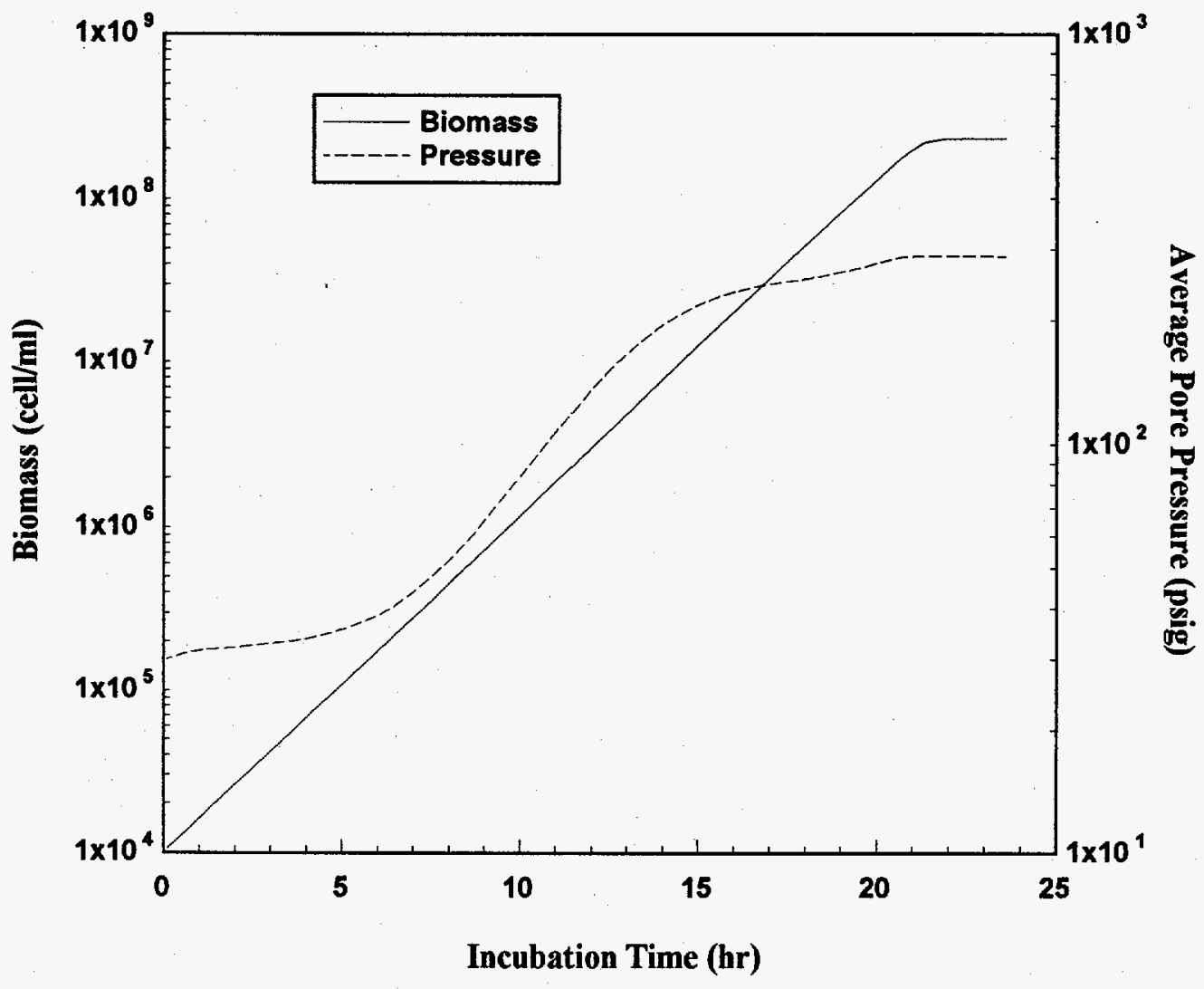

Figure 7.22: Comparison of Biomass Growth and Pore Pressure Increase during Incubation for $\mathrm{CO}_{2}$-Producing Bacterium Treatment Processes 


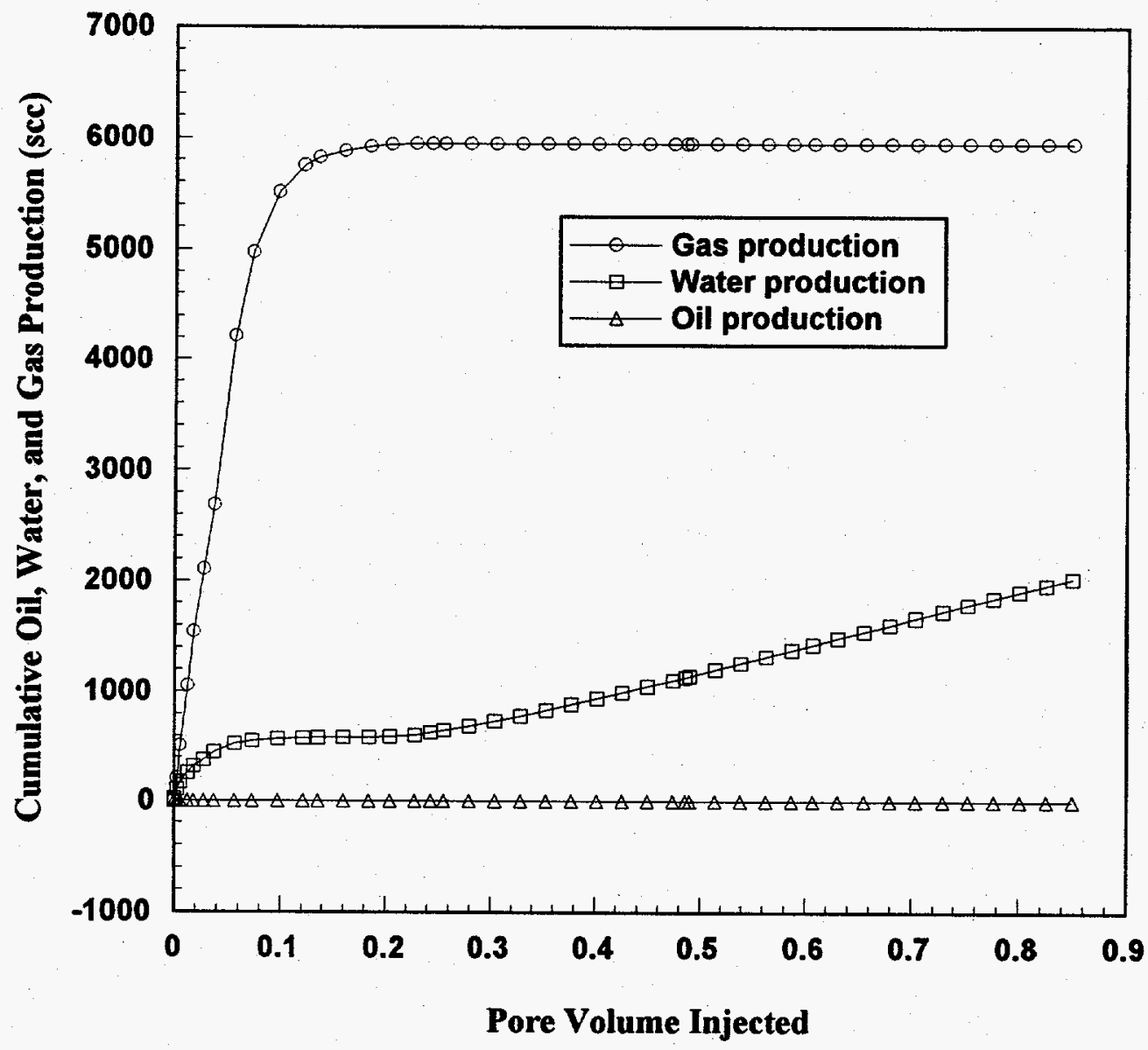

Figure 7.23: Computed Cumulative Oil, Water, and Gas Production during Post-Flushing for $\mathrm{CO}_{2}$-Producing Bacterium Treatment Processes 


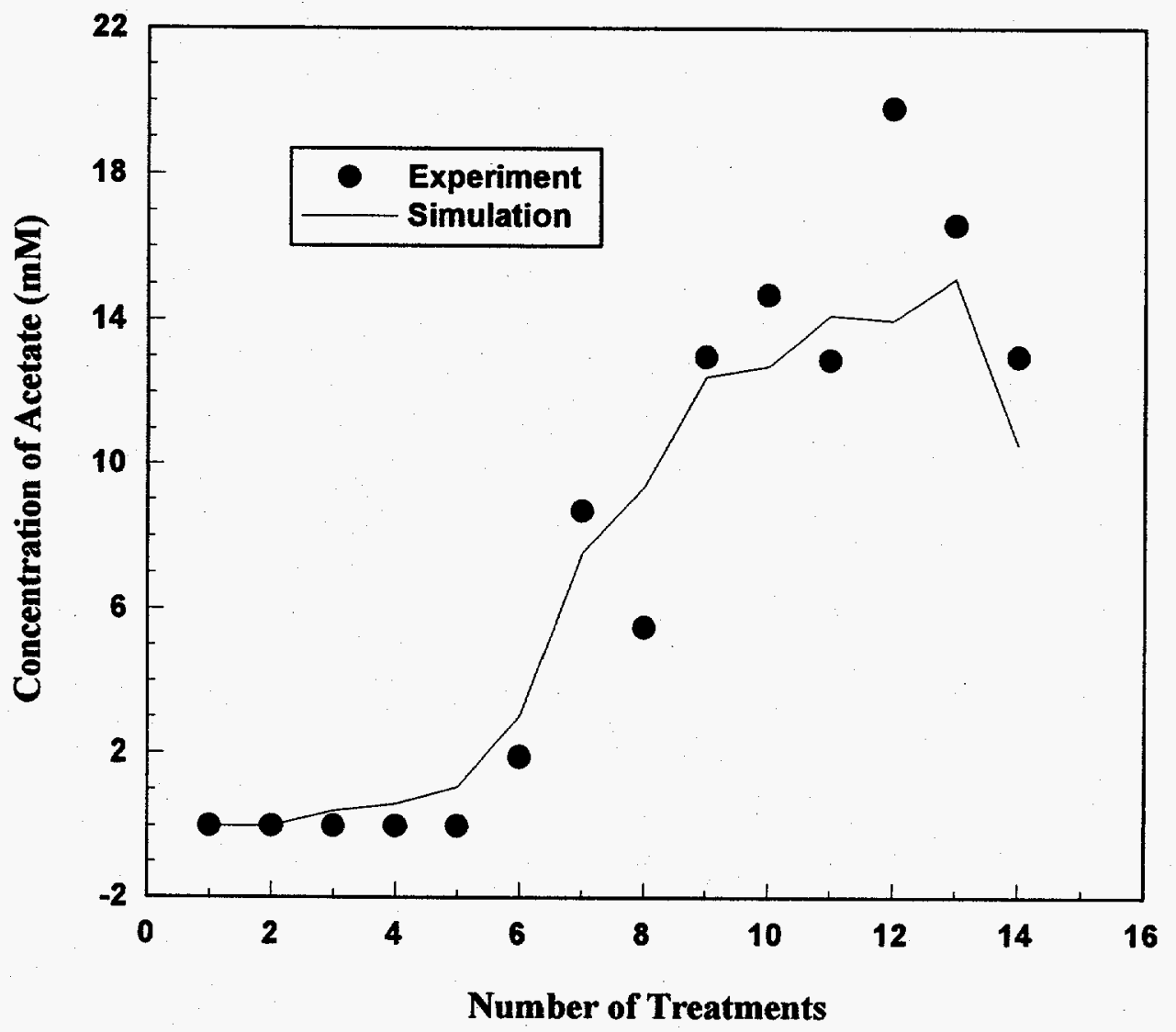

Figure 7.24: Comparison of Experimental Data and Simulation Results for Acetate Production from the Berea Core Incubated with Indigenous Bacteria 


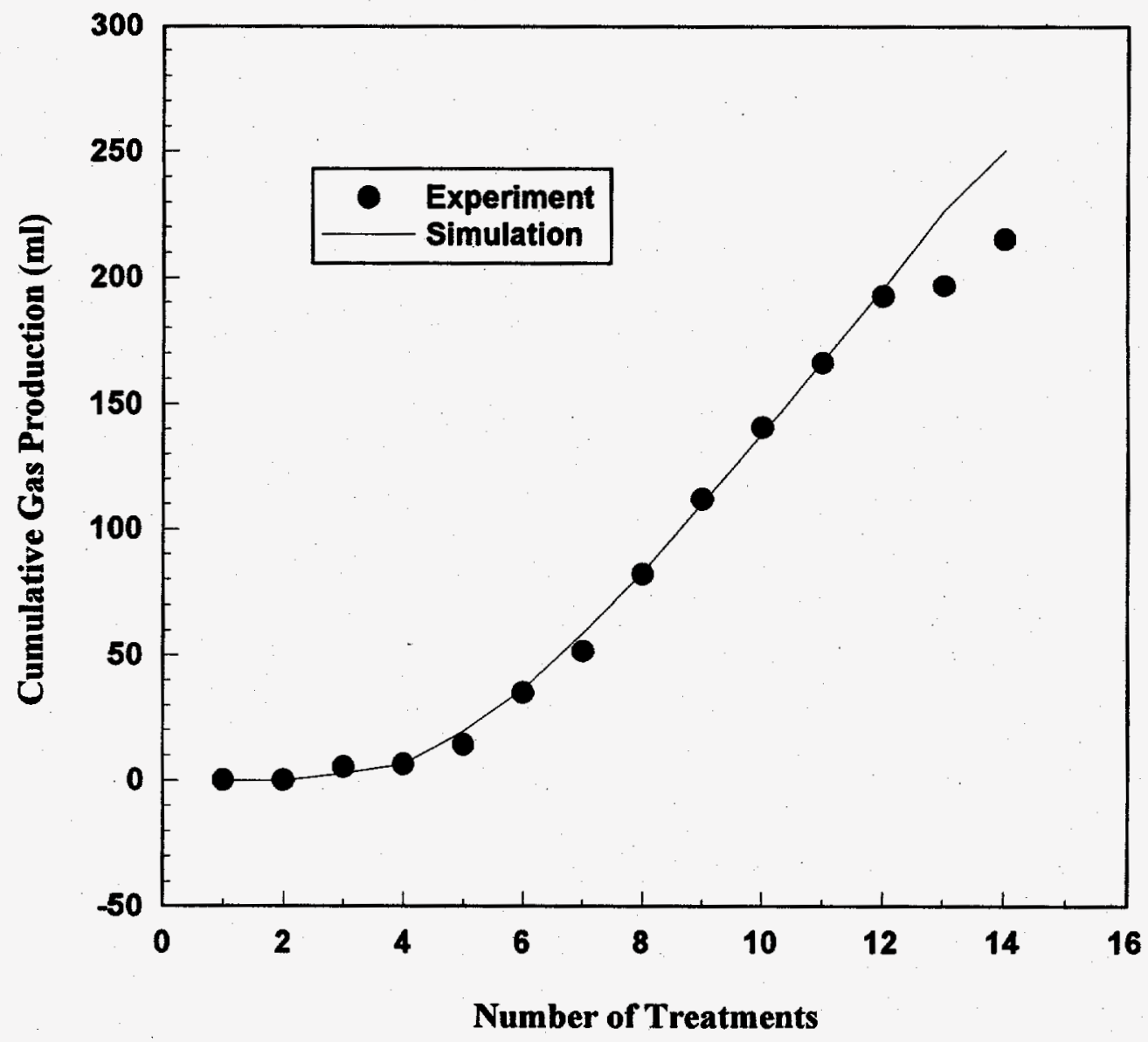

Figure 7.25: Comparison of Experimental Data and Simulation Results for Cumulative Gas $\left(\mathrm{CO}_{2}+\mathrm{N}_{2}\right)$ Production from the Berea Core Incubated with Indigenous Bacteria 


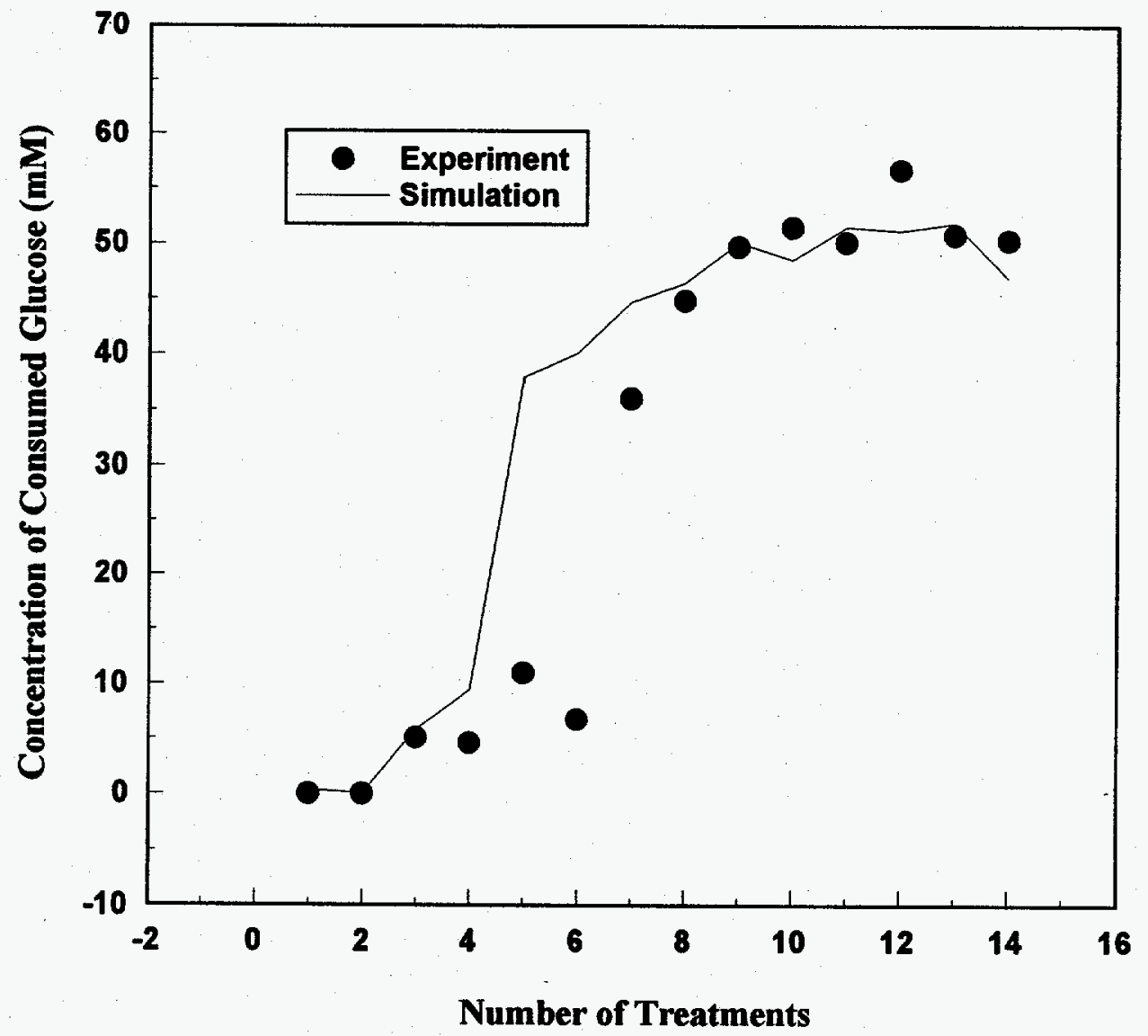

Figure 7.26: Comparison of Experimental Data and Simulation Results for Glucose Consumption in the Berea Core Incubated with Indigenous Bacteria 


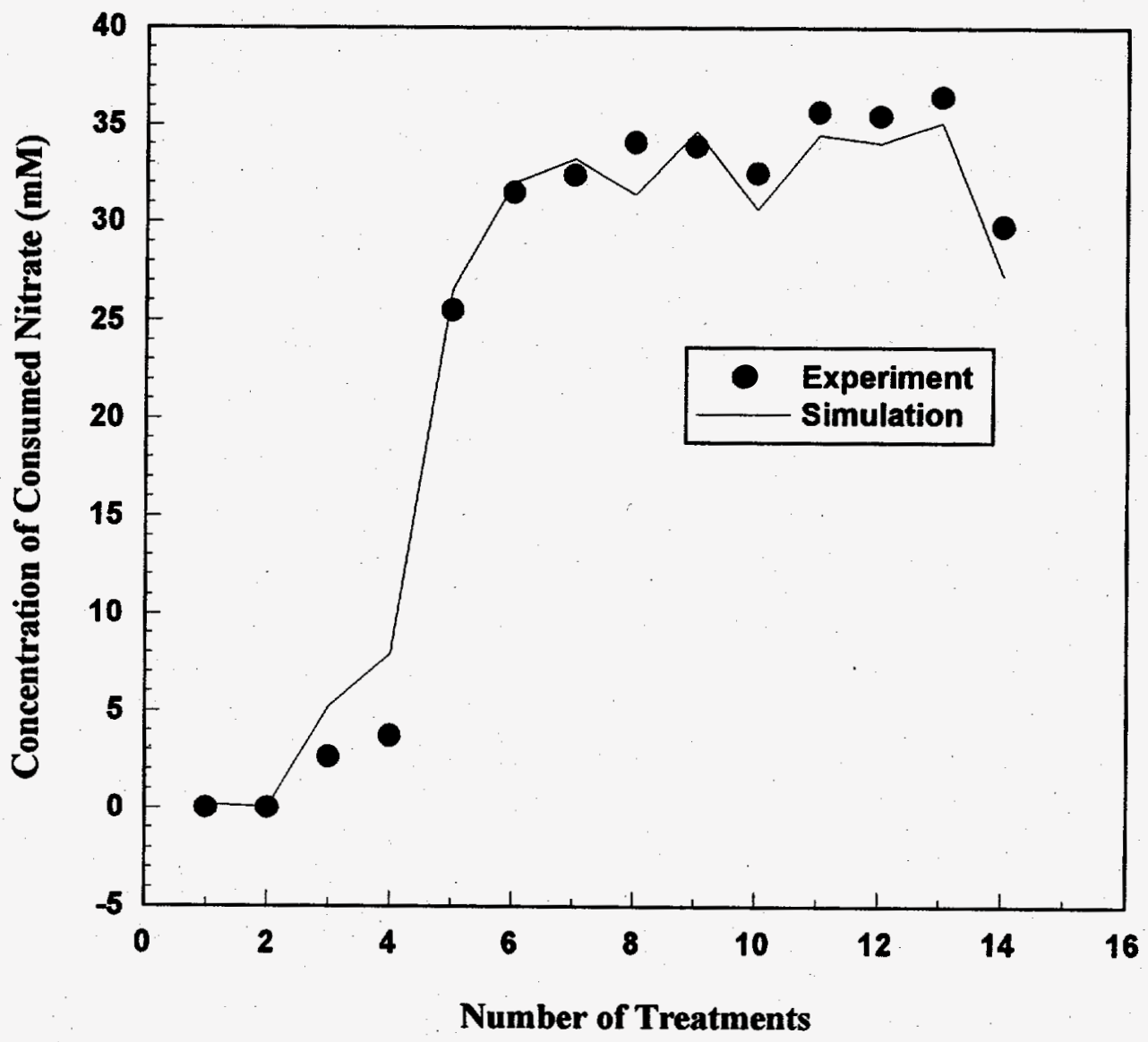

Figure 7.27: Comparison of Experimental Data and Simulation Results for Nitrate Consumption in the Berea Core Incubated with Indigenous Bacteria 


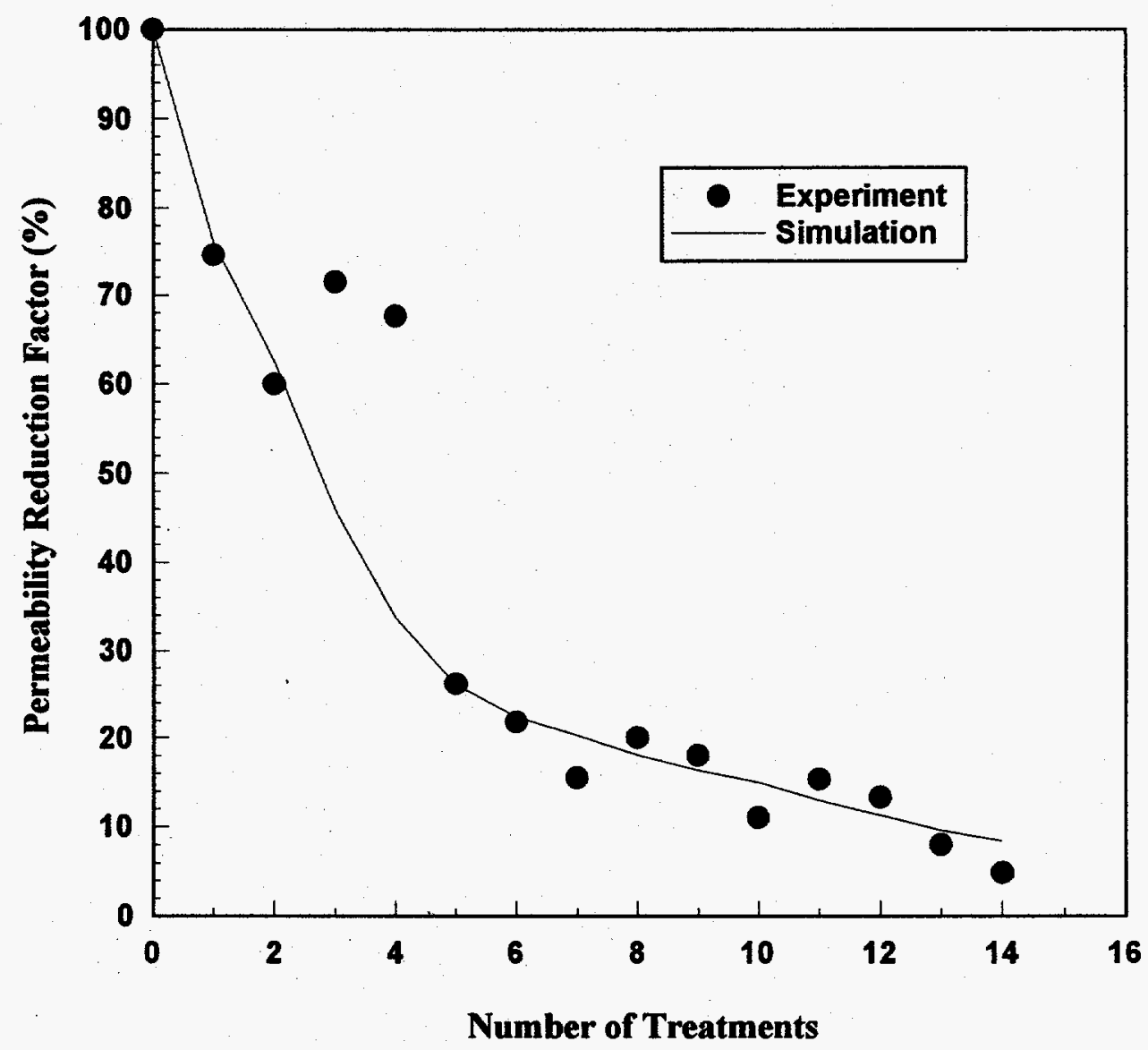

Figure 7.28: Comparison of Experimental Data and Simulation Results for Permeability Reduction in the Berea Core Incubated with Indigenous Bacteria 


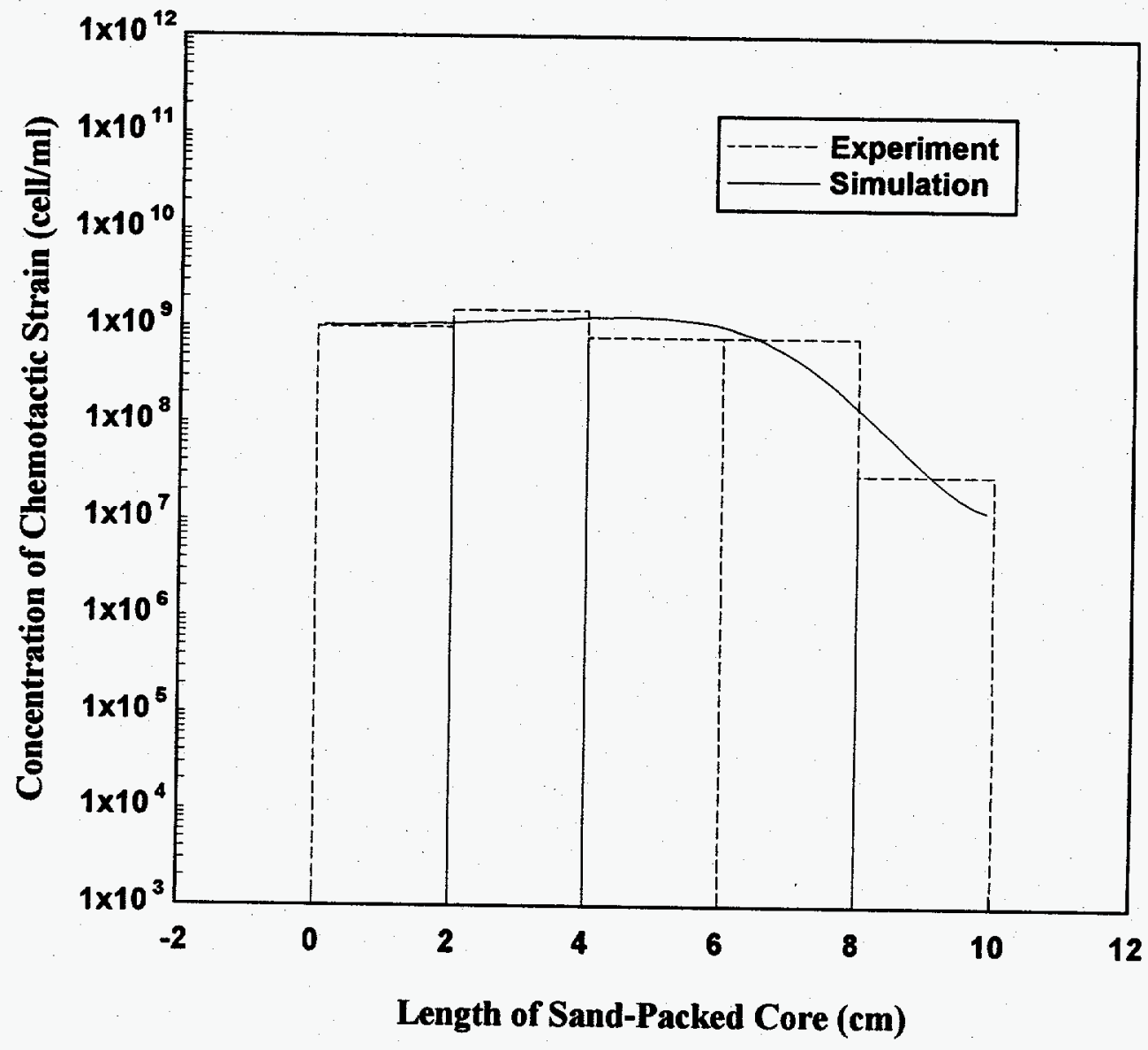

Figure 7.29: Comparison of Experimental Data and Simulation Results for Concentration Profiles of Chemotactic Strain RP437 in the Sand-Packed Core under Static Conditions after 70 Hours of Incubation 


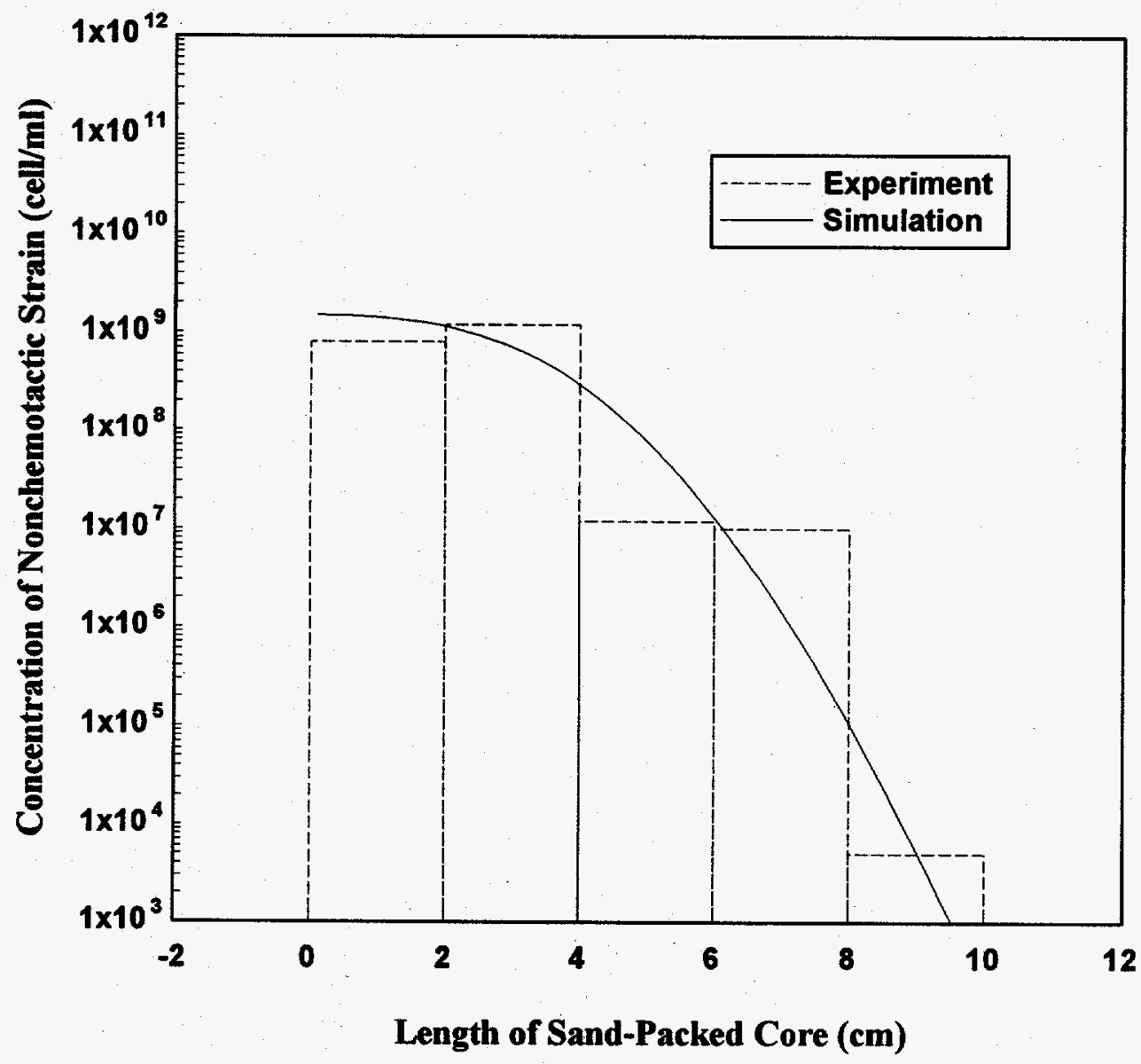

Figure 7.30: Comparison of Experimental Data and Simulation Results for Concentration Profiles of Nonchemotactic Strain RP5323 in the Sand-Packed Core under Static Conditions after 60.5 Hours of Incubation 


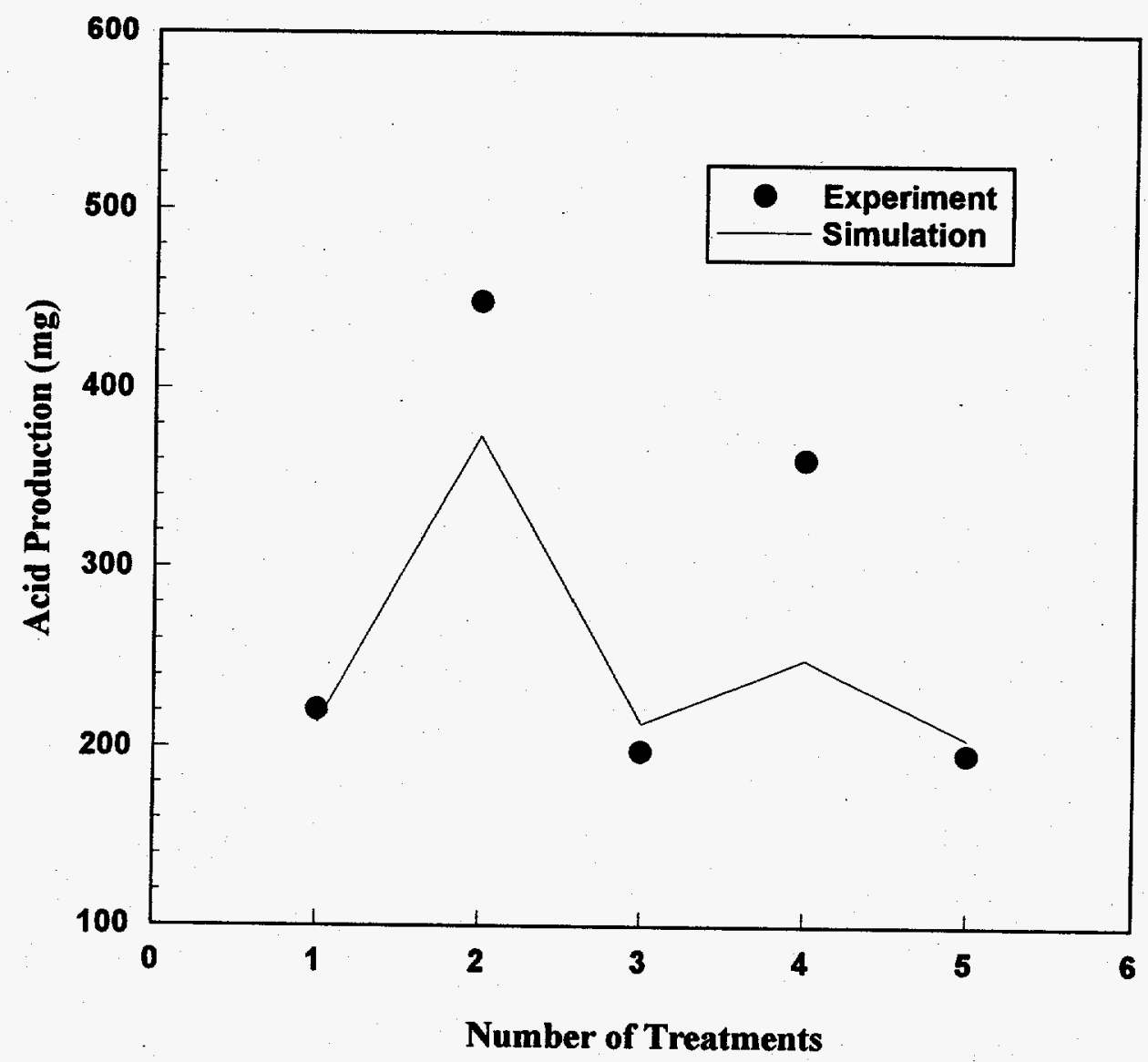

Figure 7.31: Comparison of Experimental Data and Simulation Results for Acid Production from the Berea Core Incubated with Clostridium acetobutylicum 


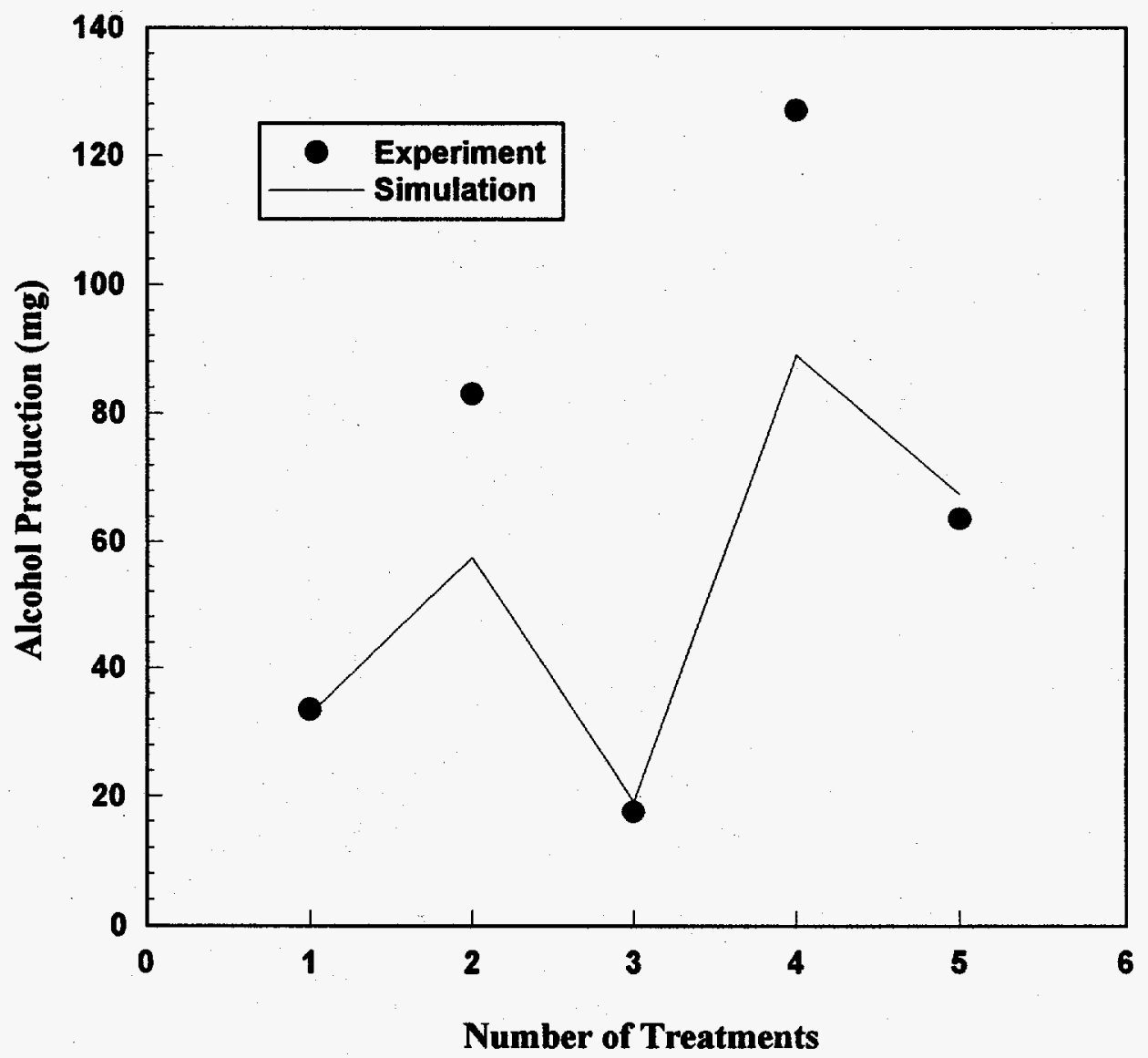

Figure 7.32: Comparison of Experimental Data and Simulation Results for Alcohol Production from the Berea Core Incubated with Clostridium acetobutylicum 


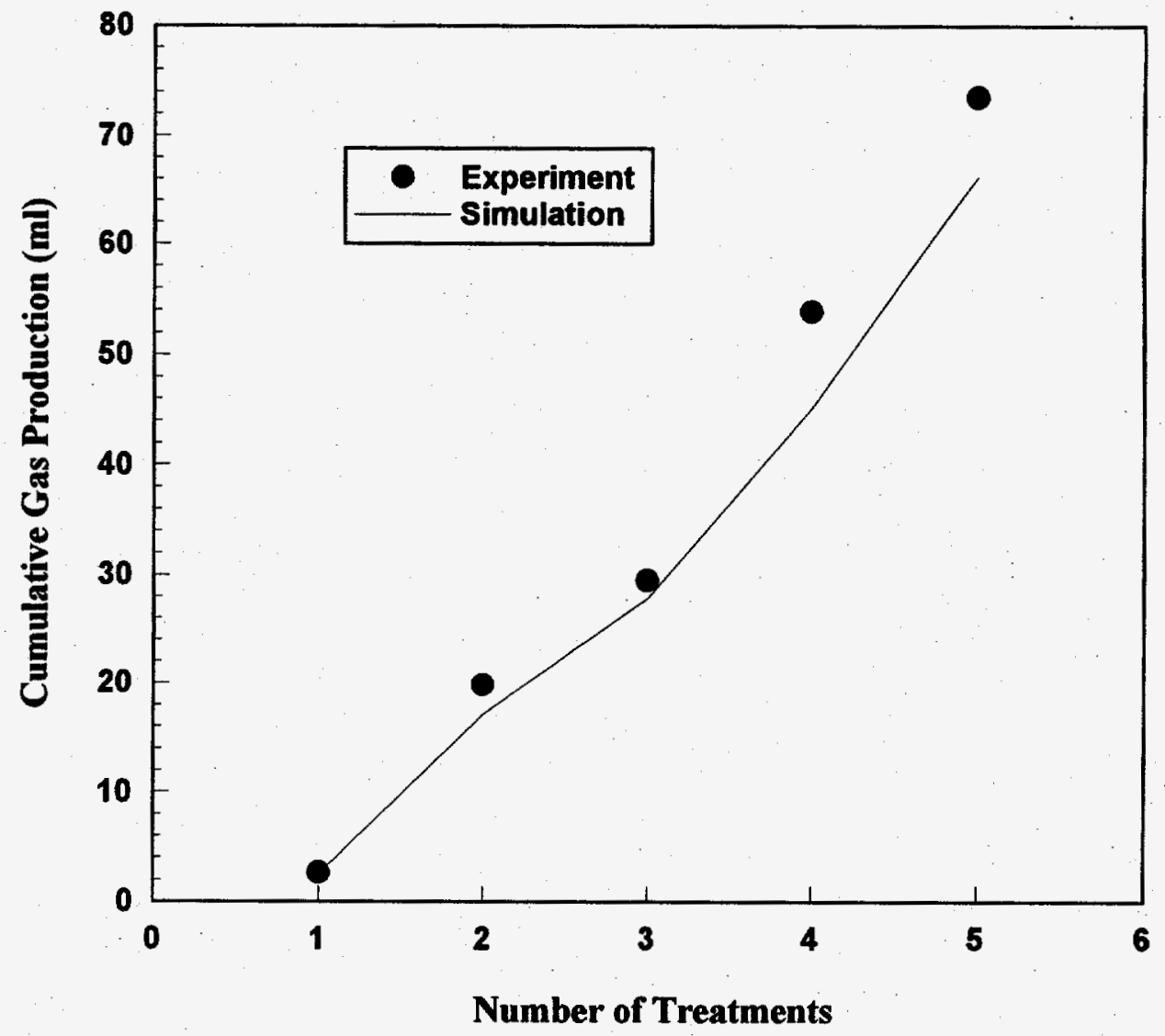

Figure 7.33: Comparison of Experimental Data and Simulation Results for Cumulative Gas Production from the Berea Core Incubated with Clostridium acetobutylicum 


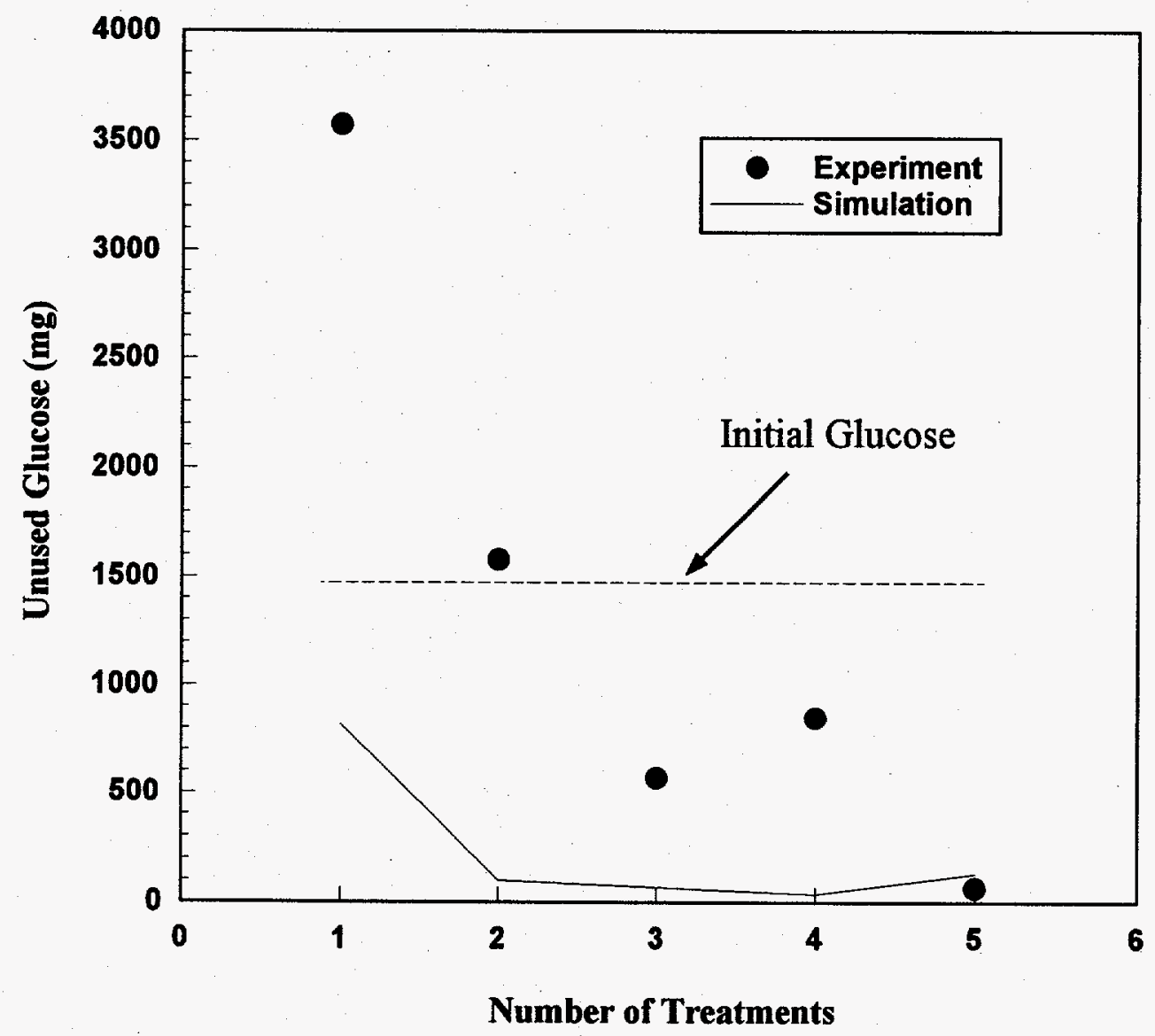

Figure 7.34: Comparison of Experimental Data and Simulation Results for Glucose Consumption in the Berea Core Incubated with Clostridium acetobutylicum 


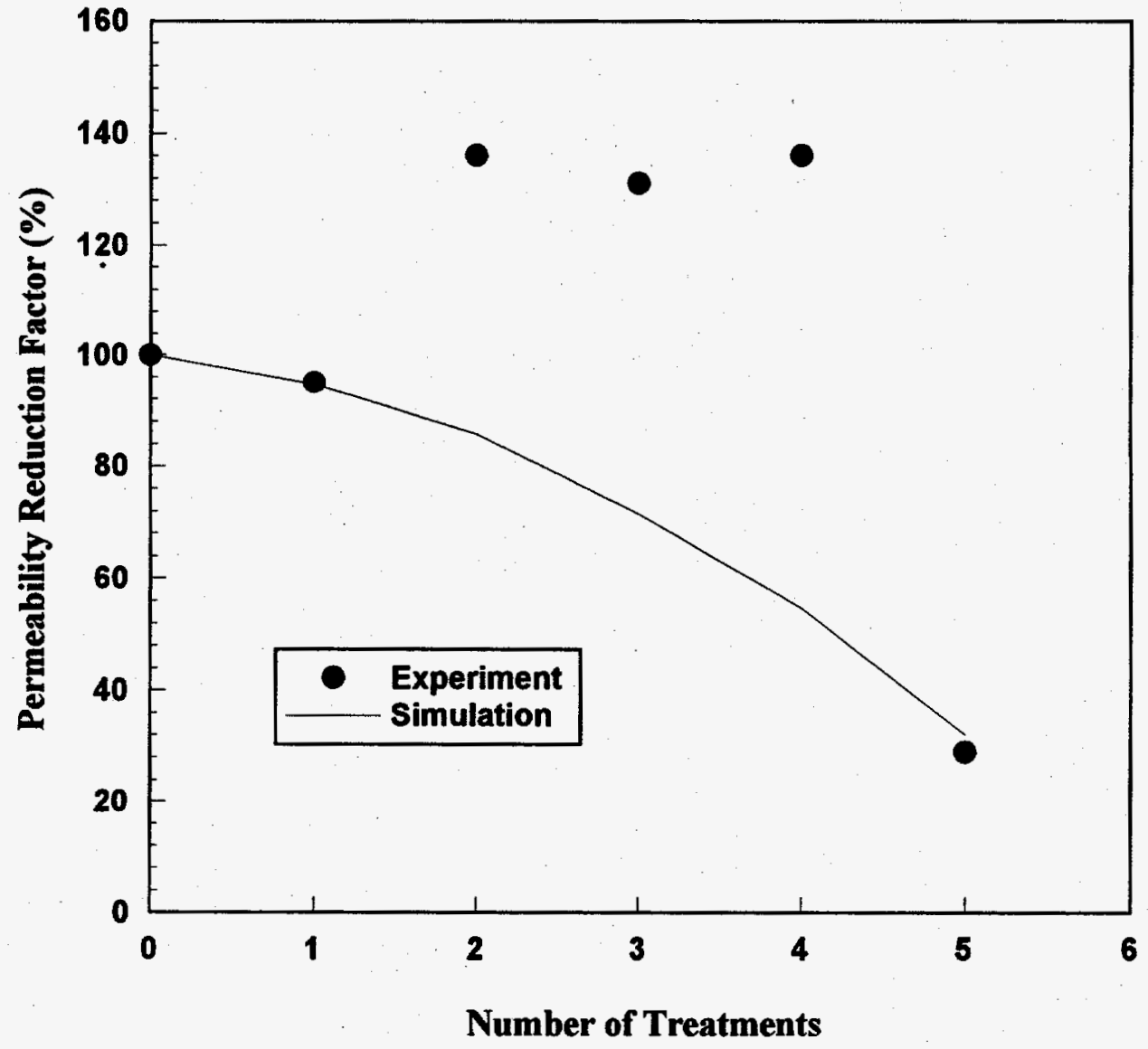

Figure 7.35: Comparison of Experimental Data and Simulation Results for Permeability Reduction in the Berea Core Incubated with Clostridium acetobutylicum 


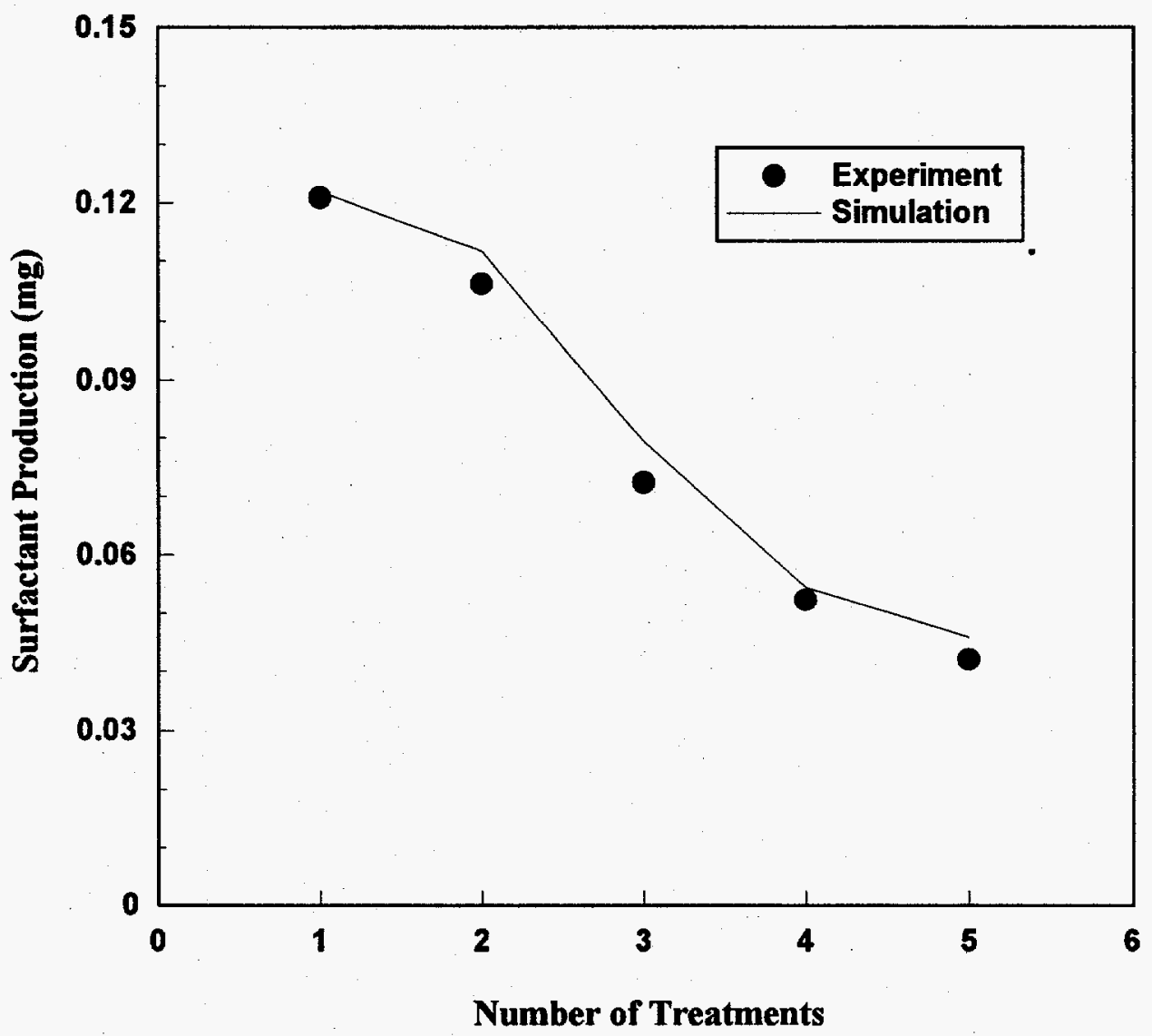

Figure 7.36: Comparison of Experimental Data and Simulation Results for Surfactant Production from the Berea Core Incubated with Bacillus Strain JF-2 


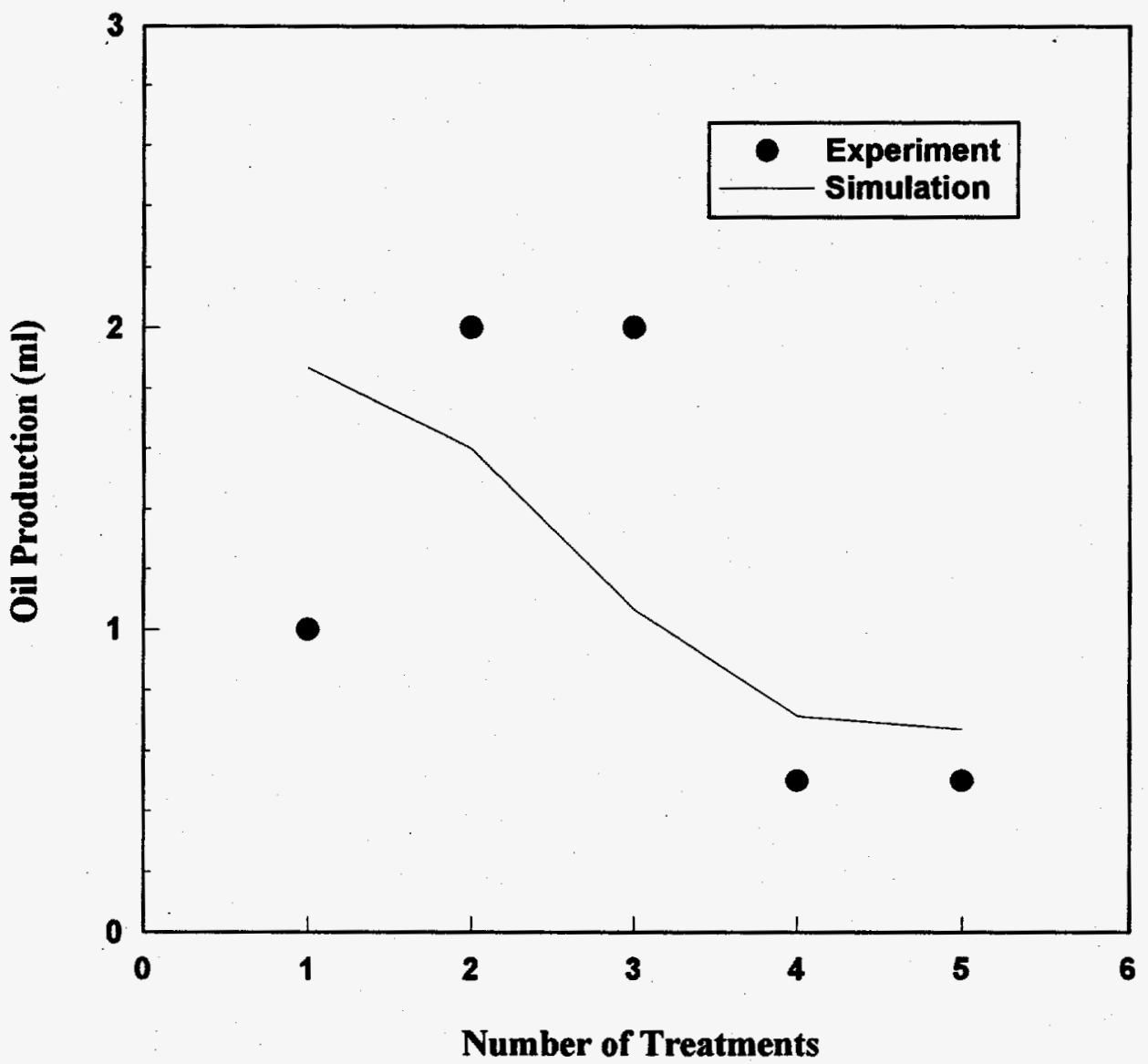

Figure 7.37: Comparison of Experimental Data and Simulation Results for Oil Production from the Berea Core Incubated with Bacillus Strain JF-2 


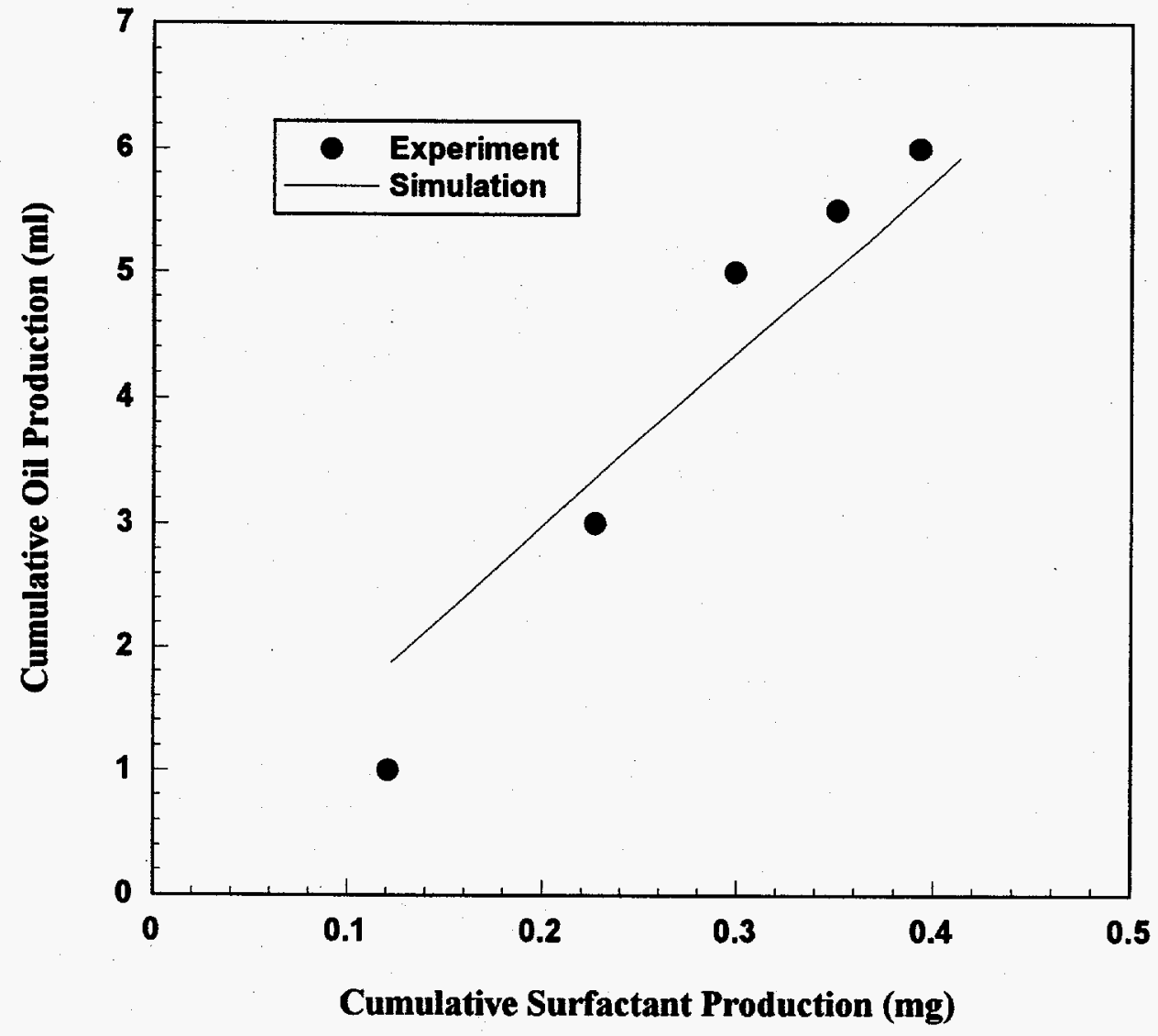

Figure 7.38: Comparison of Experimental Data and Simulation Results for Correlation between Cumulative Oil and Surfactant Production from the Berea Core Incubated with Bacillus Strain JF-2 


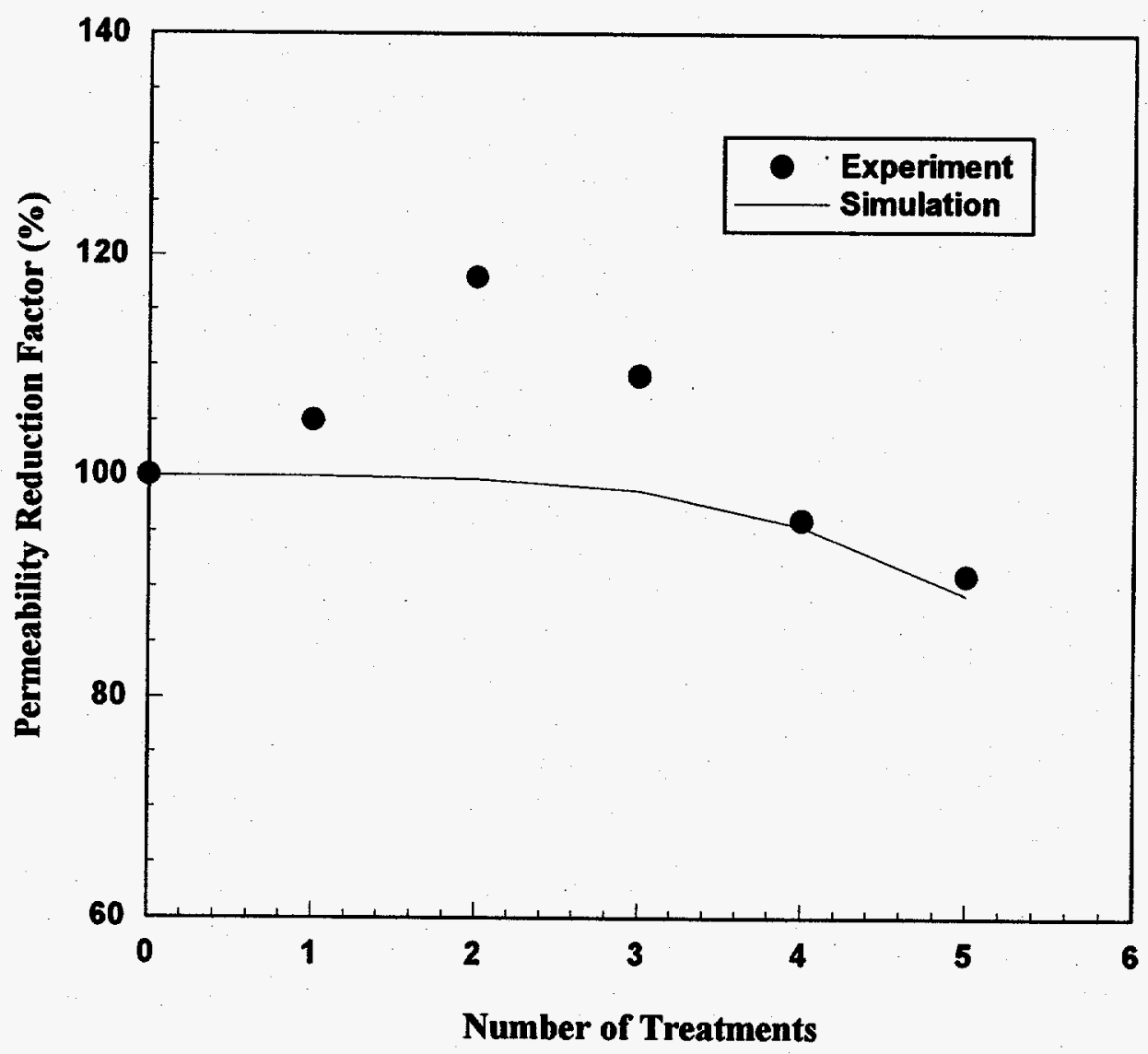

Figure 7.39: Comparison of Experimental Data and Simulation Results for Permeability Reduction in the Berea Core Incubated with Bacillus. Strain JF-2 


\section{CONCLUSIONS AND RECOMMENDATIONS}

\subsection{Conclusions}

1. A three-dimensional, three-phase, multiple-component numerical simulator was developed to investigate transport and growth of microorganisms in porous media and impacts of microbial activities on enhanced oil recovery processes.

2. The simulator was verified by comparison of the numerical solutions from this simulator with the results from analytical equations, a commercial simulator, and laboratory experiments.

3. The model verification indicated that the simulator was capable of quantifying microbial transport and metabolism in porous media and predicting additional oil recovery as results of microbial processes.

4. Case studies conducted using this simulator showed that the major mechanisms for oil recovery by MEOR processes include: (1) improvement of sweep efficiency due to microbial plugging and mobility control, and (2) an increase in capillary number due to reduction of interfacial tension between oil and water phases.

5. Simulation results suggested that gases generated during microbial growth and metabolism could not be expected to contribute much to additional oil recovery by MEOR processes. 


\subsection{Recommendations}

1. Effects of produced acids and alcohols, and $\mathrm{pH}$ on the MEOR processes should be investigated.

2. Change in wettability of rock during the MEOR processes and its impact on oil recovery should be examined. 


\section{NOMENCLATURE}

$a_{k} \quad=$ Langmuir adsorption constants for component $k$

$b_{k} \quad=$ Langmuir adsorption constants for component $\mathrm{k}$

$\mathrm{B}_{\ell} \quad=$ Formation volume factor for phase $\ell$ ( $\left.\mathrm{rcc} / \mathrm{scc}\right)$

$\mathrm{C}_{\mathrm{i}} \quad=$ Concentration for inhibitor $\mathrm{i}(\mathrm{mg} / \mathrm{scc})$

$\mathrm{C}_{\mathrm{k}}=$ Concentration for flowing component $\mathrm{k}(\mathrm{mg} / \mathrm{scc})$

$\mathrm{C}_{\mathrm{ks}}=$ Concentration for sorbed component $\mathrm{k}(\mathrm{mg} / \mathrm{scc})$

$\mathrm{C}_{\mathrm{s}} \quad=$ Concentration for substrate $\mathrm{s}(\mathrm{mg} / \mathrm{scc})$

$\mathrm{C}_{6, \min }=$ Minimum concentration for biosurfactant

$\mathrm{C}_{6, \max }=$ Minimum concentration for biosurfactant

$\mathrm{C}_{\mathrm{g}} \quad=$ Compressibility for gas phase $\left(\mathrm{psia}^{-1}\right)$

$\mathrm{C}_{\mathrm{o}} \quad=$ Compressibility for oil phase $\left(\mathrm{psia}^{-1}\right)$

$\mathrm{C}_{\mathrm{r}} \quad=$ Compressibility for rock $\left(\mathrm{psia}^{-1}\right)$

$\mathrm{C}_{\mathrm{t}} \quad=$ Total compressibility $\left(\mathrm{psia}^{-1}\right)$

$\mathrm{C}_{\mathrm{w}} \quad=$ Compressibility for water phase $\left(\mathrm{psia}^{-1}\right)$

$\Delta \mathrm{C}_{\max }=$ Maximum relative change in component concentration (fr)

$\Delta \mathrm{C}_{\mathrm{lim}}=\mathrm{Up}$ limit for relative change in component concentration (fr)

$\overline{\bar{D}}_{\mathrm{wk}}=$ Dispersion tensor for component $\mathrm{k}$ in water phase $\left(\mathrm{cm}^{2} / \mathrm{hr}\right)$

$\mathrm{D}_{\mathrm{k}} \quad=$ Molecular diffusion coefficient for component $\mathrm{k}\left(\mathrm{cm}^{2} / \mathrm{hr}\right)$

$\mathrm{D}_{\mathrm{kw}, \mathrm{mm}}=$ Element of dispersion tensor for component $\mathrm{k}\left(\mathrm{cm}^{2} / \mathrm{hr}\right), \mathrm{m}, \mathrm{m}^{\prime}=\mathrm{X}, \mathrm{Y}, \mathrm{Z}$

$e_{1}, e_{2}=$ Exponent parameters for bimodal distribution

$\mathrm{e}_{\mathrm{s}} \quad=$ Exponent parameters for IFT

f $\quad=$ Flow efficiency factor 
$\mathrm{K}_{\mathrm{b} / \mathrm{s}} \quad=$ Saturation constant for biomass growth from substrate $(\mathrm{mg} / \mathrm{scc})$

$\mathrm{K}_{\mathrm{p} / \mathrm{s}} \quad=$ Saturation constant for formation of product from substrate $(\mathrm{mg} / \mathrm{scc})$

$\mathrm{K}_{\mathrm{i}} \quad=$ Inhibition coefficient for inhibitor $\mathrm{i}(\mathrm{mg} / \mathrm{scc})$

$\mathrm{K}_{\mathrm{c}} \quad=$ Chemotactic coefficient $\left(\mathrm{cm}^{2} / \mathrm{hr}\right)$

$\mathrm{K}_{\mathrm{T}} \quad$ = Coefficient for bacterial retention $\left(\mathrm{cm}^{-1}\right)$

$\mathrm{K}_{\mathrm{d}} \quad=$ Coefficient for bacterial detachment $(\mathrm{cm} / \mathrm{psia} / \mathrm{hr})$

$\mathrm{K}_{\mathrm{pol}} \quad$ = Coefficient for computing viscosity for biopolymer solution (cp.scc/mg)

$\overrightarrow{\overrightarrow{\mathbf{K}}} \quad=$ Diagonal permeability tensor (md)

$\mathrm{K}_{\mathrm{m}} \quad=$ Permeability in $\mathrm{m}$-direction ( $\mathrm{md}$ ), $\mathrm{m}=\mathrm{X}, \mathrm{Y}, \mathrm{Z}$

$\mathrm{K}_{\mathrm{r} \ell} \quad=$ Relative permeability for phase $\ell(\mathrm{md} / \mathrm{md})$

$\mathrm{K}_{\mathrm{r} \ell}^{\mathrm{h}} \quad=$ Relative permeability for phase $\ell$ at high capillary number ( $\mathrm{md} / \mathrm{md}$ )

$\mathrm{K}_{\mathrm{r} \ell}^{\mathrm{w}} \quad=$ Relative permeability for phase $\ell$ at low capillary number $(\mathrm{md} / \mathrm{md})$

$\mathrm{m}_{1}, \mathrm{~m}_{2}=$ Exponent parameters for bimodal distribution function

$m_{s} \quad=$ Coefficient of maintenance energy provided by consuming substrate $s\left(h r^{-1}\right)$

$\tilde{\mathrm{m}}_{\ell} \quad=$ Mass injection/production rate per unit rock bulk volume for phase $\ell(\mathrm{mg} / \mathrm{ml} / \mathrm{hr})$

$\mathrm{N}_{\mathrm{c} \ell} \quad$ Capillary number for phase $\ell$

$\mathrm{N}_{\mathrm{c} \ell}^{\mathrm{h}} \quad=$ High capillary number for phase $\ell$

$\mathrm{N}_{\mathrm{c} \ell}^{\mathrm{w}} \quad$ = Low capillary number for phase $\ell$

$\mathrm{p}_{\text {cow }}=$ Oil-water capillary pressure (psia)

$\mathrm{p}_{\mathrm{cgo}}=$ Gas-oil capillary pressure (psia)

$\mathrm{p}_{\mathrm{cow}}^{\mathrm{w}}=$ Oil-water capillary pressure at low capillary number (psia)

$\mathrm{p}_{\ell} \quad=$ Pressure for phase $\ell$ (psia)

$\mathrm{p}_{\mathrm{wf}, \mathrm{z}}=$ Bottom hole pressure at layer $\mathrm{z}$ (psia)

$\Delta \mathrm{p}_{\max }=$ Maximum relative change in block pressure (fr)

$\Delta \mathrm{p}_{\mathrm{lim}}=\mathrm{Up}$ limit for relative change in block pressure (fr) 
$\delta \mathrm{p} \quad=$ Perturbation in pressure $(\mathrm{psia})$

$\mathrm{Q}_{\ell} \quad=$ Mass injection/production rate per unit bulk volume for phase $\ell(\mathrm{mg} / \mathrm{scc} / \mathrm{hr})$

$\mathrm{q}_{\ell} \quad=$ Volumetric injection/production rate for phase $\ell(\mathrm{scc} / \mathrm{hr})$

$\mathrm{q}_{\ell, \mathrm{z}}=$ Volumetric injection/production rate for phase $\ell$ at layer $\mathrm{z}(\mathrm{scc} / \mathrm{hr})$

$\mathrm{q}_{\mathrm{g} 2}=$ Volumetric production rate for $\mathrm{N}_{2}$ generated form MEOR processe (scc/hr)

$\mathrm{q}_{\mathrm{g} 3}=$ Volumetric production rate for $\mathrm{CO}_{2}$ generated form MEOR processe (scc/hr)

$\mathbf{R}_{\mathrm{k}}=$ Growth, production, or consumption rate for component $\mathrm{k}(\mathrm{mg} / \mathrm{scc} / \mathrm{hr})$

$R_{\mathrm{bf}} \quad=$ Growth rate for flowing bacteria $(\mathrm{mg} / \mathrm{scc} / \mathrm{hr})$

$\mathrm{R}_{\mathrm{bs}} \quad=$ Growth rate for sorbed bacteria $(\mathrm{mg} / \mathrm{scc} / \mathrm{hr})$

$\mathrm{R}_{\mathrm{T}} \quad=$ Bacterial retention rate $(\mathrm{mg} / \mathrm{scc} / \mathrm{hr})$

$\mathbf{R}_{\mathrm{d}} \quad=$ Bacterial detachment rate $(\mathrm{mg} / \mathrm{scc} / \mathrm{hr})$

$\mathrm{S}_{\ell} \quad=$ Saturation for phase $\ell$ (rcc/rcc)

$\mathrm{S}_{\ell \mathrm{r}} \quad=$ Residual saturation for phase $\ell(\mathrm{rcc} / \mathrm{rcc})$

$\mathrm{S}_{\ell \mathrm{r}}^{\mathrm{h}} \quad=$ Residual saturation for phase $\ell$ at high capillary number ( $\mathrm{rcc} / \mathrm{rcc}$ )

$\mathrm{S}_{\ell \mathrm{r}}^{\mathrm{w}} \quad=$ Residual saturation for phase $\ell$ at low capillary number $(\mathrm{rcc} / \mathrm{rcc})$

$\Delta \mathrm{S}_{\max }=$ Maximum relative change in saturation (fr)

$\Delta \mathrm{S}_{\mathrm{lim}}=\mathrm{Up}$ limit for relative change in saturation (fr)

$\mathrm{R}_{\mathrm{so}} \quad=$ Solution gas-oil ratio $(\mathrm{scc} / \mathrm{scc})$

$\mathrm{R}_{\mathrm{sw}} \quad=$ Solution gas-water ratio ( $\left.\mathrm{scc} / \mathrm{scc}\right)$

$\overrightarrow{\mathrm{u}}_{\ell} \quad=$ Darcy velocity vector for phase $\ell(\mathrm{cm} / \mathrm{hr})$

$\mathrm{u}_{\ell \mathrm{m}}=$ Element of Darcy velocity for phase $\ell$ in $\mathrm{m}$-direction $(\mathrm{cm} / \mathrm{hr}), \mathrm{m}=\mathrm{X}, \mathrm{Y}, \mathrm{Z}$

$\overrightarrow{\mathrm{u}}_{\mathrm{c}} \quad=$ Chemotactic velocity vector for bacteria $(\mathrm{cm} / \mathrm{hr})$

$\mathrm{V}_{\mathrm{b}} \quad=$ Bulk volume of grid block (scc)

$\mathrm{w} \quad=$ Weighting factor $(\mathrm{fr})$

$\mathrm{x}_{\mathrm{ctt}} \quad=$ Critical pore throat size for plugging $(\mu \mathrm{m})$ 
$x_{\min }=$ Minimum pore throat size $(\mu \mathrm{m})$

$\mathrm{x}_{\max }=$ Maximum pore throat size $(\mu \mathrm{m})$

$\mathrm{x}_{\mathrm{cb}} \quad=$ Cell body size $(\mu \mathrm{m})$

$\mathbf{x}_{\mathrm{c} \ell}=$ Mass fraction of component $\mathrm{c}$ in phase $\ell(\mathrm{mg} / \mathrm{mg})$

$\Delta \mathrm{X}=$ Grid block size in the $\mathrm{X}$-direction $(\mathrm{cm})$

$\Delta \mathrm{Y}=$ Grid block size in the $\mathrm{Y}$-direction $(\mathrm{cm})$

$\Delta \mathrm{Z} \quad=$ Grid block size in the Z-direction $(\mathrm{cm})$

$\mathrm{Y}_{\mathrm{b} / \mathrm{s}} \quad$ = factor of yield of bacteria from substrate $(\mathrm{mg} / \mathrm{mg})$

$\mathrm{Y}_{\mathrm{p} / \mathrm{s}} \quad=$ factor of yield of product from substrate $(\mathrm{mg} / \mathrm{mg})$

\section{Greek Symbols}

$\alpha_{\mathrm{e}}, \quad=$ Empirical parameters for computing critical pore-throat size

$\beta_{\mathrm{e}}, \quad=$ Empirical parameters for computing critical pore-throat size

$\gamma_{\mathrm{e}}=$ Empirical parameters for computing critical pore-throat size

$\alpha_{\mathrm{lw}} \quad=$ Longitudinal dispersivity for water phase (cm)

$\alpha_{\mathrm{tw}} \quad=$ Longitudinal dispersivity for water phase (cm)

$\phi \quad=$ Rock porosity (rcc/rcc)

$\Phi_{\ell} \quad=$ Potential for phase $\ell(\mathrm{psi} / \mathrm{cm})$

$\mu_{\ell} \quad=$ Viscosity for phase $\ell$ (cp)

$\mu_{\mathrm{bm}} \quad=$ Maximum specific growth rate for bacteria $\left(\mathrm{hr}^{-1}\right)$

$\mu_{\mathrm{pm}} \quad=$ Maximum specific production rate for product $\mathrm{p}\left(\mathrm{hr}^{-1}\right)$

$\mu_{\text {pol }} \quad=$ Viscosity for biopolymer solution (cp)

$\sigma \quad=$ Pore volume fraction occupied by sessile bacteria $(\mathrm{rcc} / \mathrm{rcc})$

$\sigma_{\min }=$ Minimum interfacial tension between oil and water $(\mathrm{mN} / \mathrm{m})$

$\sigma_{\max }=$ Maximum interfacial tension between oil and water $(\mathrm{mN} / \mathrm{m})$ 
$\sigma_{\text {ow }} \quad=$ Interfacial tension between oil and water $(\mathrm{mN} / \mathrm{m})$

$\rho_{\mathrm{bse}}=$ Density for bacteria at surface condition $(\mathrm{mg} / \mathrm{scc})$

$\mathrm{P}_{\mathrm{ksc}} \quad=$ Density for component $\mathrm{k}$ at surface condition $(\mathrm{mg} / \mathrm{scc})$

$P_{\text {ose }}=$ Density for oil at surface condition $(\mathrm{mg} / \mathrm{scc})$

$\rho_{\mathrm{wsc}} \quad=$ Density for water at surface condition $(\mathrm{mg} / \mathrm{scc})$

$P_{\mathrm{gsc}} \quad=$ Density for gas at surface condition $(\mathrm{mg} / \mathrm{scc})$

$\lambda_{\ell} \quad=$ Mobility for phase $\ell(\mathrm{md} / \mathrm{md} / \mathrm{cp})$

$\bar{\gamma}_{\mathrm{z}}=$ Average specific weight for fluids at producer at layer $\mathrm{z}(\mathrm{mg} / \mathrm{scc})$

$\gamma_{\text {inj,z }}=$ Specific weight for injected fluid at injector at layer $\mathrm{z}(\mathrm{mg} / \mathrm{scc})$

\section{$\underline{\text { Subscript }}$}

$\mathrm{b}=$ Bacteria

$\mathbf{k}=1,2,3, \ldots \ldots, 10$, representing components such as bacteria, nitrogen, carbon dioxide, acid, alcohol, surfactant, polymer, carbon-nutrient, nitrogen-nutrient \#1, nitrogen-nutrient \#2, respectively

$\mathrm{ks} \quad=$ Sorbed component $\mathbf{k}$

$\ell \quad=$ Phase such as oil, water, or gas

$\mathrm{p} \quad=$ Product such as nitrogen, carbon dioxide, acid, alcohol, surfactant, or polymer

$\mathrm{s} \quad=$ Substrate such as carbon-nutrient, nitrogen-nutrient \#1, and nitrogen-nutrient \#2

$\mathrm{o}, \mathrm{w}, \mathrm{g}=$ Oil, water, and gas phases

$\mathrm{X}, \mathrm{Y}, \mathrm{Z}=$ Orthogonal geometrical directions

$\mathrm{x}, \mathrm{y}, \mathrm{z}=$ Coordinates in $\mathrm{X}-, \mathrm{Y}-$, and $\mathrm{Z}$-directions 


\section{REFERENCES}

1. Jenneman, G.E., R.M. Knapp, M.J. McInerney, M.J. Menzie, and D.E. Revus: "Experimental Studies of In Situ Microbial Enhanced Oil Recovery," Soc. Pet. Eng. J., 24, (1984) 33-37.

2. Jenneman, G.E., M.J. McInerney, and R.M. Knapp: "Microbial Penetration through Nutrient-Saturated Berea Sandstone," Appl. Environ. Microbiol., 50, (1985) 383-391.

3. Raiders, R.A., R.M. Knapp, and M.J. McInemey: "Microbial Selective Plugging and Enhanced Oil Recovery," J. Indust. Microbiol., 4, (1989) 215-230.

4. Taylor, S.T. and P.R. Jaffe: "Biofilm Growth and the Related Changes in the Physical Properties of a Porous medium - 1. Experimental Investigation," Water Resources Research, Vol. 26, No. 9, (Sept. 1990) 2153-2159.

5. Taylor, S.T., P.C.D. Milly, and P.R. Jaffe: " Biofilm Growth and the Related Changes in the Physical Properties of a Porous medium - 2. Permeability," Water Resources Research, Vol. 26, No. 9, (Sept. 1990) 2153-2159.

6. Brown, M.J., V. Moses, J.P. Robinson, and D.G. Springham: "Microbial Enhanced Oil Recovery: Progress and Prospects," CRC Critical Reviews in Biotechnology, Vol. 3, Issue 2, (1986).

7. Bryant, R.S. and J. Douglas: "Evaluation of Microbial System in Porous Media for EOR," SPERE, (May, 1988) 489-495; Trans., AIME, 285.

8. Chisholm, J.L., S.V. Kashikar, R.M. Knapp, M.J. McInerney, D.E. Menzie, and N.J. Silfanus: "Microbial Enhanced Oil Recovery: Interfacial Tension and Gas 
Induced Relative Permeability Effects," SPE 20481, Presented at the 65th Ann. Conf., Dallas, TX, Sept., 1990.

9. Grula, E.A., H.H. Russell, D.Bryant, M. Kenaga, and M. Hart: "Isolation and Screening of Clostridium for Possible use in Microbially Enhanced Oil Recovery," Proc., Intl. Conference on Microbial Enhanced Oil Recovery, Afton, OK, May 16-21, 1982, DOE Conf-8205140, 43-47.

10. Jenneman, G.E., M.J. McInerney, R.M. Knapp, J.B. Clark, J.M. Feero, D.E. Revus, and D.E. Menzie: "A Halotolerant Biosurfactant-Producing Bacillus Species Potentially Useful for Enhanced Oil Recovery," Developments in Industrial Microbiology, Soc. for Industrial Microbiology, Vol. 24, Chap. 45, (1983) 485-492.

11. Knapp, R.M., M.J. McInerney, and D.E. Menzie: Microbial Strains and Products for Mobility Control and Oil Displacement, DOE/BC/110300-45, (1987).

12. Knapp, R.M., F. Civan, and M.J. McInerney: "Modeling Growth and Transport of Microorganisms in Porous Formations," Presented at IMACS, Paris, France, Jul. 18-22, 1988, Proceedings of 12th World Congress on Scientific Computation, Edited by R. Vichnevetsky, P. Borne, and J. Vignes, Vol. 3, (1988) 676-679.

13. Zhang, X., R.M. Knapp, and M.J. McInerney: "A Mathematical Model for Microbially Enhanced Oil Recovery Processes," Proceedings of the 1992 International Conference on Microbial Enhanced Oil Recovery, Developments in Petroleum Science, Edited by E. Premuzic and A. Woodhead, Vol. 39, (1993) 171-186.

14. Sarkar, A.K., M.M. Sharma, and G. Georgiou: "Compositional Numerical Simulation of MEOR Processes," Paper No. R-21, Presented at International Conference on Microbially Enhanced Oil Recovery, Norman, OK, May 27 - 
June 1, 1990, Developments in Petroleum Science, Edited by E.C. Donaldson, Vol., 31, (1991) 331-343.

15. Islam, M.R.: "Mathematical Modeling of Microbial Enhanced Oil Recovery," SPE 20480, Presented at the 65th SPE Ann. Conf., New Orleans, LA, Sept. $23-26,1990$

16. Chang, M.M., F.T.H. Chung, R.S. Bryant, H.W.Gao, and T.E. Burchfield: "Modeling and Laboratory Investigation of Microbial Transport Phenomena in Porous Media," SPE 22845, Presented at the 66th SPE Ann. Conf., Dallas, TX, Oct. 6-9, 1991.

17. Chang, M.M., R.S. Bryant, A.K. Stepp, and K.M. Bertus: Modeling and Laboratory Investigations of Microbial Oil Recovery Mechanisms in Porous Media, DE/93000105, NIPER-629, (1992).

18. Corapcioglu, M.Y and A. Haridas: "Transport and Fate of Microorganisms in Porous Media: A Theoretical Investigation," J. of Hydrol., Vol. 72, (1984) 149-169.

19. Bear, J: Dynamics of Fluids in Porous Media, New York, Elsevier, (1972) 605-616

20. Bu' Lock, J. and B. Kristiansen: Basic Biotechnology, Academic Press, New York, (1987) $75-131$.

21. Bajpai, R.K. and M. Reuss: "Coupling of Mixing and Microbial Kinetics for Evaluating the Performance of Bioreactor," Can. J. Chem. Eng., 60, (Jun. 1982) 384-392.

22. Cernansky, A. and R. Siroky: "Deep-Bed Filtration on Filament Layers of Particles Polydispersed in Liquids," International Chemical Engineering, Vol. 25, No. 2, (1985) 364-375. 
23. Adamson, A.W.: Physical Chemistry of Surfaces, 3rd Edition, Joh Wiley \& Sons, Inc., New York, (1976).

24. Chang, F.F, and F. Civan: "Modeling of Formation Damage Due to Physical and Chemical Interactions between Fluids and Reservoir Rocks," SPE 22656, Presented at the 66th Ann. Conf., Dallas, TX, Oct. 6-9, 1991.

25. Popplewell, L.M., O.H. Campanella, and M. Peleg: "Quantitative Characterization of Particle Size Distributions of Instant Coffee Mechanical Attrition," J. of Food Science, Vol. 53, No.3, (1988) 877-881.

26. Thomas, G.W.: Principles of Hydrocarbon Reservoir Simulation, International Human Resources Development Corporation, Boston, (1982).

27. Fanchi, J.R., K.J. Harpole, and S.W. Bujnowski: BOAST, A Three-Dimensional, Three-Phase Oil Applied Simulation Tool (Version 1.1), Vol. I: Technical Description and Fortran Code, U.S. Dept. of Energy Report No. DOE/BC/10033-3, Sept. 1982.

28. Bang, H.W. and B.H. Caudle: "Modeling of a Micellar/Polymer Process," SPEJ, (Dec. 1984) 617-627.

29. Lake, L.W.: Enhanced Oil Recovery, Prentice Hall, New Jersey, (1989).

30. Saad, N.: Field Scale Simulation of Chemical Flooding, Ph.D. Dissertation, University of Texas at Austin, (1989).

31. Chang, Y.B.: Development and Application of an Equation of State Compositional Simulator, Ph.D. Dissertation, University of Texas at Austin, (1990).

32. Dombrowski, H.S. and L.E. Brownell: "Residual Equilibrium Saturation of Porous Media," Industrial and Engineering Chemistry, 46, (1954) 1207. 
33. Leonard, B.P.: "Third-Order Upwinding as a Rational Basis for Computational Fluid Dynamics," Computational Techniques and Applications, ATAC-83, Editor, J. Noye and C. Fletcher, (1984) 106-120.

34. Peaceman, D.W.: "Interpretation of Well Block Pressure in Numerical Reservoir Simulation with Nonsquare Grid Blocks and Anisotropic Permeability," SPEJ, (Jun. 1983) 531-543.

35. Mattax, C.C. and R.L. Dalton: Reservoir Simulation, SPE Monograph Vol. 13, Richardson, TX, (1990).

36. Peaceman, D.W.: Fundamentals of Numerical Reservoir Simulation, Elsevier Scientific Publishing, New York, (1977).

37. Ames, W.F.: Numerical Methods for Partial Differential Equations, 2nd edition, Academic Press, New York, (1977).

38. Fehlberg, E: "Low-Order Classical Runge-Kutta Formula with Stepwise Control and Their Application to Some Heat Transfer Problems," National Aeronautics and Space Administration, Report No. NASA TR-315, (1969).

39. Buckley, S.E. and M.C. Leverett: "Mechanism of Fluid Displacement in Sand," Trans., AIME, Vol. 146, (1942) 107-116.

40. Zhang, X.: Mathematical Modeling of Microbially Enhanced Oil Recovery, M.S. Thesis, University of Oklahoma, (1990).

41. Abbaszadeh-Dehghani, M. and W.E. Brigham: "Analysis of Well-to-Well Tracer Flow to Determine Reservoir Layering," JPT, Vol. 36, No. 11, (1984) 1753-1762.

42. Sharma, P.K., M.J. McInerney, and R.M. Knapp: "In Situ Growth and Activity and Modes of Penetration of Escherichia coli in Unconsolidated Porous Materials," Appl. Environ. Microbiol., Vol. 59, No. 11, (1993) 3686-3694. 
43. Silfanus, N.J.: Microbial Mechanisms for Enhanced Oil Recovery from High Salinity Core Environments, M.S. Thesis, Uinversity of Oklahoma, (1990).

44. Pirson, S.J., Ed.: Oil Reservoir Engineering, McGraw Hill, New York, (1958).

45. Corey, A.T.: Mathematics of Immiscible Fluids in Porous Media, Water Resources Publication, Littleton, Co. (1986).

46. Beeson, D.M. and G.D. Ortloff: "Laboratory Investigation of the Water-Driven Carbon Dioxide Process for Oil Recovery," Trans., AIME, Vol. 216, (1959) 388-391.

47. Holm, L.W.: "Carbon Dioxide Solvent Flooding for Increased Oil Recovery," Trans., AIME, Vol. 216, (1959) 216-231.

48. Craft, B.C., M.F. Hawkins, and R.E. Terry: Applied Petroleum Reservoir Engineering, 2nd. Ed., Prentice Hall, New Jersey, (1991).

49. McInerney, M.J., R.M. Knapp: Quantitation of Microbial Products and Their Effectiveness in Enhanced Oil Recovery, Annual Report, Bartlesville Project Office, U.S. Dept. of Energy, DOE/BC/14662-7, (1992).

50. McInerney, M.J., R.M. Knapp: "Quantitation of Microbial Products and Their Effectiveness in Enhanced Oil Recovery, Second Annual Report, submitted. 